UNIVERSIDADE DE SÃO PAULO
HOSPITAL DE REABILITAÇÃO DE ANOMALIAS CRANIOFACIAIS

BRUNA CONDI PEREIRA DE MORAES

Avaliação da angulação e inclinação dos dentes anteriores por meio da tomografia computadorizada por feixe cônico, em pacientes com fissura transforame incisivo unilateral

\title{
BAURU
}





\title{
BRUNA CONDI PEREIRA DE MORAES
}

\section{Avaliação da angulação e inclinação dos dentes anteriores por meio da tomografia computadorizada por feixe cônico, em pacientes com fissura transforame incisivo unilateral}

\author{
Dissertação apresentada ao Hospital de \\ Reabilitação de Anomalias Craniofaciais da \\ Universidade de São Paulo para obtenção do \\ título de Mestre em Ciências da Reabilitação. \\ Área de Concentração: Fissuras Orofaciais e \\ Anomalias Relacionadas \\ Orientador: Prof. Dr. Leopoldino Capelozza \\ Filho
}

\section{BAURU}




\section{AUTORIZO A REPRODUÇÃO E DIVULGAÇÃO DESTE TRABALHO, POR QUALQUER MEIO CONVENCIONAL OU ELETRÔNICO, PARA FINS DE ESTUDO E PESQUISA, DESDE QUE CITADA A FONTE.}

Moraes, Bruna Condi Pereira de

M791a Avaliação da angulação e inclinação dos dentes anteriores por meio da tomografia computadorizada por feixe cônico, em pacientes com fissura transforame incisivo unilateral / Bruna Condi Pereira de Moraes. Bauru, 2010.

125p.; il.; $30 \mathrm{~cm}$.

Dissertação (Mestrado - Área de Concentração: Fissuras Orofaciais e Anomalias Relacionadas) Hospital de Reabilitação de Anomalias Craniofaciais, Universidade de São Paulo.

Orientador: Prof. Dr. Leopoldino Capelozza Filho

1. Inclinação dentária 2. Angulação dentária

3. Tomografia computadorizada 4. Fissura labiopalatina

5. Ortodontia 


\section{FOLHA DE APROVAÇÃO}

Bruna Condi Pereira de Moraes

Dissertação apresentada ao Hospital de Reabilitação de Anomalias Craniofaciais da Universidade de São Paulo para obtenção do titulo de Mestre em Ciências da Reabilitação.

Área de Concentração: Fissuras Orofaciais e Anomalias Relacionadas

Aprovado em:

Banca Examinadora

Prof. Dr.

Instituição Assinatura

Prof. Dr.

Instituição Assinatura

Prof. Dr.

Instituição (Orientador):

Prof.(a) Dr.(a)

Presidente Pós Graduação HRAC

Data do depósito da dissertação junto ao SPG: 



\section{DEDICATÓRIA}

Em primeiro lugar, agradeço a Deus, por todas graças que tenho em minha vida, por todas as oportunidades que me foram dadas e por todas as pessoas que tive o prazer de conviver.

Aos meus pais, Carlos Armendes e Maria Antonieta, agradeço por todo o amor e apoio que sempre deram a mim e a meu irmão. Sem a ajuda de vocês eu não estaria aqui hoje. Vocês sempre foram e sempre serão meu exemplo de vida! Amo muito vocês!

Ao meu marido, Luís Eduardo, agradeço pelo apoio, compreensão e "paciência" nos momentos em que estive mais estressada. Obrigada por ser meu amigo e companheiro. Amo você!

Ao meu irmão, Caio, sou muito feliz por ser sua irmã! Obrigada por tudo que passamos juntos. Você é meu grande amigo e sinto muito orgulho de você! Você e a minha mais nova "irmã", Flavinha, moram no meu coração! Amo vocês! 



\section{AGRADECIMENTOS}

Ao meu orientador e grande mestre Prof. Dr. Leopoldino Capelozza Filho

Agradeço pela confiança e pelo exemplo. Seus ensinamentos sempre serão de extrema importância em minha vida profissional. Obrigada por ser meu guia em busca do conhecimento e da prática da Ortodontia, e pelo exemplo em como ser humana com os meus pacientes. Espero que este seja o início de muitos encontros! Sou e sempre serei sua "fã"!

Ao meu primeiro mestre na Ortodontia, Dr. Omar Gabriel da Silva Filho ou mais carinhosamente "Tio Zizo"

Agradeço pelos ensinamentos e pela amizade. Você nasceu para ensinar! Foi amor à primeira vista quando assisti a sua primeira aula; desde então a Ortodontia nunca mais saiu da minha vida. Você encanta a todos com sua inteligência e simplicidade.

\section{A Prof. Dra. Terumi Okada Ozawa}

Agradeço pelos ensinamentos e amizade. Você acolheu a mim e ao Tulio quando chegamos ao Centrinho, em 2003. Aprendi muito com você! Sua colaboração foi imprescindível para o desenvolvimento desta pesquisa. Sem a sua ajuda tudo teria sido muito mais complicado. Obrigada de coração por tudo!

A todos os meus queridos professores e amigos da Ortodontia, Aiello, Araci, Rita, Dra. Arlete, Tio Flávio, Daniela Garib, Dra. Silvia e Celeste

Aprendi muito com todos vocês! Sou muito feliz por vocês terem feito parte da minha formação como profissional e ser humano. Obrigada por estarem sempre presentes na minha vida! 
A minha parceira de mestrado e amiga Fernanda

Obrigada por toda a ajuda que me deu! Você foi muito importante para que este trabalho estivesse finalizado... e sua amizade é muito preciosa para mim! Obrigada por tudo de coração!!!

A todos os profissionais do Setor de Ortodontia, Gleisieli, Thiago, Rogério

Obrigada por toda a ajuda para o desenvolvimento desta pesquisa e pela carinho com que sempre me trataram!

As auxiliares do Setor de Ortodontia, Denise, Soninha, Solange, Suzana, Marisaura, Celina e Letícia

Só tenho a agradecer a todas as "meninas da Orto", que sempre me receberam com muito carinho e colaboraram muito para que este trabalho fosse realizado! Vocês moram no meu coração!

Aos residentes do Setor de Ortodontia

Obrigada pela ajuda e amizade de todos vocês!

Aos meus queridos amigos ortodontistas, Emiliana, Elisa, Tulio, Camila, Adriano, Maurício, Heloisa, Gisele, Maria Fernanda, Anderson, Juliana Bastos, Fernanda Nieckele, Juliana Borborema, Maria Helena, Tati, Paloma, Elaine, Guilherme Bibiano e Porciuncula e todos os outros que não foram citados

Obrigada por fazerem parte da minha vida. Amo todos vocês!

As minhas queridas amigas de faculdade Andreia, Karin e Ana Luisa

Não poderia deixar de falar de vocês, que acompanharam todas as fases da minha vida, me apoiando sempre! Amo vocês!!!

A minha auxiliar e amiga Mariane

Obrigada por toda a colaboração em minha ausência no consultório. Você foi muito importante para a realização deste trabalho! 
Aos queridos amigos do Setor de Pós-Graduação do HRAC, Andréia, Rogério e Zezé

Obrigada pela colaboração e paciência! Vocês são pessoas incríveis! São muito queridos para mim e já os considero meus amigos!

A presidente da Pós-Graduação Profa. Dra. IngeTrindade

Agradeço pela oportunidade e pelo exemplo de competência e dedicação que você nos dá! Obrigada por tudo!

Aos meus colegas de Mestrado

Obrigada pela ajuda e amizade de todos vocês!

Ao Prof. David Normando

Sem você eu não teria dados estatísticos. Meu sincero agradecimento pela sua inestimável ajuda, sempre com a melhor boa vontade!

Aos pacientes e profissionais do HRAC

Meu eterno agradecimento! 



\section{RESUMO}

Moraes BCP. Avaliação da angulação e inclinação dos dentes anteriores por meio de tomografia computadorizada por feixe cônico, em pacientes com fissura transforame incisivo unilateral [dissertação]. Bauru: Hospital de Reabilitação de Anomalias Craniofaciais, Universidade de São Paulo; 2010.

Com a evolução da imaginologia, a tomografia computadorizada vem sendo amplamente utilizada na Odontologia. Este exame nos fornece detalhada identificação das estruturas anatômicas, e possibilita inúmeras mensurações em diversos planos, sendo uma boa indicação para avaliar indivíduos com fissura transforame incisivo, onde há a ruptura da continuidade óssea na região do rebordo alveolar e palato duro, causando várias alterações dentárias e faciais, tornando a reabilitação deste paciente um processo muito complexo. O presente estudo tem por objetivo avaliar as angulações e inclinações dentárias induzidas pelo tratamento ortodôntico corretivo, em pacientes com fissura transforame incisivo unilateral, e analisar morfologicamente o osso alveolar e contorno radicular após finalização do tratamento ortodôntico. Foram selecionados 10 pacientes, na fase de contenção após finalização do tratamento ortodôntico corretivo, e foram realizados cortes tomográficos dos seis dentes anteriores superiores e inferiores. Os dados coletados foram submetidos aos testes estatísticos. Concluímos que houve diferença significativa nas medidas do arco superior entre os lados com e sem fissuras; também foi possível a nítida visualização da relação entre as raízes dentárias com o osso alveolar. Com relação ao método utilizado, contatamos que este se mostrou confiável e reproduzível. Entretanto, novas pesquisas serão necessárias para sua consolidação.

Descritores: tomografia computadorizada, angulação dentária, inclinação dentária, ortodontia, fissura de lábio e palato 



\begin{abstract}
Moraes BCP. Long axis and tipping evaluation of mandible and maxilla anterior teeth by cone beam tomography in patients with unilateral cleft lip and palate [dissertation]. Bauru: Hospital de Reabilitação de Anomalias Craniofaciais, Universidade de São Paulo; 2010.
\end{abstract}

Recent developments on the field of imaginology allowed computed tomography to become largely used in dentistry. Details of anatomic structures can be visualized with high quality images and measurements can be taken on several plans helping all professionals involved on the treatment of patients with alveolar bone defect, malocclusion and facial deformities caused by cleft lip and palate.

Objectives: to evaluate tooth tipping and long axis angulation of mandible and maxilla anterior teeth produced by corrective orthodontic treatment in patients with unilateral cleft lip and palate and to analyze the morphology of alveolar bone and teeth roots after orthodontic treatment in the same group of patients.

Methods: Ten patients that had received orthodontic treatment at the Craniofacial Anomalies Rehabilitation Hospital (HRAC-USP) were selected and submitted to computed tomography exam. All images taken during the exam were transferred to Dolphin Imaging Software and specific areas of anterior teeth were selected to be cutted. Measurements were taken and submitted to statistical analyses.

Results: There were statistical differences between measurements of anterior teeth on both sides of the upper arch and the alveolar bone and roots interface could be well visualized.

Conclusion: The results showed that this method is reliable and reproducible; however, new researches are necessary.

Key words: Tomography, orthodontics, cleft lip and cleft palate. 



\section{LISTA DE FIGURAS}

$\begin{array}{lll}\text { Figura 2.1 Angulação } & 37\end{array}$

$\begin{array}{lll}\text { Figura } 2.2 & \text { Inclinação } & 37\end{array}$

Figura 2.3 Valores de inclinação das prescrições Padrão I, II e III Capelozza 40

Figura 2.4 Valores de angulação das prescrições Padrão I, II e III Capelozza

Figura 2.5 Princípio da tomografia computadorizada por feixe cônico 44

$\begin{array}{lll}\text { Figura 2.6 } & \text { Fissura transforame incisivo unilateral } & 47\end{array}$

$\begin{array}{lll}\text { Figura 4.1 Tomógrafo i-CAT } & 58\end{array}$

Figura 4.2 Exemplos da utilização do software (DOLPHIN IMAGING) 60

Figura 4.3

Figura 4.4 Ferramenta de Orientação do Objeto para posicionamento da Figura 4.5 cabeça de acordo com o Plano de Andrews dos dentes Figura 4.6 superiores (DOLPHIN IMAGING)

Figura 4.7 Ilustração do Eixo Vestibular da Coroa Clínica (EVCC), do Ponto EV e demarcação do Plano de Andrews passando pelo ponto EV dos dentes de cada arcada dentária

Figura 4.8 Imagem selecionada pela ferramenta do software denominada "Build X-Ray" - "Cross Section" (DOLPHIN IMAGING)

Figura 4.9 Angulação da cabeça de modo que o longo eixo do dente ficasse selecionado (DOLPHIN IMAGING)

Figura 4.10 Demarcação dos limites da coroa anatômica

Figura 4.11 Reta representando a distância da coroa anatômica

Figura 4.12 Retas perpendiculares à reta da coroa anatômica

Figura 4.13 Medida do tamanho da coroa anatômica 
Figura 4.14 Medida do tamanho da coroa clínica (coroa anatômica-1,8mm) 66

Figura 4.15 Arrastando a régua até tocar a face vestibular do dente 66

Figura 4.16 Demarcação do ponto extremo cervical da coroa clínica 66

Figura 4.17 Reta representando o longo eixo da coroa clínica 67

$\begin{array}{lll}\text { Figura 4.18 Medida do tamanho da coroa clinica } & 67\end{array}$

$\begin{array}{lll}\text { Figura 4.19 Demarcação do ponto EV } & 68\end{array}$

Figura 4.20 Remoção das linhas guia e visualização de todos os pontos demarcados 68

Figura 4.21 Linha sobre ponto EV e tangenciando face vestibular 68

$\begin{array}{lll}\text { Figura 4.22 Medida da inclinação } & 68\end{array}$

$\begin{array}{ll}\text { Figura 4.23 Valor positivo da inclinação } & 69\end{array}$

Figura 4.24 Valor negativo da inclinação 69

Figura 4.25 Imagem selecionada pela ferramenta do software denominada "Build X-Ray" - "Panoramic" (DOLPHIN IMAGING) 70

Figura 4.26 Seleção através da ferramenta do software da região a ser $\begin{array}{ll}\text { demarcada na panorâmica } & 71\end{array}$

$\begin{array}{lll}\text { Figura 4.27 Visão da panorâmica } & 71\end{array}$

Figura 4.28 Linha demarcando o longo eixo dentário 72

Figura 4.29 Exclusão da dilaceração para não alterar de maneira errônea a medida de angulação $\quad 72$

$\begin{array}{lll}\text { Figura 4.30 Medida de angulação } & 72\end{array}$

$\begin{array}{lll}\text { Figura 6.1 Tábua óssea vestibular muito fina } & 100\end{array}$

Figura 6.2 Tábua óssea vestibular praticamente inexistente 100

Figura 6.3 Tábua óssea palatina somente no terço apical 100

Figura 6.4 Presença de tecido ósseo somente na região apical 100 
Figura 6.5 Tábua óssea vestibular somente no terço apical

Figura 6.6 Osso presente somente na região apical

Figura 6.7 Reabsorção radicular moderada nos incisivos (remodelação apical)

Figura 6.8 Reabsorção radicular mais acentuada nos incisivos 101

Figura 6.9 Reabsorção óssea vertical leve na região do enxerto (implante) 102

Figura 6.10 Reabsorção óssea vertical acentuada na região da fissura 



\section{LISTA DE TABELAS}

Tabela 5.1 Testes estatísticos para inclinação no arco superior 77

Tabela 5.2 Testes estatísticos para angulação no arco superior 78

Tabela 5.3 Testes estatísticos para inclinação no arco inferior 78

Tabela 5.4 Testes estatísticos para angulação no arco inferior 79

Tabela 6.1 Valores de inclinação e angulação dos caninos superiores 87

Tabela 6.2 Valores de inclinação dos caninos superiores em oclusão normal não tratada comparada a este estudo 88

Tabela 6.3 Valores de angulação dos caninos superiores em oclusão normal não tratada comparada a este estudo 90

Tabela 6.4 Valores de angulação e inclinação dos incisivos superiores 90

Tabela 6.5 Valores médios da inclinação dos dentes superiores deste trabalho comparados com o padrão de normalidade 91

Tabela 6.6 Valores médios da angulação dos dentes superiores deste trabalho comparados com o padrão de normalidade 92

Tabela 6.7 Valores de angulação e inclinação dos caninos inferiores 93

Tabela 6.8 Valores de inclinação dos caninos inferiores em oclusão normal não tratada comparada a este estudo 94

Tabela 6.9 Valores de angulação dos caninos inferiores em oclusão normal não tratada comparada a este estudo 95

Tabela 6.10 Valores de angulação e inclinação dos incisivos inferiores 96

Tabela 6.11 Valores médios da inclinação dos dentes inferiores deste trabalho comparados com o padrão de normalidade 96

Tabela 6.12 Valores médios da angulação dos dentes inferiores deste trabalho comparados com o padrão de normalidade 



\section{LISTA DE QUADROS}

Quadro 2.1 Valores de inclinação padrão no estudo de Andrews

Quadro 2.2 Valores de angulação padrão no estudo de Andrews 



\section{LISTA DE ABREVIATURAS}

ed. Edição

EVCC Eixo vestibular da coroa clínica

p. Página

Fig. $\quad$ Figura

Ponto EV Ponto do eixo vestibular

T1 Tempo 1

T2 Tempo 2

3D Três dimensões

TC Tomografia Computadorizada

TCFC Tomografia Computadorizada por Feixe Cônico 



\section{SUMÁRIO}

$\begin{array}{lll}1 & \text { INTRODUÇÃO } & 27\end{array}$

2 REVISÃO DE LITERATURA 33

2.1 ESTUDOS SOBRE O POSICIONAMENTO DENTÁRIO IDEAL 35

2.2 EVOLUÇÃO DOS MEIOS DIAGNÓSTICOS 41

2.3 CARACTERÍSTICAS DOS PACIENTES COM FISSURA TRANSFORAME INCISIVO 45

3 PROPOSIÇÃO

4 MATERIAL E MÉTODOS

4.1 SELEÇÃO DA AMOSTRA

4.2 OBTENÇÃO DAS IMAGENS TOMOGRÁFICAS 58

4.3 MENSURAÇÃO DAS IMAGENS TOMOGRÁFICAS 60

5 RESULTADOS $\quad 73$

6 DISCUSSÃO

6.1 METODOLOGIA

6.2 AVALIAÇÃO DAS INCLINAÇÕES E ANGULAÇÕES DENTÁRIAS 86

6.3 AVALIAÇÃO DAS REGIÕES ÓSSEAS E RADICULARES 99

$7 \quad$ CONCLUSÕES 103

8 REFERÊNCIAS 107

$\begin{array}{ll}\text { ANEXOS } & 117\end{array}$ 

INTRODUÇÃO 



\section{INTRODUÇÃO}

A preocupação da Ortodontia, desde o seu início, tem sido alcançar uma oclusão normal ao término do tratamento. Com a evolução das técnicas ortodônticas fixas através dos anos, caminhos mais breves e seguros foram desenvolvidos para chegar ao objetivo comum entre todas elas: um correto posicionamento dos dentes em suas bases ósseas e uma boa intercuspidação entre os arcos dentários (Capelozza Filho et al, 1994).

Na década de 70, Andrews (Andrews, 1972) inovou a Ortodontia com as "Seis Chaves da Oclusão Normal”, uma pesquisa que avaliava oclusões ótimas naturais. Ele mensurou as inclinações e angulações de todos os dentes superiores e inferiores, definindo o posicionamento dentário individual normal, em todos os planos do espaço. Esse conjunto foi a base para o conceito e desenvolvimento do aparelho Straight-Wire.

Após esse trabalho, muitos autores começaram a estudar sobre 0 posicionamento dentário. A metodologia de alguns estudos apresentou semelhança à descrita por Andrews, utilizando medições das coroas dentárias em modelos de estudo (Vardimon e Lambertz 1986, Ribas 2003, Reis et al 2008, Zanelato 2003, 2006 e Bastia 2005); outros trabalhos utilizaram radiografias bidimensionais, como telerradiografia em norma lateral e panorâmica (Hans et al 1994, Machado 2001, Almeida 1999, Capelozza Filho et al 1994, Tavano et al 1989 e Ursi et al 1990). A utilização de radiografias bidimensionais possui como desvantagens a presença de distorções e a sobreposição de estruturas anatômicas, dificultando a visualização de certas regiões e podendo levar a erros de diagnóstico e plano de tratamento (Müssig, Wörtche e Lux 2005 e Mah et al 2003). 
Com a evolução da imaginologia, a tomografia computadorizada passou a ser fortemente empregada nas especialidades da Odontologia. Este exame fornece detalhada identificação das estruturas anatômicas e inúmeras mensurações em diversos planos, sendo uma boa indicação para avaliar indivíduos com fissura transforame incisivo, onde há a ruptura da continuidade óssea na região do rebordo alveolar e palato duro, tornando a reabilitação deste paciente um processo muito complexo. Através do exame tomográfico é possível avaliar a quantidade e qualidade óssea nas regiões da fissura, analisar o enxerto ósseo alveolar que é necessário para reconstrução do defeito ósseo e também avaliar a relação que as dentes adjacentes mantêm com a área da fenda (Trindade e Silva Filho, 2007).

O paciente com fissura transforame incisivo, a mais grave e de maior incidência dentre as fissuras labiopalatinas, apresenta grandes alterações dentárias e faciais devido à ruptura dos tecidos duros e moles impostos pela fissura, dificultando seu tratamento reabilitador. Como a presença da fissura provoca várias alterações dentárias, tais como agenesias, supranumerários, incisivos laterais dismórficos e caninos impactados após enxerto ósseo, a tomografia computadorizada pode ser um grande aliado no diagnóstico e correto plano de tratamento desses pacientes, e também pode ser indicada para a avaliação do tratamento realizado, no período de pós-tratamento.

Por este motivo, propusemo-nos a avaliar as inclinações e angulações dos dentes anteriores superiores e inferiores obtidas na fase de contenção do tratamento ortodôntico corretivo, no intuito de investigar a relação e posicionamento dos dentes com a área da fissura e analisar morfologicamente o contorno radicular e osso alveolar nesta região, por meio da tomografia computadorizada por feixe cônico. Também tecemos uma breve correlação entre a posição dentaria de pacientes com 
fissura transforame incisivo unilateral que apresentavam uma satisfatória finalização do tratamento ortodôntico e a posição dentária descrita na literatura para pacientes com oclusão normal natural, com algumas prescrições de braquetes e também com uma amostra de pacientes com o mesmo tipo de fissura antes do tratamento ortodôntico corretivo. 

REVISÃO DE LITERATURA 



\section{REVISÃO DE LITERATURA}

\subsection{ESTUDOS SOBRE O POSICIONAMENTO DENTÁRIO IDEAL}

Desde a divulgação do aparelho Edgewise por Angle, as inclinações e angulações dentárias têm sido amplamente estudadas. Com o desenvolvimento do aparelho arco de canto, em que o correto posicionamento dos dentes é dado pelas informações contidas nas dobras dos fios de nivelamento inseridos nas canaletas, Angle deu o primeiro passo em direção a uma Ortodontia corretiva mais individualizada (Graber e Vanarsdall Junior, 1996).

Até o final do século XIX a mecânica ortodôntica era rudimentar, o que dificultava a padronização e os procedimentos de movimentação dentária, comprometendo, desta forma, a qualidade dos resultados obtidos. Essas dificuldades levaram Edward H. Angle, em 1887, a criar o Sistema Angle, que serviu de base filosófica para a introdução, em 1928, do aparelho Edgewise (Zanelato et al, 2006).

A evolução das pesquisas seguia com o objetivo de transferir aos braquetes recursos que simplificassem o trabalho dos ortodontistas. Holdaway (1952), fez a primeira modificação, uma leve angulação, visando substituir as dobras de segunda ordem. Jarabak (1960), utilizou a mesma angulação mesiodistal preconizada por Holdaway e também uma angulação na canaleta dos braquetes, possibilitando a mecânica de terceira ordem com o emprego de arcos retangulares.

Na década de 70, Andrews inovou a Ortodontia a partir do desenvolvimento de uma pesquisa que avaliava oclusões normais naturais. Ele selecionou 120 modelos de oclusão normal natural, e com eles, determinou seis características comuns, publicando um dos trabalhos mais importantes da história da Ortodontia, as 
"Seis Chaves da Oclusão Normal" (Andrews, 1972). Andrews considerou que todo objetivo de tratamento deve se basear em objetivos oclusais, pois desta forma é alcançada uma boa finalização funcional. A presença das "Seis Chaves da Oclusão Normal", permite a função oclusal com padrão de proteção mútua, sem interferências e problemas relacionados à disfunção têmporo-mandibular (Fattori, 2006).

Utilizando os modelos de oclusão normal natural, Andrews mensurou as inclinações e angulações de todos os dentes superiores e inferiores, definindo o posicionamento dentário individual, em todos os planos do espaço, o que forneceu base para o surgimento do aparelho "Straight-Wire" (Andrews, 1989), o primeiro aparelho ortodôntico totalmente pré-ajustado, incorporando aos braquetes informações referentes à angulação e à inclinação das coroas dentárias e também inserindo variações de espessuras, que eliminassem as dobras de primeira, segunda e terceira ordens (Zanelato et al, 2006). Os valores de inclinação e angulação encontrados na amostra de oclusão normal natural por Andrews estão descritos nas figuras abaixo (Quadros 2.1 e 2.2).

\begin{tabular}{|c|c|c|c|c|c|c|c|}
\hline \multirow{3}{*}{$\begin{array}{c}\text { DENTES } \\
\text { SUPERIORES }\end{array}$} & \multicolumn{7}{|c|}{ INCLINAÇÃO } \\
\hline & $2^{\circ} \mathrm{M}$ & $1^{\circ} \mathrm{M}$ & 2º PM & 1ㅇ PM & C & IL & IC \\
\hline & -90 & $-9 ㅇ$ & $-7^{\circ}$ & $-7^{\circ} \stackrel{0}{0}$ & $-7^{\circ}$ & $3^{\circ}$ & $7^{0}$ \\
\hline \multirow{2}{*}{$\begin{array}{c}\text { DENTES } \\
\text { INFERIORES }\end{array}$} & $2^{\circ} \mathrm{M}$ & $1^{\circ} \mathrm{M}$ & 2을 & 1ㅇ PM & C & IL & IC \\
\hline & $-35^{\circ}$ & $-30 \div$ & $-22 ㅇ$ & $-17^{\circ} \stackrel{0}{ }$ & $-11^{\circ}$ & -10 & -10 \\
\hline
\end{tabular}

Quadro 2.1 - Valores de inclinação padrão no estudo de Andrews (Andrews, 1989) 


\begin{tabular}{|c|c|c|c|c|c|c|c|}
\hline \multirow{3}{*}{$\begin{array}{c}\text { DENTES } \\
\text { SUPERIORES }\end{array}$} & \multicolumn{7}{|c|}{ ANGULAÇÃO } \\
\hline & $2^{\circ} \mathrm{M}$ & $1^{\circ} \mathrm{M}$ & $2^{\circ} \mathrm{PM}$ & 1ㅇ PM & C & IL & IC \\
\hline & $5^{\circ}$ & $5^{\circ}$ & 2o & $2^{\circ}$ & $11^{\circ}$ & 9응 & $5^{\circ}$ \\
\hline \multirow{2}{*}{$\begin{array}{c}\text { DENTES } \\
\text { INFERIORES }\end{array}$} & 2ㅇ M & 1M $\mathrm{M}$ & 2ㅇ PM & 1으 PM & C & IL & IC \\
\hline & 2음 & 2음 & 2음 & 2응 & 5응 & 20 & 20 \\
\hline
\end{tabular}

Quadro 2.2 - Valores de angulação padrão no estudo de Andrews (Andrews, 1989)

Entende-se como angulação da coroa clínica, o ângulo formado entre a linha que passa pelo eixo vestibular da coroa clínica (EVCC) e uma linha perdendicular ao plano oclusal (Figura 2.1), e inclinação da coroa clínica, o ângulo formado entre uma linha posicionada perpendicular ao plano oclusal e outra paralela e tangente ao EVCC no seu ponto central (ponto EV) (Figura 2.2).

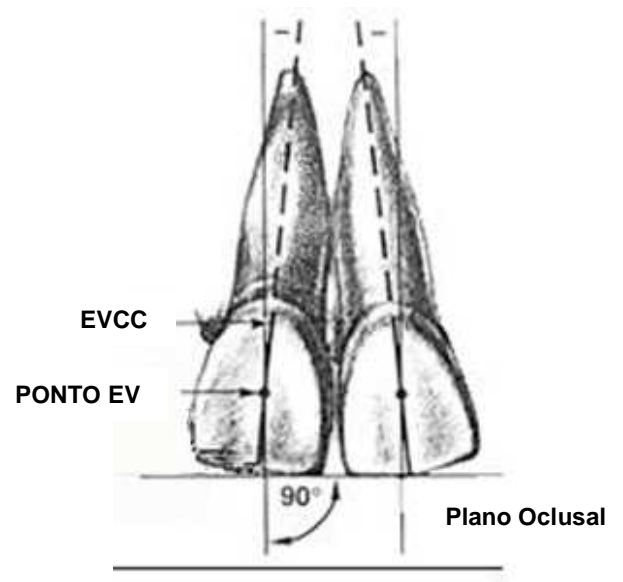

Figura 2.1 - Angulação

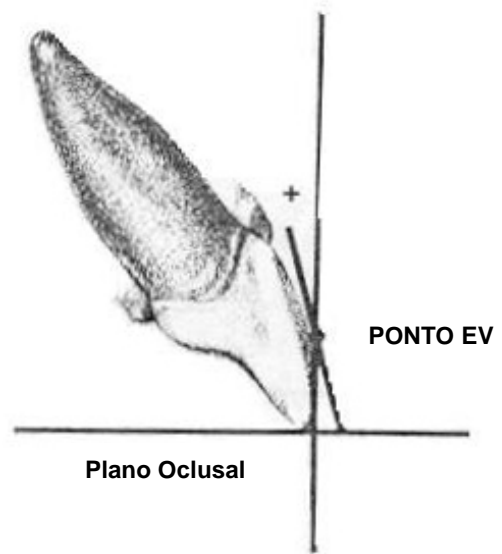

Figura 2.2 - Inclinação

Uma prescrição padrão foi criada por Andrews baseado na média das medidas de angulação, inclinação, proeminência, compensação e curva de Spee obtidas nos modelos analisados. Após essa primeira pesquisa em pacientes com oclusão normal natural, Andrews fez outra pesquisa avaliando as características 
oclusais de modelos de pacientes pós-tratamento ortodôntico bem finalizado, e comparou com a amostra de oclusão perfeita natural para checar até onde as Seis Chaves estavam presentes em resultados de tratamentos de ótima qualidade. Foi concluído que poucos resultados pós-tratamento atingem o padrão das Seis Chaves da Oclusão (Andrews, 1989).

Andrews enfatizou que a compreensão do tratamento ortodôntico com fios retos abrange muito mais do que apenas a prescrição padrão. O aparelho StraightWire padrão é indicado, sobretudo, para casos que não necessitam de extrações dentárias. Se utilizado para casos com extrações, as dobras de todas as ordens devem ser confeccionadas. Por este motivo, Andrews modificou algumas características na prescrição padrão, especificamente para os casos com extrações, incluindo aos bráquetes características de anti-angulação e anti-rotação, pela impossibilidade de, nos movimentos de translação, aplicar-se a força exatamente no centro de resistência do dente, local onde esta teria sua máxima eficiência (Andrews, 1989).

Com o passar dos anos, muitos autores modificaram a prescrição de Andrews apenas com base em suas experiências clínicas, comprovada em casos finalizados (Bennet e McLaughlin 1994, McLaughlin, Bennett e Trevisi 2002, Roth 1987 e Capelozza Filho et al 1999). Roth (1987) desenvolveu uma nova prescrição que visasse à sobrecorreção dos dentes e que fosse aplicável na maioria dos casos ortodônticos. Seu intuito foi de modificar alguns fatores que ocorriam com a prescrição padrão, como por exemplo, a necessidade de incorporar efeitos antiinclinação, anti-rotação, anti-angulação e diminuir a curva de Spee para diminuir as chances de recidiva, levando os dentes para posições sobrecorrigidas àquelas determinadas como ideais. Além disso, os bráquetes são posicionados mais para 
incisal, no intuito de eliminar dobras de compensação ou dobras reversas nos arcos de finalização.

Creekmore e Kunik (1993) descreveram sua experiência na utilização da prescrição Straight-Wire padrão. Os autores demonstraram neste trabalho que os objetivos para o posicionamento de cada dente não são atingidos apenas utilizando arcos retos, e que dobras são necessárias para se alcançar os resultados ideais. A conclusão foi que é impossível que uma única prescrição do aparelho pré-ajustado sirva para todos os pacientes, e que prescrições individualizadas devem ser fabricadas.

Capelozza Filho et al (1999), seguindo o conceito de individualização do tratamento ortodôntico, criaram uma nova seleção de braquetes que estejam de acordo com as características da má-oclusão, do tratamento a ser adotado e do prognóstico para finalização. Com base em sua vasta experiência clínica, Capelozza Filho sugeriu três prescrições para tratamento compensatório de más oclusões de Padrão I, II e III, que tem como objetivo facilitar a finalização compensatória de cada caso. São elas: Padrão I, indicada nos tratamentos que apresentam relação maxilomandibular normal; Padrão II, indicada para os casos com relação maxilomandibular padrão II (deficiência de mandíbula e/ou prognatismo maxilar); e Padrão III, indicada em casos de relação maxilo-mandibular padrão III (deficiência de maxila e/ou prognatismo mandibular); nestas duas últimas prescrições, há angulações e inclinações compensatórias nos dentes anteriores, de maneira a aumentar o perímetro do arco inferior no Padrão II, e diminuir o perímetro do arco inferior no Padrão III, permitindo assim, uma oclusão ótima, apesar do erro na relação maxilomandibular (Figuras 2.3 e 2.4). O autor cita também que para a correção da má- 
oclusão, além de braquetes individualizados, é necessário um correto diagnóstico, plano de tratamento e mecânica individualizados.

\section{Inclinação}
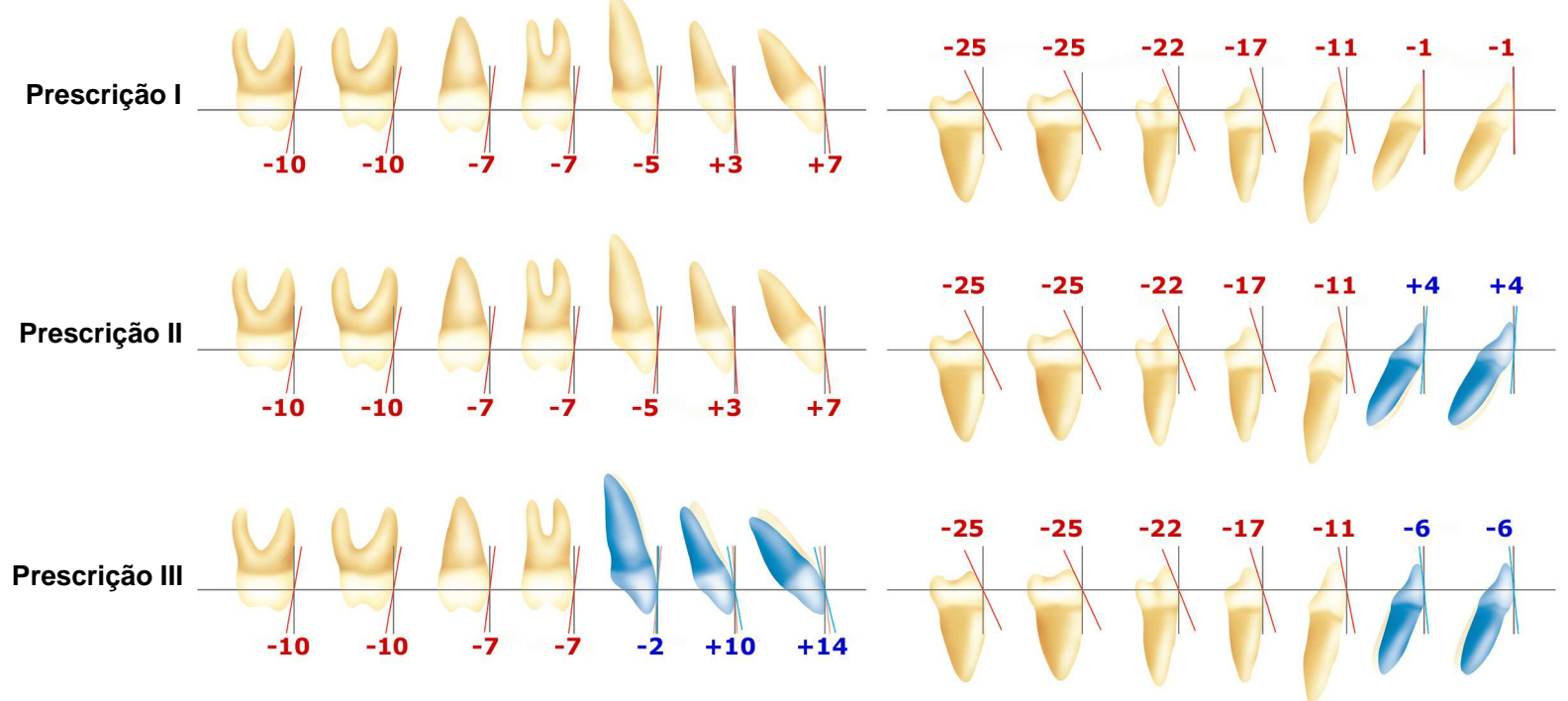

Figura 2.3 - Valores de inclinação das prescrições Padrão I, II e III Capelozza (Abzil 3M)

\section{Angulação}
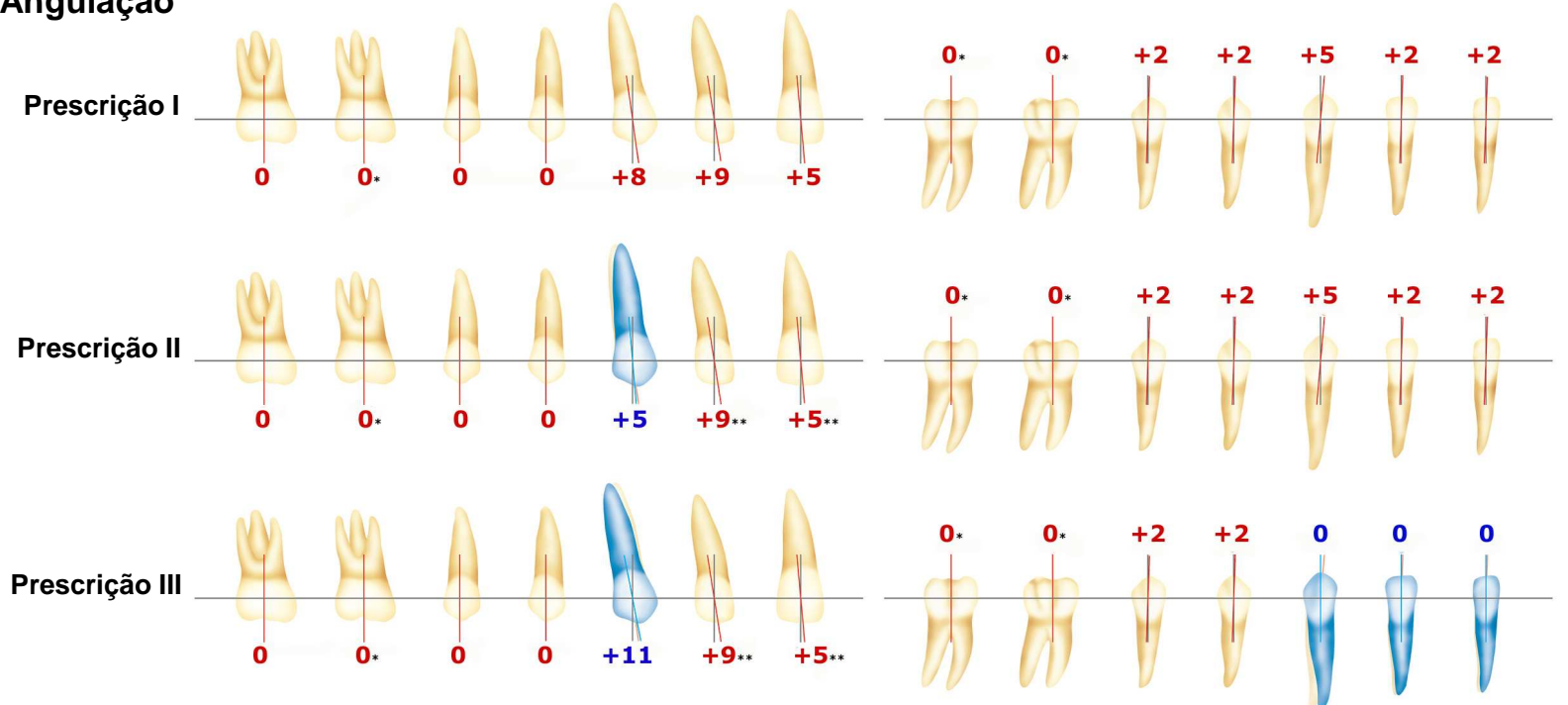

*A angulação de $5^{\circ}$ para os primeiros molares superi ores e $2^{\circ}$ para os primeiros e segundos molares infe riores é dada pela banda ou deve ser introduzida na colagem direta. O segundo molar superior tem angulação $0^{\circ}$.

${ }^{* *} \mathrm{~A}$ angulação pode ser manipulada na colagem direta. A superfície plana do dente e do braquete em torno do ponto EV nos incisivos permite isto sem que nenhuma outra prescrição do braquete seja afetada. Isto propicia individualizar cada caso, com intenção de ocupar mais ou menos espaço e tornar o nivelamento mais ou menos protrusivo.

Figura 2.4 - Valores de angulação das prescrições Padrão I, II e III Capelozza (Abzil 3M) 
Seguindo os passos de Andrews, muitos autores começaram a pesquisar o posicionamento dentário individual. Alguns trabalhos se basearam na metodologia proposta por Andrews utilizando modelos de gesso para avaliação das angulações e inclinações dentárias (Vardimon e Lambertz 1986, Ribas 2003 e Reis et al 2008); Zanelato $(2003,2006)$ e Bastia (2005) propuseram uma modificação na metodologia descrita por Andrews, utilizando um novo dispositivo, criado pelo Departamento de Pós-Graduação em Ortodontia da Universidade Metodista de São Paulo, para aferição da angulação e inclinação das coroas dentárias, pois encontraram dificuldades em reproduzir com precisão o posicionamento da régua e transferidor, criando dúvidas e alta variabilidade nos resultados.

Normando, Azevedo e Torres (2009) analisaram as angulações dentárias em imagens digitalizadas de modelos de gesso e, com o auxílio de um programa gráfico, realizaram as medições.

Alguns pesquisadores avaliaram as inclinações dentárias através de telerradiografias em norma lateral (Hans et al 1994 e Machado 2001), e outros mediram as angulações dentárias com o auxílio de radiografias panorâmicas (Almeida 1999, Capelozza Filho et al 1994, Tavano et al 1989 e Ursi et al 1990).

Fattori (2006) e Capelozza Filho $(2005,2008)$ publicaram métodos inovadores para o estudo das posições dentárias. Eles mediram as angulações e inclinações dentárias em cortes tomográficos com precisão e confiabilidade, realizados em tomógrafos computadorizados volumétricos.

\subsection{EVOLUÇÃO DOS MEIOS DIAGNÓSTICOS}

Durante muito tempo, o diagnóstico ortodôntico e o plano de tratamento foram confinados às imagens radiográficas bidimensionais (Macchi et al, 2006). A 
Ortodontia utilizava a telerradiografia em norma lateral como exame principal para definir condutas, baseada em valores normativos obtidos nas análises cefalométricas existentes, que ditavam o plano de tratamento a ser seguido. Porém, as radiografias bidimensionais possuem como desvantagens a presença de distorções e a sobreposição de estruturas anatômicas, dificultando muitas vezes um diagnóstico mais acurado, como por exemplo, em casos com canino impactado e distúrbios de irrupção (Müssig, Wörtche e Lux 2005, Mah et al 2003 e Capelozza Filho et al 2008).

Com a evolução da imaginologia na Odontologia os meios diagnósticos se tornaram mais precisos, mais confiáveis e permitiram um maior detalhamento das estruturas em três dimensões (Capelozza Filho, Fattori e Maltagliati 2005 e Capelozza Filho et al 2008). A tecnologia digital ortodôntica abriu uma nova porta para o diagnóstico e planejamento (Miller, Kuo e Choi, 2003).

A tomografia computadorizada é um método diagnóstico por imagem que utiliza a radiação $X$ e permite a reprodução de partes do corpo em três planos do espaço, mostrando essas partes em "fatias" (Garib et al, 2007).

$\mathrm{Na}$ técnica tomográfica, filme e fonte de raios $X$ movem-se de maneira sincrônica e antagonista, criando um plano focal. Assim, todas as estruturas dentro do plano focal permanecem nítidas para visualização e as demais áreas ficam embaçadas (Cavalcanti e Sales, 2008).

Sudovic (2003) descreveu os princípios da tomografia computadorizada (TC). Segundo seus relatos, o primeiro tomógrafo foi desenvolvido em 1967 por Sir Godfrey N. Hounsfield, um engenheiro. A partir deste momento, inúmeras inovações ocorreram no intuito de melhorias na forma de aquisição e avaliação dos dados obtidos, sendo reconhecidas quatro gerações de tomógrafos para tomografia computadorizada que 
ficaram conhecidas como TC convencional. Nelas o tubo de raios $\mathrm{X}$ e os detectores são rigidamente acoplados e fazem um movimento rotacional sobre o paciente, que fica estático durante a exposição. Entretanto, a desvantagem deste sistema era a chance do paciente se movimentar devido ao tempo muito longo para a aquisição do exame, podendo ocorrer artefatos na imagem (Cavalcanti e Sales, 2008).

$\mathrm{Na}$ evolução, surgiu o TC espiral singleslice, que produzia 1 corte por segundo e utilizava um único anel de detectores em movimento continuo, o que não eliminava os possíveis artefatos provenientes de restaurações metálicas ou de movimentos respiratórios do paciente. Em 1998, sucedeu uma nova geração de tomógrafos, chamada de TC espiral multislice. Recebem esta nomina por serem baseados no uso de múltiplos anéis detectores que escaneam mais de dois cortes por cada rotação da ampola (múltiplos cortes por 0,5 segundo), permitindo, desta forma, que sejam obtidos vários cortes transversais ao mesmo tempo, reduzindo o tempo de escaneamento, e, portanto o tempo de exposição (Yajima et al 2006 e Cavalcanti e Sales 2008).

Nos últimos anos, com o advento da tomografia computadorizada por feixe cônico (TCFC), o exame tomográfico tem sido amplamente utilizado para avaliação de regiões maxilo-mandibulares (Tsiklasis et al 2005 e Yamamoto et al 2003). Este tem sido o exame de escolha para análise de componentes ósseos e estruturas dentárias (Firooznia et al, 1992).

Na TCFC o feixe de raios $X$ é em forma de cone, e é produzido num ângulo constante de $14^{\circ}$ pela sobreposição de um filtro de alumínio de $0,7 \mathrm{~mm}$. Os raios X são capturados por um intensificador de imagem (substituto do filme radiográfico) ou um sensor sólido que, juntamente com a fonte de raios $\mathrm{X}$, rotaciona ao redor da cabeça do paciente durante o mapeamento. Neste processo são produzidas várias imagens 
que são unidas por um programa, que acompanha o equipamento, formando assim o modelo tridimensional do crânio (Cavalcanti e Sales, 2008) (Figura 2.5).

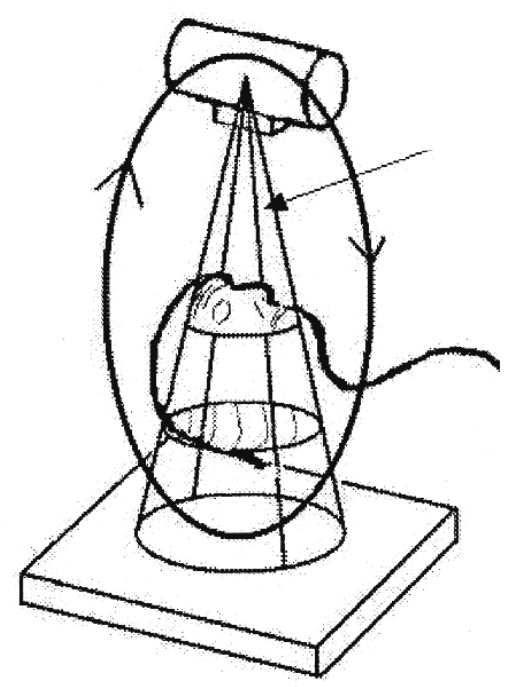

Figura 2.5 - Princípio da tomografia computadorizada por feixe cônico (Sudovic, 2003)

Como exemplos de tomógrafo por feixe cônico, podem ser citados os aparelhos NewTom 3G (QR-NIM SRL, Verona, Itália), Galileos (Sirona Dental Alemanha A.G.), Implagraph (Vatech, Korea), 3D Accuitomo (J. Morita MFG Corporation - Kyoto, Japan) e o i-CAT (Xoran Tecnologies, Ann Arbor, Mich., e Imaging Sciences International, Hatfield, PA), Planmeca ProxMax 3D (Planmeca Ou - Finlândia), lluma (Imtec Imaging Corporation, EUA), Skyview 3D(Cefla Dental Group, Itália), Prexion (TeraRecon, EUA), NewTom VG (Verona, Itália) e Scandora 3D (Soredex, Finlândia).

Este tipo de tomógrafo permite a obtenção de imagens volumétricas semelhantes às obtidas em centros médicos, e proporciona uma dose de radiação mais baixa, alta qualidade de imagem, fácil manuseio e um custo relativamente menor quando comparados à tomografia convencional (Heiland et al 2003, Mah et al 
2003, Hatcher e Aboudara 2004, Lascala, Panella e Marques 2004, Rouas et al 2006, Scarfe, Farman e Sukovic 2006, Korbmacher et al 2007, Ludlow et al 2006, Tsiklasis et al 2005, Vannier 2003, Cohnen et al 2002, Farman 2003 e Maki et al 2003), e possui a vantagem de que com apenas um exame pode-se fazer reconstruções nos mais diversos planos, com o auxílio de um software, proporcionando múltiplas imagens, como, por exemplo, imagens semelhantes à telerradiografias lateral e frontal, panorâmica, oclusal, transaxial e coronal (Capelozza Filho, Fattori e Maltagliati, 2005). A criação dessas imagens não é feita apenas no plano axial, mas também bidimensionais nos planos coronal, sagital, e até mesmo imagens oblíquas ou curvas (Scarfe, Farman e Sukovic, 2006).

A tomografia computadorizada de feixe cônico fornece detalhada identificação das estruturas anatômicas e inúmeras mensurações em diversos planos, sendo já utilizada para diversas finalidades em odontologia como, por exemplo, identificação de cistos e processos inflamatórios e tumorais, localização de dentes impactados, como auxiliar no planejamento em implantodontia e o acompanhamento pré e pós-cirúrgico, avaliar a quantidade e qualidade óssea nas regiões de fissuras de lábio e palato completas, áreas onde ocorrem a ruptura da continuidade óssea na região do rebordo alveolar e palato duro, necessitando desta forma da realização de enxerto ósseo secundário para reconstrução da área afetada (Silva Filho et al 1995, Schulze et al 2004, Trindade e Silva Filho 2007, Enciso, Memon e Mah 2003 e Suri et al 2008).

\subsection{CARACTERÍSTICAS DOS PACIENTES COM FISSURA TRANSFORAME INCISIVO}

As fissuras labiopalatinas são malformações congênitas decorrentes de falhas na maturação ou desenvolvimento dos processos embrionários, e ocorrem com uma 
prevalência média que varia entre 1 a 2 indivíduos para cada 1.000 nascimentos (Greene, 1968). No Brasil, admite-se que a incidência deste tipo de anomalia seja em torno de 1:650 nascimentos (Nagem Filho, Morais e Rocha, 1968). Sua etiologia é multifatorial, incluindo fatores genéticos (hereditariedade) e ambientais (Cerqueira et al 2005 e Trindade e Silva Filho 2007). Essas alterações são as mais comuns dentre as deformidades faciais congênitas e acometem todos os tipos raciais e étnicos, independente do sexo e classe sócio-econômica (Ribas 2003 e Suri et al 2008).

As fissuras labiopalatinas se manifestam na vida intra-uterina, no período embrionário e no princípio do período fetal. Sua formação é estabelecida até a $8^{\text {a }}$ semana gestacional, para as fissuras de lábio e rebordo alveolar, e até a $12^{\underline{a}}$ semana gestacional para as fissuras de palato, pois é nesta época que ocorre a fusão dos processos faciais embrionários (Diewert 1983 e Sperber 1989).

$\mathrm{Na}$ busca de simplicidade e objetividade, foi adotada no Hospital de Reabilitação de Anomalias Craniofaciais a classificação de Spina (1972), modificada por Silva Filho (1992). Esta classificação, fundamentada na teoria embriológica, reconhece os mecanismos independentes de formação das estruturas anteriores (palato primário) e posteriores (palato secundário) ao forame incisivo, ponto de referência anatômico elegido para esta classificação. Desta forma, as fissuras foram selecionadas em: Grupo I - Pré-forame Incisivo; Grupo II - Transforame Incisivo; Grupo III - Pós-forame Incisivo e Grupo IV - Fissuras Raras da Face (Spina et al 1972 e Silva Filho et al 1992).

Dentre todos os tipos de fissuras existentes, a mais freqüente é a fissura transforame incisivo unilateral, com predominância do lado esquerdo (Capelozza Filho e Silva Filho 1992 e Silva Filho, Okada e Souza Freitas 2000). Segundo Silva 
Filho, Okada e Souza Freitas (2000), a freqüência de fissura nos pacientes cadastrados no Hospital de Reabilitação de Anomalias Craniofaciais (HRAC) é de $19,53 \%$ para pacientes transforame unilateral esquerda e 10,13\% para pacientes transforame unilateral direita, sendo quase um terço dos pacientes do Hospital.

Clinicamente, a fissura transforame incisivo unilateral estende-se do lábio até a úvula, atravessando o rebordo alveolar. Ela divide a maxila em dois segmentos nítidos, o segmento maior, ou segmento "não fissurado", e o segmento menor, ou segmento "fissurado" (Figura 2.6). A separação entre esses segmentos denuncia a amplitude da fissura, a qual influencia no prognóstico de tratamento a longo prazo, sendo pior o resultado terapêutico quanto maior for a amplitude da fissura. $O$ segmento maior, o qual se encontra unido ao septo nasal, apresenta-se deslocado para fora, com projeção da sua extremidade anterior para vestibular.

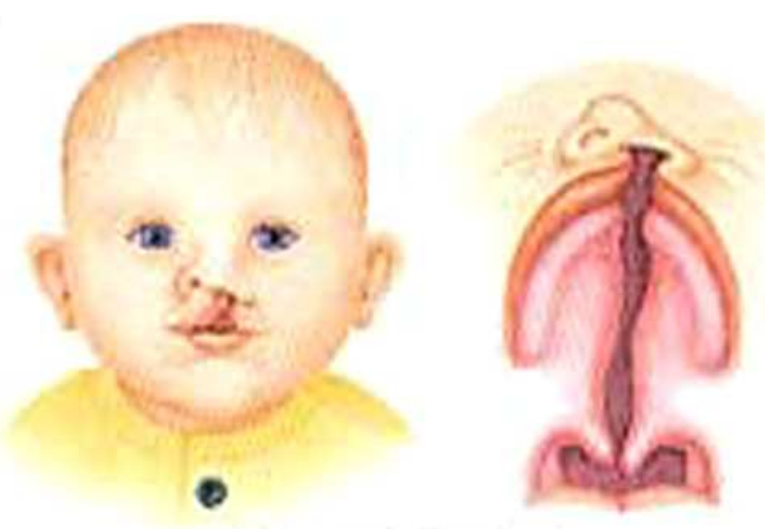

UNILATERAL

Figura 2.6 - Fissura transforame incisivo unilateral

Devido à ruptura dos tecidos duros e moles, a fissura acarreta alterações dentárias e faciais, que alteram toda a seqüência normal de desenvolvimento e crescimento craniofacial e dentário. Devido às transformações na face média e a influência das cirurgias primárias, principalmente a queiloplastia, há a ocorrência de 
significantes alterações faciais e dentárias tais como: restrição no crescimento sagital e transversal da maxila, podendo levar a um aumento da convexidade facial ao longo do crescimento; face mais longa e mandíbula mais aberta (rotação no sentido horário); assimetria nasal (achatamento da cartilagem alar do lado da fissura e desvio do septo nasal); mordida cruzada anterior e posterior em graus variados; agenesias dentárias (geralmente do incisivo lateral superior do lado fissurado); presença de dentes supranumerários adjacentes à fissura. $\mathrm{O}$ defeito ósseo imposto pela fissura causa deficiência na largura, altura e espessura do osso alveolar, que por conseqüência compromete a condição periodontal dos dentes adjacentes. Isso pode ser eliminado através da realização do enxerto ósseo alveolar, que resgata a continuidade do rebordo (Silva Filho et al 1995 e Silva Filho e Cavassan 2007). Todas essas alterações tornam o tratamento dos pacientes fissurados muito mais complexo, necessitando de uma equipe interdisciplinar e experiente (Suzuki et al 1992, Capelozza Filho, Taniguchi e Silva Filho 1993 e Trindade e Silva Filho 2007).

$\mathrm{Na}$ avaliação de pacientes adultos com fissura transforame incisivo, que não realizaram as cirurgias primárias para reabilitação, constatou-se que a fissura por si só não impede o crescimento da face, muito embora altere a forma da maxila e da face. Foi observado que a maxila não havia sofrido restrição no crescimento. $O$ trespasse horizontal aumentado e a presença de classe II desvelam a manifestação do potencial genético do crescimento da maxila e da face na presença da fissura (Capelozza Filho, Normando e Silva Filho, 1996).

Entretanto, com o tratamento, a face passa a crescer sob influência das cirurgias plásticas realizadas durante a infância. Uma grande parcela dos pacientes com fissura transforame incisivo apresenta um crescimento maxilar muito comprometido, característico do Padrão III, segundo Capelozza Filho (2004). 
Contudo, a severidade da deficiência varia de individuo para individuo, pois há vários fatores associados no grau de comprometimento como amplitude da fissura, atuação das cirurgias primárias, fatores hereditários e características individuais (Geraedts et al 2007 e Trindade e Silva Filho 2007). Em muitos casos, há a necessidade de realização de cirurgia ortognática para a completa reabilitação do paciente.

Como a presença da fissura provoca várias alterações tais como agenesias, supranumerários, incisivos laterais dismórficos e caninos impactados após enxerto ósseo, a imaginologia digital em três dimensões pode ser um grande aliado no diagnóstico e correto plano de tratamento desses pacientes (Wörtche et al, 2006).

Encontramos na literatura trabalhos com metodologia semelhante a este que avaliaram angulação e inclinação dentárias através de tomografia computadorizada (Fattori 2006 e Capelozza Filho 2005, 2008). Entretanto, não encontramos pesquisas que avaliassem a posição dentária em pacientes com fissura através da tomografia, mas somente utilizando modelos de gesso (Ribas 2003 e Reis et al 2008). 

PROPOSIÇÃO 



\section{PROPOSIÇÃO}

Este estudo, em pacientes com fissuras transforame incisivo unilateral, por meio de imagens tomográficas de feixe cônico, visou:

- Avaliar as angulações e inclinações dentárias induzidas pelo tratamento ortodôntico corretivo.

- Analisar morfologicamente o osso alveolar e contorno radicular após finalização do tratamento ortodôntico. 

MATERIAL E MÉTODOS 



\section{MATERIAL E MÉTODOS}

\subsection{SELEÇÃO DA AMOSTRA}

A amostra deste trabalho foi composta por dez pacientes do Hospital de Reabilitação de Anomalias Craniofaciais (HRAC) com fissura transforame incisivo unilateral, sendo 9 pacientes com fissura do lado esquerdo e 1 do lado direito, de ambos os sexos ( 6 homens e 4 mulheres). Todos os indivíduos estavam em fase de contenção após finalização do tratamento ortodôntico, e foram incluídos na amostra de modo aleatório, considerando apenas a obtenção de resultados de finalização satisfatórios e oportunidade de exame tomográfico, sem alterar, desta forma, a rotina do Hospital e dos pacientes.

A amostra foi caracterizada por algumas peculiaridades:

- Ausência de incisivo lateral do lado fissurado em quase todos os pacientes (exceto 1 paciente)

- Reabilitação com implante e prótese em regiões de ausência dentária no arco fissurado ou apenas espaço protético mantido em 5 dos 10 pacientes

- Dentes 13 no lugar do 12, 14 no lugar do 13, 23 no lugar do 22 ou 24 no lugar do 23 em 5 pacientes da amostra

- 3 pacientes foram submetidos à cirurgia ortognática

- Todos os pacientes foram submetidos ao enxerto ósseo alveolar

- Pequena reabsorção óssea na região do enxerto em 1 paciente

- Extração de um incisivo inferior (dente 41) em 1 paciente

- Reabilitação com prótese de três elementos 13 - 12 (pôntico) - 11 em 1 paciente

- Dentes com coroa disforme ou possível desgaste da coroa para futura reabilitação com prótese em 1 paciente (dentes 21 e 23) 


\subsection{OBTENÇÃO DAS IMAGENS TOMOGRÁFICAS}

Para a aquisição das imagens tomográficas foi utilizado o tomógrafo computadorizado por feixe cônico i-CAT (Imaging Sciences International, Pennsylvania, EUA) (Fig. 4.1), no setor de Radiologia da Faculdade de Odontologia de Bauru (FOB) - USP, em convênio com o Hospital de Reabilitação de Anomalias Craniofaciais (HRAC). As imagens foram realizadas em pacientes da amostra em fase de contenção após finalização do tratamento ortodôntico, substituindo as radiografias finais solicitadas nesta fase, para desta forma não expor os pacientes à radiação desnecessária.

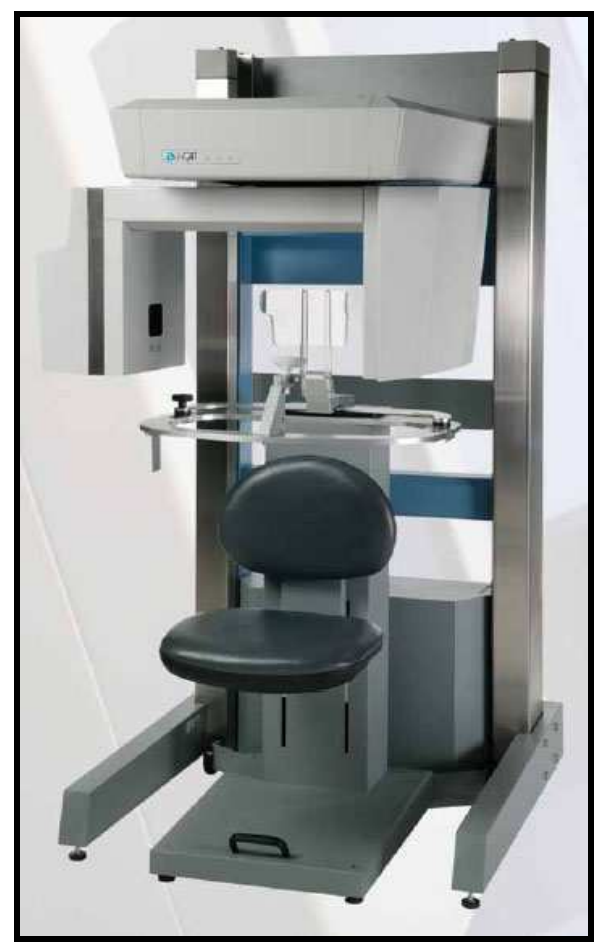

Figura 4.1 - Tomógrafo i-CAT (Imaging Sciences International, 2007)

O exame foi realizado por técnicos habilitados em radiologia. Os pacientes foram posicionados sentados, com a cabeça presa em um suporte na testa para diminuir a possibilidade de movimentação durante a aquisição da imagem. Não foi 
utilizada a mentoneira, um equipamento que é acoplado ao tomógrafo e serve para apoio do mento, auxiliando no posicionamento da cabeça, para evitar, desta forma, a sobreposição de imagem desta região, o que poderia dificultar futuras medidas cefalométricas. Para ajudar no posicionamento da cabeça, utilizamos linhas guias presentes no aparelho, uma vertical e outra horizontal.

Para realização do exame, o aparelho possui algumas opções de protocolo de aquisição da imagem e cada protocolo tem relação com a área a ser escaneada como, por exemplo, somente a maxila $(6 \mathrm{~cm})$, somente a mandíbula $(6 \mathrm{~cm})$, maxila e mandíbula $(8 \mathrm{~cm})$, maxila, mandíbula e base do crânio $(13 \mathrm{~cm})$ e crânio total $(22 \mathrm{~cm})$. Também é possível selecionar a resolução da imagem com o tamanho do voxel variando entre 0,2 a $0,4 \mathrm{~mm}$, sendo o seu tamanho inversamente proporcional a resolução e nitidez. Outra característica a ser considerada é que quanto menor é o tamanho do voxel e maior extensão da área a ser escaneada, maior será o tempo do exame e, portanto maior será a quantidade de radiação e também as chances de movimentação da cabeça.

O protocolo escolhido para aquisição das imagens foi o Extended Heigh que possibilita a visualização do crânio total do paciente. Este é o protocolo que abrange o maior tamanho de regiões escaneadas $(22 \mathrm{~cm})$. Como a amostra foi composta por adolescentes e adultos e o padrão facial comum dos pacientes com fissura é de face longa, achamos prudente padronizar o protocolo de aquisição em 22cm para evitar possíveis cortes de estruturas como o mento ou a base do crânio e desta maneira inviabilizar as medidas cefalométricas. Neste protocolo só existe um tipo de resolução de imagem que é de voxel de $0,4 \mathrm{~mm}$ e o tempo do exame é de 40 segundos. 
Após o correto posicionamento do paciente foi feito um escaneamento inicial para verificação da área que estava sendo englobada no exame. Este escaneamento inicial ou Scout View nos permite corrigir possíveis erros na posição da cabeça ou da área selecionada evitando desta maneira repetição do exame e radiação desnecessária para o paciente.

A imagem em volume da região foi adquirida com um giro de $360^{\circ}$ do tubo de raios $X$ e seu sensor ao redor da cabeça do paciente, com dois scans de 20 segundos cada que são reconstruídos para obtenção da imagem total. As imagens obtidas foram enviadas à workstation que acompanha o i-CAT para a reconstrução primária e foram gravadas no formato DICOM 3 multi-files. Para trabalhar as imagens foi utilizado o módulo 3D do software Dolphin Imaging 3D Software (Dolphin Imaging \& Manangement Solutions, Chatsworth, California, USA) (Figs. 4.2 e 4.3).
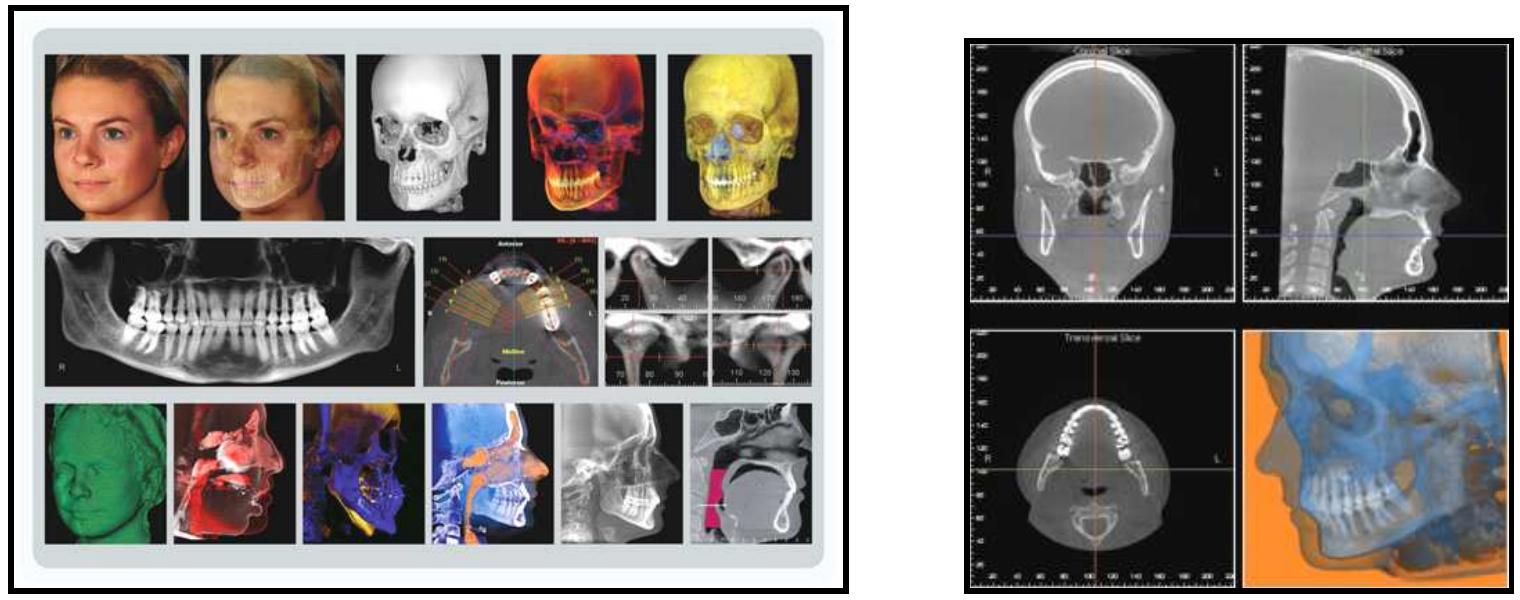

Figuras 4.2 e 4.3 - Exemplos da utilização do software (DOLPHIN IMAGING)

\subsection{MENSURAÇÃO DAS IMAGENS TOMOGRÁFICAS}

Para mensuração das imagens tomográficas foram estabelecidos protocolos de padronização para realizarmos medidas fiéis e reproduzíveis. 
A partir da ferramenta do software de "Orientação do Objeto" posicionamos a cabeça de acordo com o Plano de Andrews baseado nos dentes superiores (Andrews, 1989) (Figs. 4.4, 4.5 e 4.6), semelhante à metodologia utilizada por Fattori (2006).
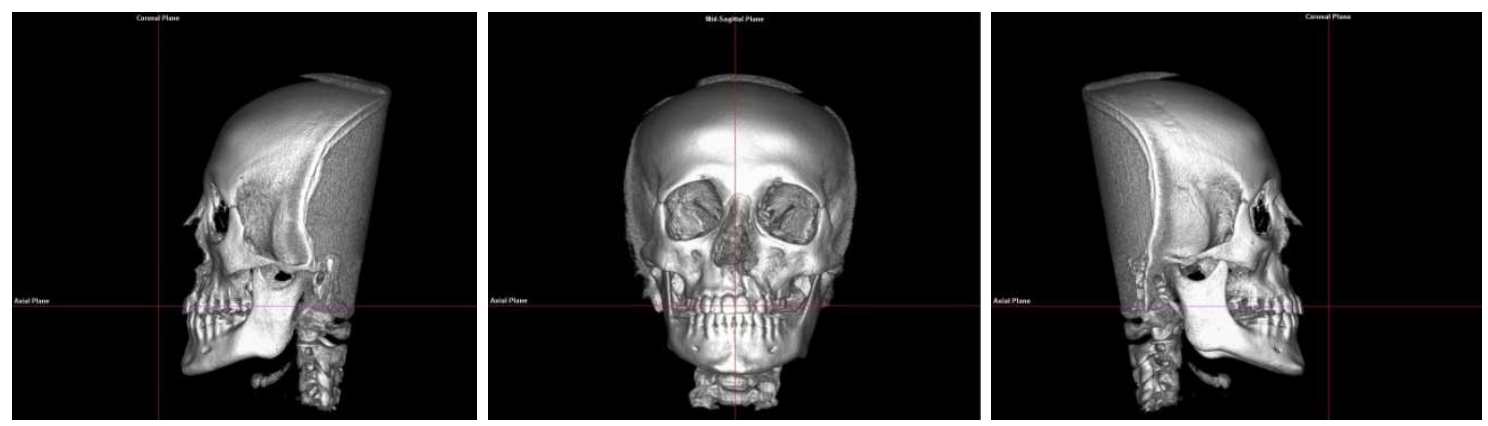

Figuras 4.4, 4.5 e 4.6 - Ferramenta de Orientação do Objeto para posicionamento da cabeça de acordo com o Plano de Andrews dos dentes superiores (DOLPHIN IMAGING)

O Plano de Andrews é uma linha imaginária que passa coincidente ao plano médio-transverso de todas as coroas de uma arcada quando os dentes encontramse bem posicionados (Andrews, 1989) (Figura 4.7). Como os pacientes da amostra já tinham finalizado o tratamento ortodôntico corretivo, observamos que os Planos de Andrews superior, inferior e o Plano Oclusal tendiam a estar todos paralelos entre si. Portanto, sempre neste trabalho o Plano de Andrews está referenciado como paralelo ao Plano Oclusal.

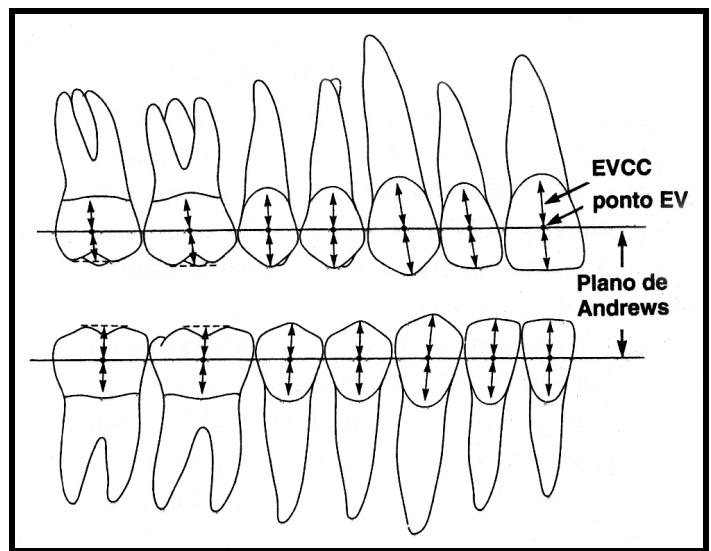

Figuras 4.7 - Ilustração do Eixo Vestibular da Coroa Clínica (EVCC), do Ponto EV e demarcação do Plano de Andrews passando pelo ponto EV dos dentes de cada arcada dentária (Andrews, 1989) 
Como a inclinação e angulação dentárias são obtidas a partir do plano oclusal, ele foi utilizado como referência para reconstrução primária da maxila e depois da mandíbula, de modo que todos os slices tenham este plano como referência e sejam paralelos a ele, viabilizando as mensurações. Definimos como angulação da coroa o ângulo formado pelo eixo vestibular da coroa clínica (EVCC) em relação a uma linha perpendicular ao plano oclusal, no sentido mésio-distal, e inclinação como o ângulo formado entre uma linha perpendicular ao plano oclusal e uma linha paralela e tangente ao EVCC no seu ponto central (ponto EV), no sentido vestibulolingual (Andrews, 1989).

Após o posicionamento da cabeça conforme o Plano Oclusal, foi utilizada a ferramenta do software denominada "Cross Section" (dentro da ferramenta Build $x$ Ray). Nesta seção é possível a visualização da posição do crânio, do corte axial selecionado, da imagem panorâmica e do corte parassagital de cada dente (Fig. 4.8). Para seleção da imagem axial, foi posicionada a linha de corte primeiramente no centro das coroas clínicas dos dentes superiores, para analisar os dentes 13 a 23, e depois dos inferiores, para analisar os dentes 33 a 43. Os dentes superiores e inferiores, desta forma, foram avaliados separadamente. $\mathrm{Na}$ imagem axial dos dentes superiores, com o auxílio da ferramenta Redo Path, foram demarcados os pontos que passavam mais próximos ao centro da coroa clínica de todos os dentes para geração da imagem panorâmica. Antes de gerar a panorâmica padronizamos algumas características: espessura da imagem em $32 \mathrm{~mm}$, largura do corte de $40 \mathrm{~mm}$ e espessura das fatias de $0,5 \mathrm{~mm}$. 


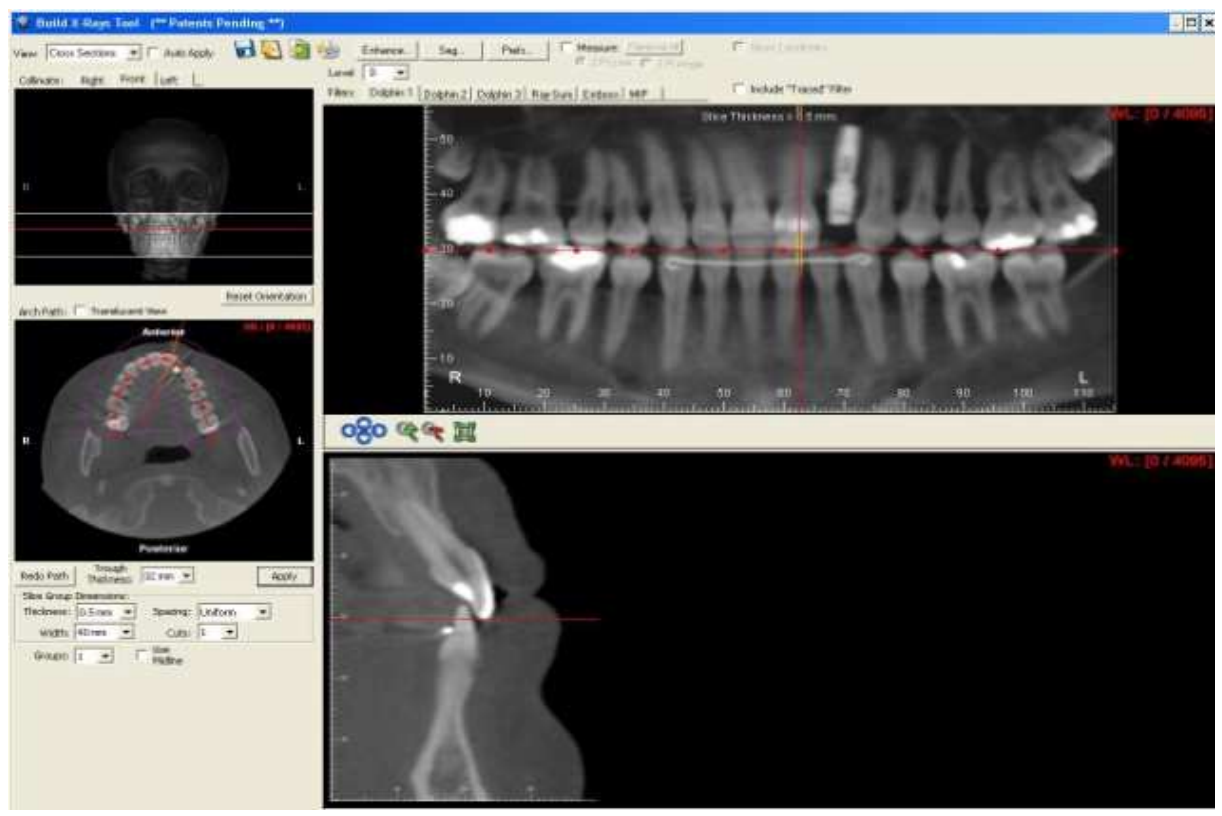

Figura 4.8 - Imagem selecionada pela ferramenta do software denominada "Build X-Ray" - "Cross Section" (DOLPHIN IMAGING)

Para realização do corte parassagital de cada um dos dentes anteriores superiores foi necessário deixar o crânio do paciente na visão frontal e angular o plano sagital mediano no sentido látero-lateral, de modo que cada dente selecionado ficasse com seu longo eixo perpendicular ao plano oclusal e, desta maneira, toda a extensão da raiz dentária fosse visualizada no corte parassagital, mas sem movimentar os dentes no sentido vestibulolingual para não alterar os valores da inclinação (Fig. 4.9). A partir desta nova imagem foram realizados os cortes parassagitais no longo eixo de cada dente e desta forma foram obtidas as imagens para medição das inclinações dentárias.

Todos os passos descritos para os dentes superiores foram repetidos nos dentes inferiores. 

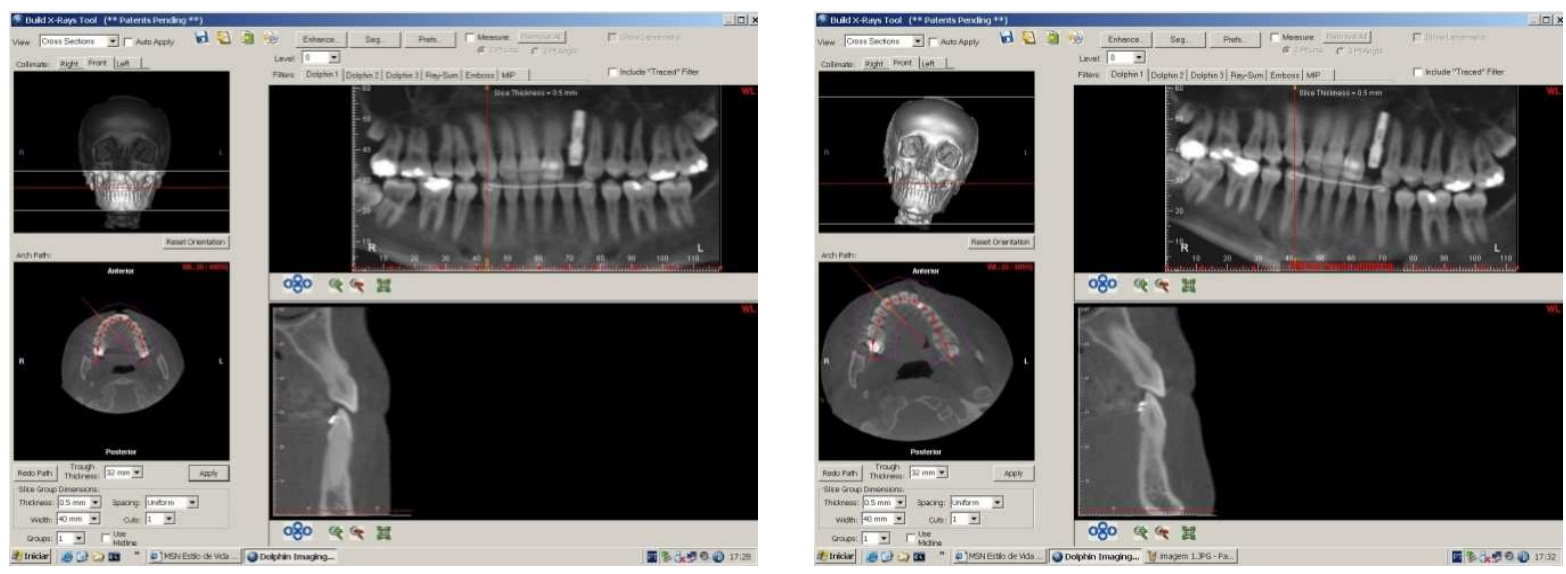

Figura 4.9 - Angulação da cabeça de modo que o longo eixo do dente ficasse selecionado (DOLPHIN IMAGING)

As imagens foram salvas no formato JPEG para serem trabalhadas posteriormente em outro software de imagem, que não identifica a extensão DICOM. Para medir os ângulos desejados foi utilizado o programa Adobe Photoshop 7.0.1 ${ }^{\circledR}$ (Adobe Systems Incorporated, USA), pois a ferramenta de medir ângulos do software Dolphin era incompleta segundo a metodologia determinada neste trabalho.

Para analisar as medidas de inclinação e angulação nos baseamos na metodologia descrita por Fattori (2006).

Primeiramente foi selecionada a imagem parassagital de cada dente. Então foi demarcado um ponto no limite inferior da vestibular da coroa clínica e outro na junção amelocementária (JAC). Estas demarcações estabelecem o limite da coroa anatômica do dente (Fig. 4.10). 


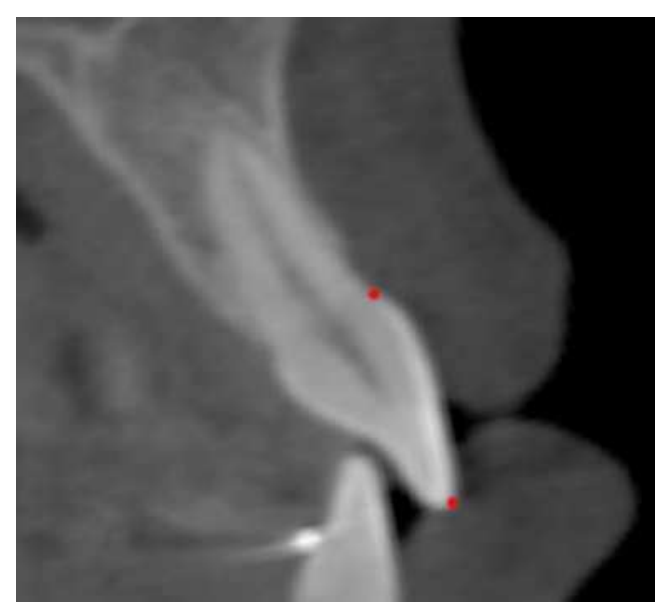

Figura 4.10 - Demarcação dos limites da coroa anatômica

A partir de dados preconizados por Orban e citado por Andrews (1989) e Fattori (2006), foi subtraído a partir da JAC a medida de $1,8 \mathrm{~mm}$, que é a diferença entre a coroa anatômica e coroa clínica, medida necessária para determinação do ponto EV (eixo vestibular), que se localiza no centro da coroa clínica sobre EVCC (eixo vestibular da coroa clínica). Após demarcar os 2 pontos iniciais foi traçada uma reta ligando os dois pontos (Fig. 4.11); esta reta foi duplicada e girada em 90; esta segunda reta também foi duplicada e estas duas retas foram posicionadas sobre os pontos demarcados na incisal e JAC, respectivamente (Fig. 4.12).

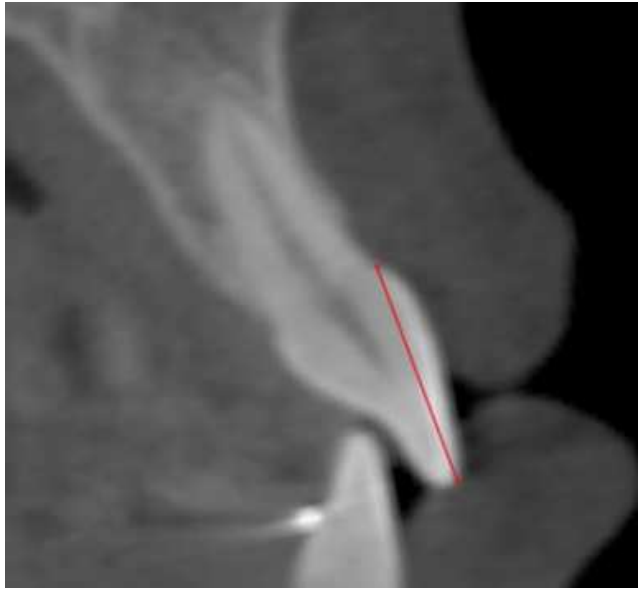

Figura 4.11 - Reta representando a distância da coroa anatômica

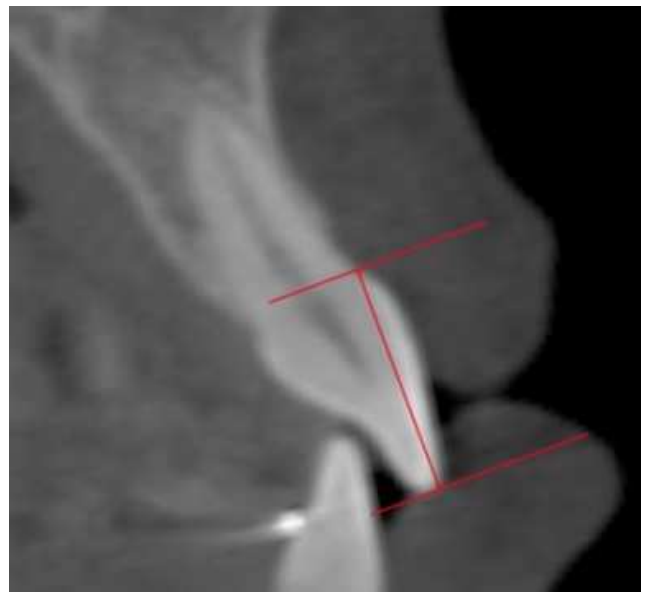

Figura 4.12 - Retas perpendiculares à reta da coroa anatômica 
Utilizando a ferramenta de régua foi identificada a medida da coroa anatômica e subtraído 1,8mm para determinarmos o tamanho da coroa clínica (Fig. 4.13 e 4.14).

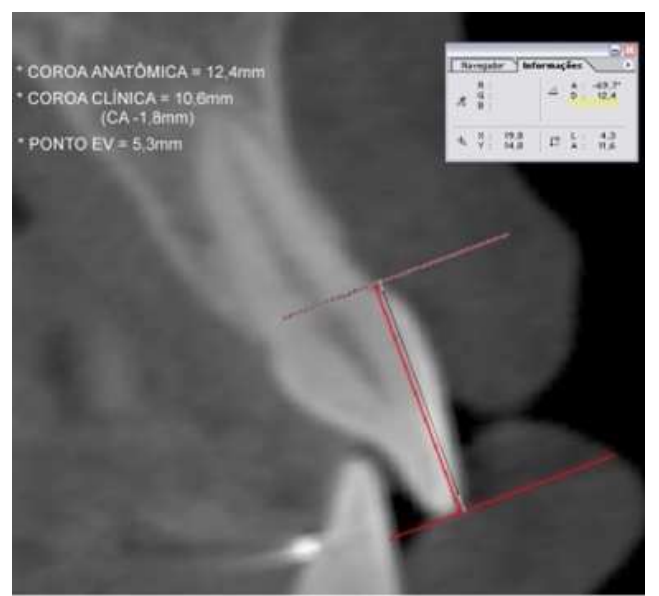

Figura 4.13 - Medida do tamanho da coroa anatômica

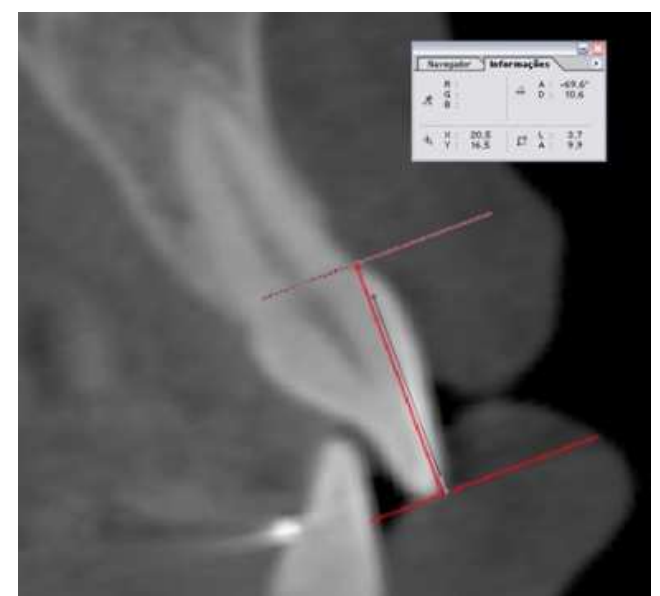

Figura 4.14 - Medida do tamanho da coroa clínica (coroa anatômica $-1,8 \mathrm{~mm}$ )

Para marcação do ponto determinando o extremo cervical da coroa clínica, a ferramenta de régua foi deslizada sobre a linha da incisal até que sua extremidade superior tocasse a face vestibular (Fig. 4.15), e então linhas de guia vertical e horizontal foram arrastadas até o ponto em questão e com a ferramenta de pincel foi demarcado o ponto extremo cervical da coroa clínica (Fig. 4.16).

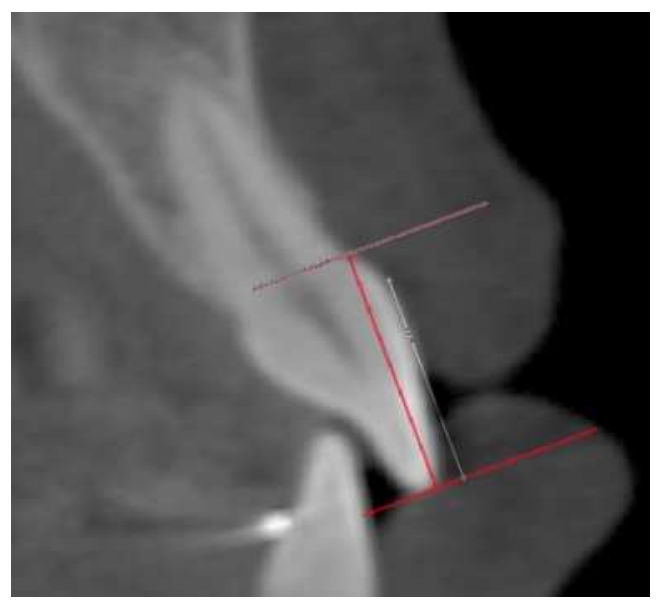

Figura 4.15 - Arrastando a régua até tocar a face vestibular do dente

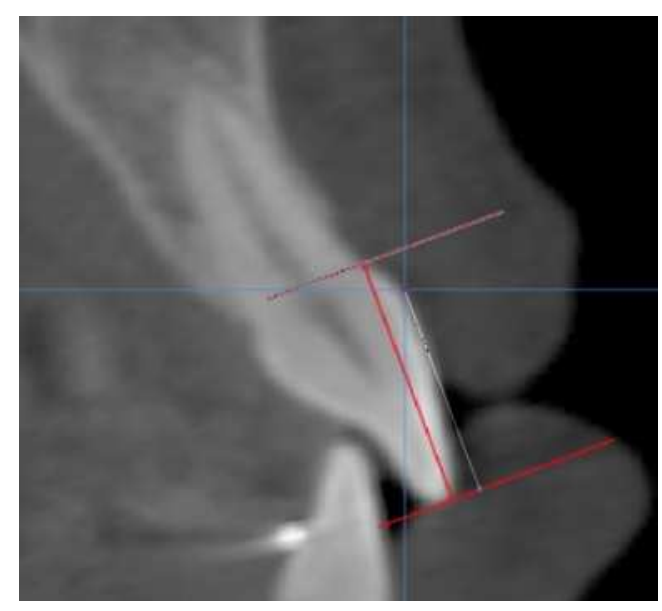

Figura 4.16 - Demarcação do ponto extremo cervical da coroa cínica 
As linhas de referência foram apagadas e uma nova linha foi traçada entre o ponto incisal e o ponto extremo cervical da coroa clínica, para desta maneira representar o longo eixo da coroa clínica (Fig. 4.17). Foram repetidos os passos de duplicação e giro de $90^{\circ}$ da nova reta e a coroa clínica foi delimitada com as duas novas retas passando sobre os pontos incisal e cervical. Com a ferramenta de régua foi mensurado o tamanho da coroa clínica (já determinado anteriormente) (Fig. 4.18), e a partir da média desta distância foi determinado o ponto EV, representando o centro da coroa clínica.

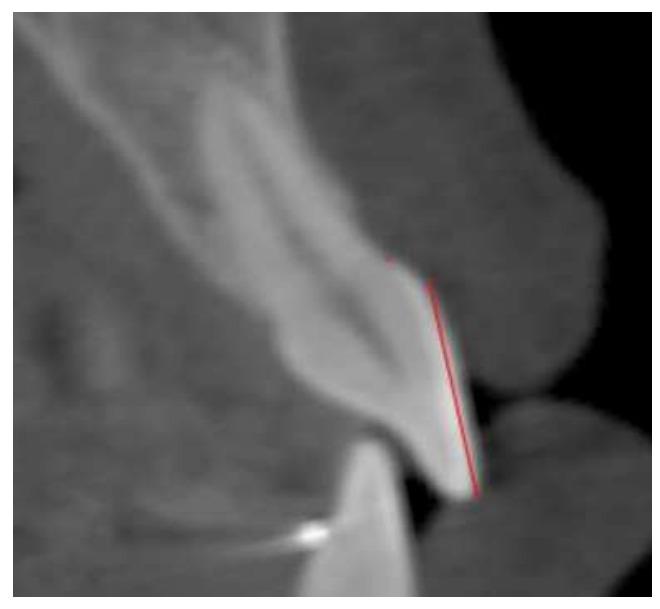

Figura 4.17 - Reta representando o longo eixo da coroa clínica

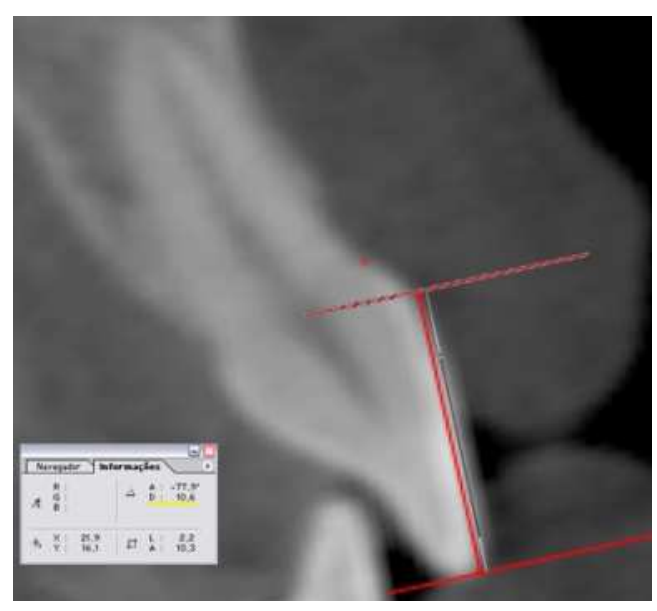

Figura 4.18 - Medida do tamanho da coroa clinica

A ferramenta de régua foi proporcionada na medida representando a distância do ponto EV até a incisal. Então a régua foi deslizada sobre a linha na incisal, permanecendo perpendicular a esta, até sua extremidade superior tocar a face vestibular da coroa clínica; as linhas de guia horizontal e vertical foram arrastadas até este ponto e então o ponto EV foi demarcado (Fig. 4.19). Estas linhas guias foram novamente apagadas e desta maneira foi possível a visualização de todos os pontos demarcados anteriormente (Fig. 4.20). 


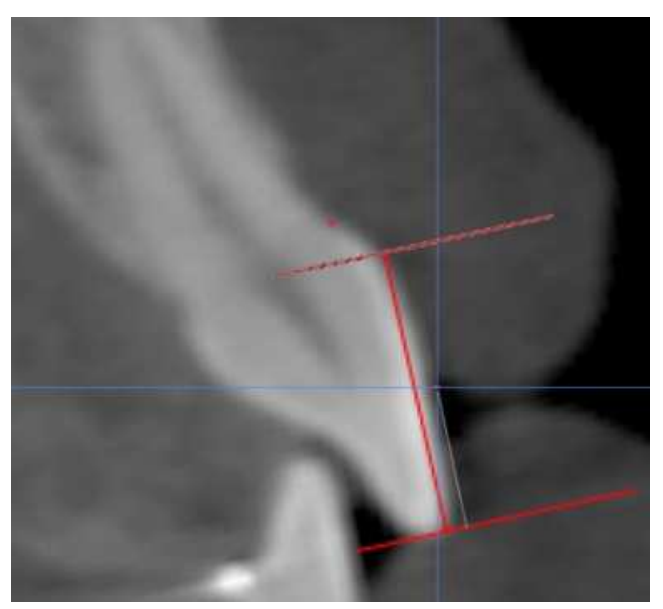

Figura 4.19 - Demarcação do ponto EV

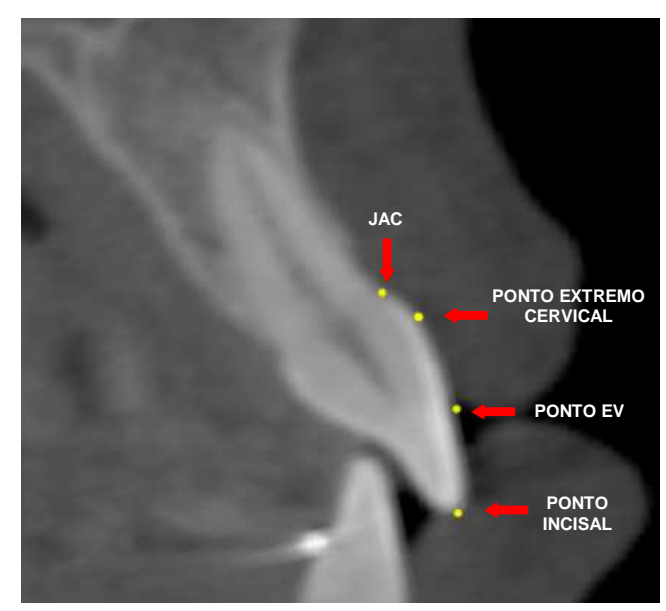

Figura 4.20 - Remoção das linhas guia e visualização de todos os pontos demarcados

A mensuração da inclinação deste dente foi medida com a ferramenta de ângulo. Foi traçada uma linha passando sobre o ponto EV e tangenciando o maior número possível de pontos na vestibular desta coroa (Fig. 4.21) e outra linha perpendicular ao plano oclusal. $O$ ângulo formado entre estas duas linhas traduziu 0 valor da inclinação da coroa clínica (Fig. 4.22).

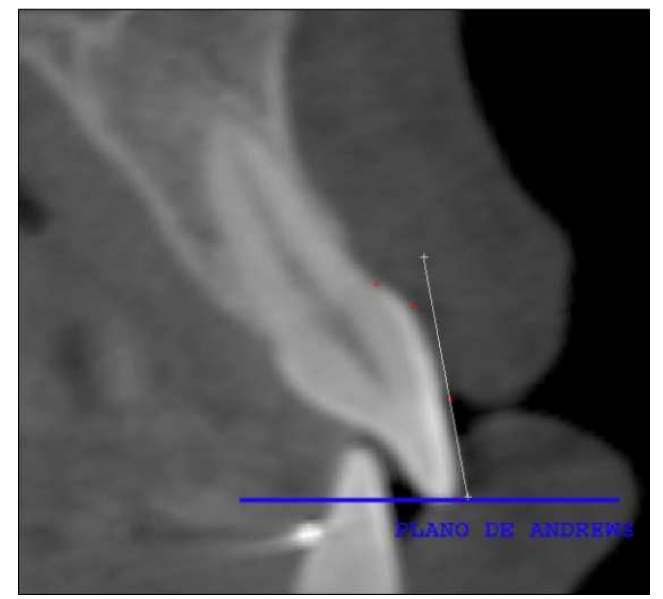

Figura 4.21 - Linha sobre ponto EV e tangenciando face vestibular

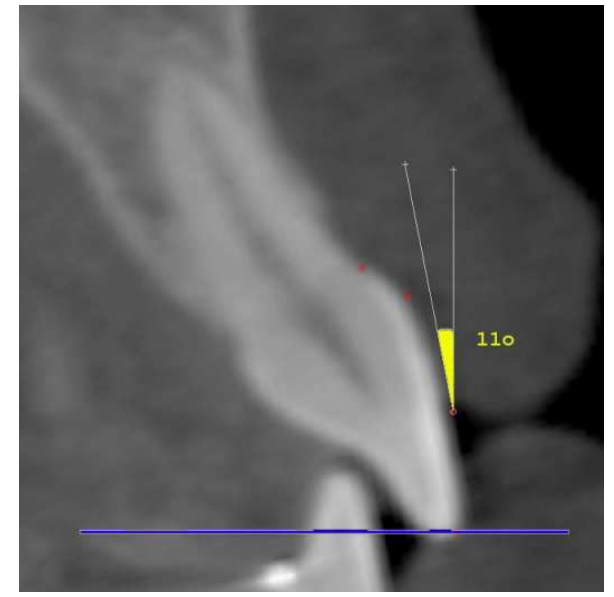

Figura 4.22 - Medida da inclinação

Quando a linha perpendicular ao plano oclusal (linha vertical) passava à frente da coroa dentária (ponto EV) o valor foi considerado positivo (Fig. 4.23). Já quando 
esta linha vertical passava sobre a coroa dentária (atrás do ponto EV) o valor foi considerado negativo (Fig. 4.24).

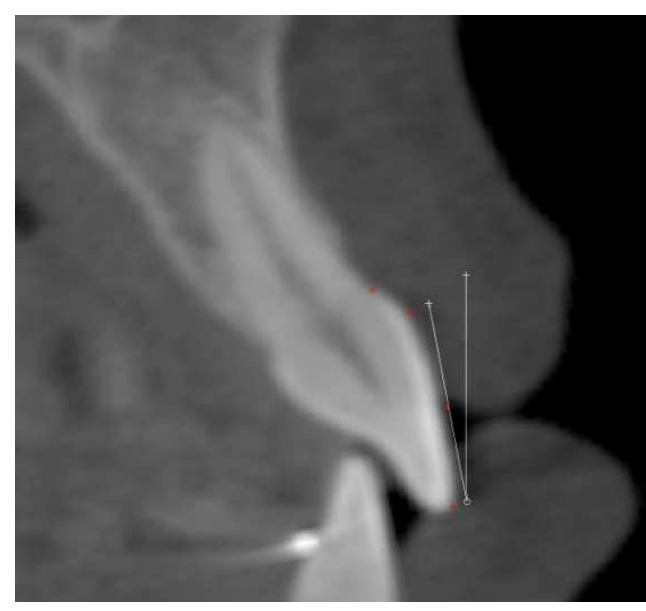

Figura 4.23 - Valor positivo da inclinação

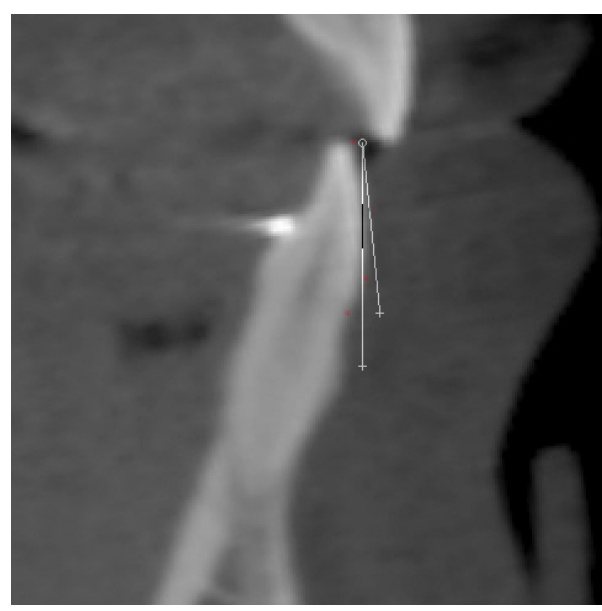

Figura 4.24 - Valor negativo da inclinação

Como forma de padronização, a avaliação dos dentes foi realizada na seguinte ordem: canino superior direito (dente 13), incisivo lateral superior direito (dente 12), incisivo central superior direito (dente 11), incisivo central superior esquerdo (dente 21), incisivo lateral superior esquerdo (dente 22), canino superior esquerdo (dente 23), canino inferior esquerdo (dente 33), incisivo lateral inferior esquerdo (dente 32), incisivo central inferior esquerdo (dente 31), incisivo central inferior direito (dente 41), incisivo lateral inferior direito (dente 42) e canino inferior direito (dente 43).

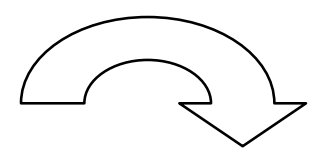

\begin{tabular}{lll|lll}
13 & 12 & 11 & 21 & 22 & 23 \\
\hline 43 & 42 & 41 & 31 & 32 & 33
\end{tabular}

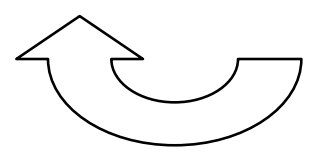


Para medir a angulação dos dentes, foi selecionada a opção Panoramic na ferramenta Build $x$-Ray do software Dolphin Imaging 3D Software (Dolphin Imaging \& Manangement Solutions, Chatsworth, California, USA) (Fig. 4.25). Na visão craniofacial frontal foi determinada a altura que seria selecionada, compreendendo desde a base da mandíbula até o côndilo e fossa condilar.

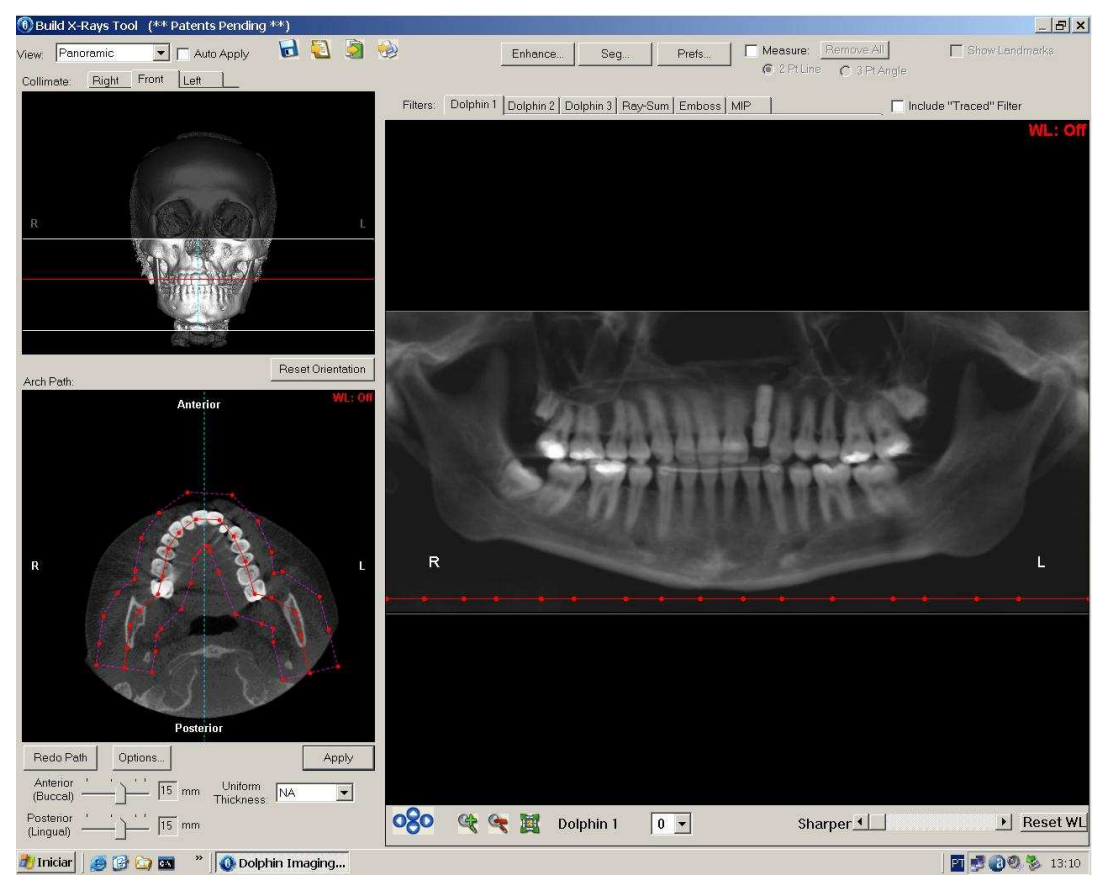

Figura 4.25 - Imagem selecionada pela ferramenta do software denominada "Build X-Ray" "Panoramic" (DOLPHIN IMAGING)

Os dentes superiores e inferiores foram analisados separadamente. Primeiramente, a linha guia horizontal foi posicionada paralela ao plano oclusal dos dentes anteriores superiores para que estas estruturas fossem visualizadas numa visão axial. No corte axial foi selecionada a área a ser visualizada na panorâmica; com a ferramenta Redopath a seleção foi realizada a partir do côndilo do lado direito até o côndilo do lado esquerdo, passando pelo centro da oclusal de todos os dentes superiores, descrevendo novamente uma trajetória parabólica semelhante ao formato da arcada dentária (Fig. 4.26). A espessura da panorâmica foi padronizada com $30 \mathrm{~mm}$, sendo $15 \mathrm{~mm}$ para região vestibular e $15 \mathrm{~mm}$ para região lingual. 


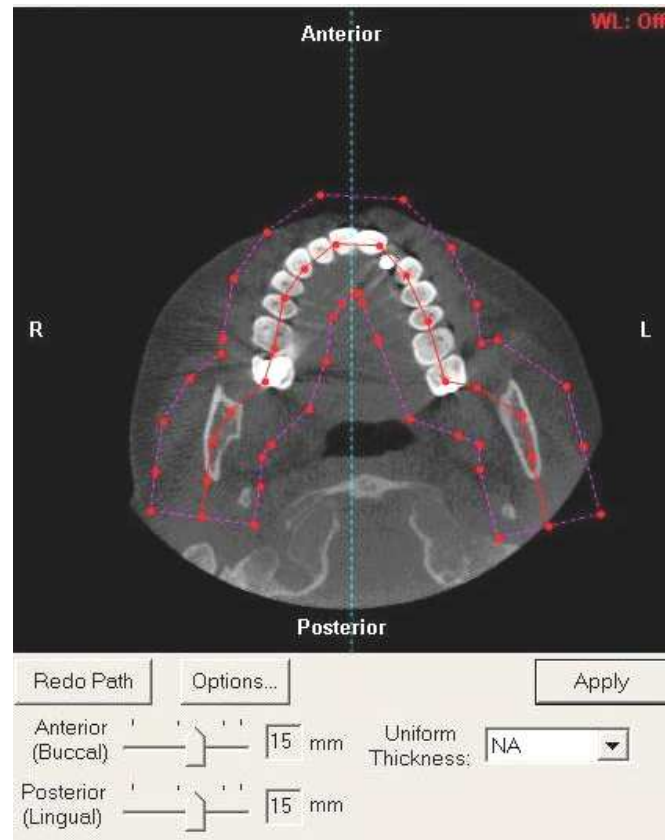

Figura 4.26 - Seleção através da ferramenta do software da região a ser demarcada na panorâmica

Depois de gerada a imagem da panorâmica (Fig. 4.27), ela foi salva no formato JPEG e para medição das angulações dentárias foi utilizado o software Adobe Photoshop 7.0.1 ${ }^{\circledR}$ (Adobe Systems Incorporated, USA).

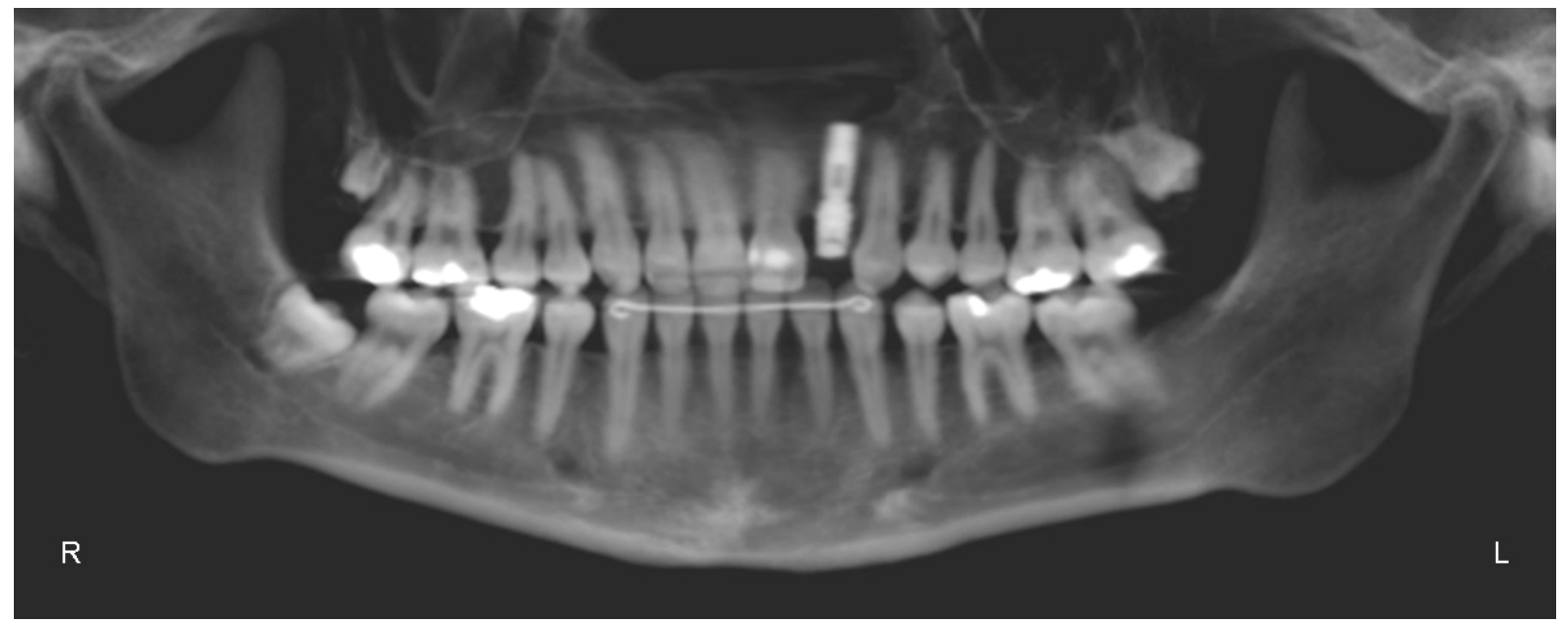

Figura 4.27 - Visão da panorâmica

Foi selecionada na panorâmica somente a região a ser estudada (dentes anteriores superiores e inferiores). Com a ferramenta de régua foi traçada uma reta 
correspondendo ao longo eixo dentário, que passava pelo maior numero de pontos no centro do canal radicular e seguia em direção incisal (Fig. 4.28); alterações como, por exemplo, dilacerações dentárias, foram excluídas (Fig. 4.29).

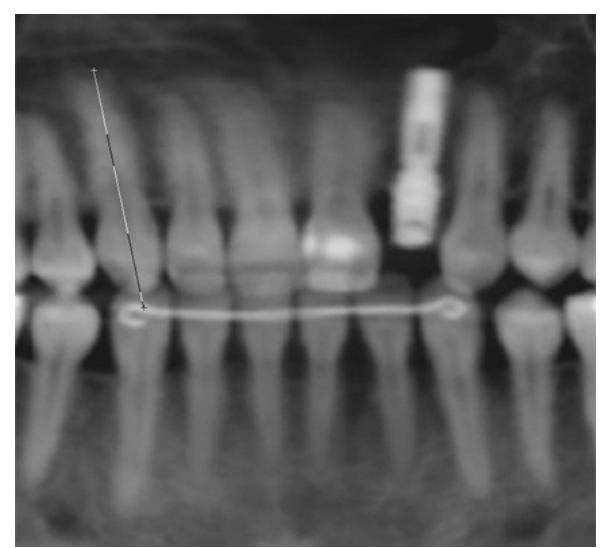

Figura 4.28 - Linha demarcando o longo eixo dentário

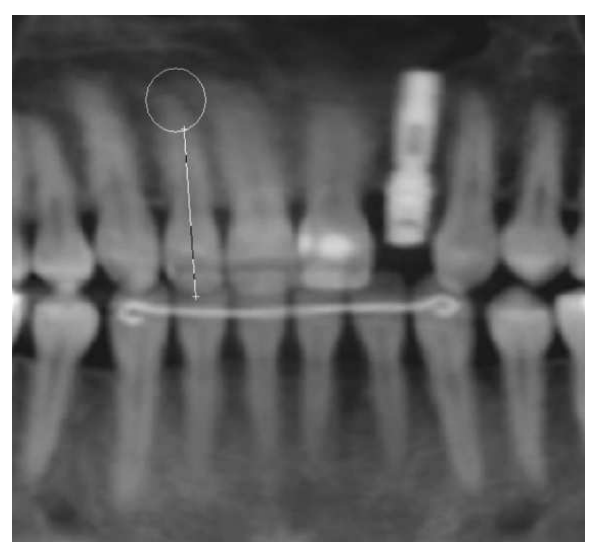

Figura 4.29 - Exclusão da dilaceração para não alterar de maneira errônea a medida de angulação

Outra reta foi traçada perpendicular ao plano oclusal e o ângulo formado entre essas duas retas proveu o valor da angulação daquele dente (Fig. 4.30). Este valor foi considerado positivo quando a coroa estava angulada para mesial e negativo quando a coroa estava angulada para distal.

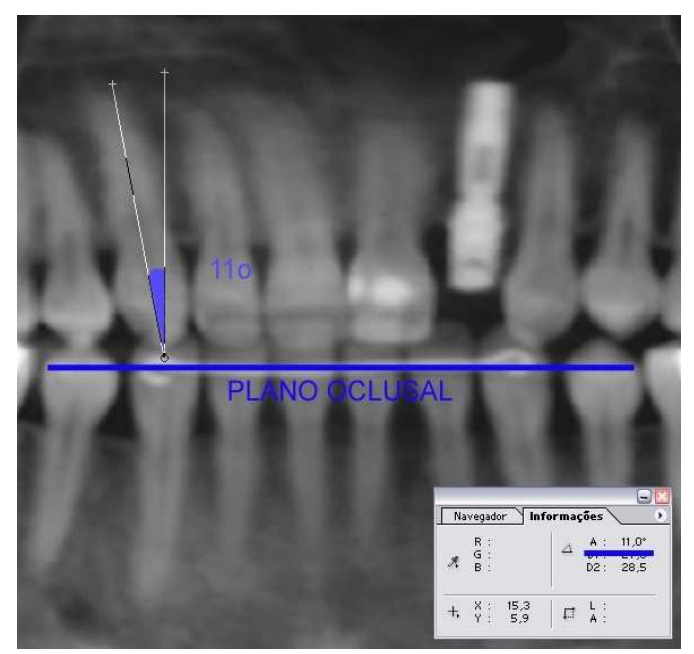

Figura 4.30 - Medida de angulação

Para a análise dos dentes inferiores foram repetidos os mesmo passos. 
RESULTADOS 



\section{RESULTADOS}

$\mathrm{Na}$ tabela de medidas foram anotados os seguintes valores: dimensão vertical da coroa anatômica, dimensão vertical da coroa clínica, distância do ponto EV em relação ao ponto incisal, inclinação e angulação.

Todas as medidas foram realizadas por um único examinador, que fez a calibração do método em $50 \%$ da amostra de maneira aleatória, no período de 15 dias antes da análise.

As medidas feitas pelo examinador foram repetidas, para todos os pacientes da amostra, após o período de uma semana, e separadas em T1 e T2 respectivamente, seguindo os passos já descritos anteriormente.

Os resultados foram enviados para análise estatística para avaliação da precisão, reprodutibilidade ou replicabilidade do método proposto. Os testes estatísticos utilizados foram:

* Media e Desvio Padrão

* Distribuição Normal (Teste de Shapiro-Wilk)

* Erro sistemático (reprodutibilidade ou replicabilidade)

- Teste de Wilcoxon

- Teste t pareado (distribuição simétrica)

* Erro Casual (precisão)

- Fórmula de Dahlberg

Para avaliação se o padrão de distribuição entre T1 e T2 era normal ou não, foi aplicado o teste de Shapiro-Wilk a um nível de significância de 0,05 ( $\alpha=5 \%$ ). A distribuição normal é um pré-requisito para utilização de testes paramétricos (ou seja, usando a média como medida de tendência central e o desvio-padrão como 
medida da variabilidade dos dados). Quando o valor P para o teste de Shapiro-Wilk for menor que 0.05 (5\%) significa que a amostra é anormal (ou assimétrica).

Outro fator a ser testado é o erro do método. Ele testa a capacidade dos dados de representarem a verdade sobre o fenômeno que está sendo examinado e de serem reproduzíveis em outro momento (Normando, Quintão e Almeida, 2008). Para teste de erro geralmente as medidas realizadas são duplicadas em um determinado intervalo de tempo. Quanto menores os erros do método, ou de mensurações, maior a validade ou confiabilidade dos dados obtidos (Houston, 1983). Espera-se, portanto, que as medidas sejam precisas.

Nesta amostra, quase todos os grupos avaliados apresentaram distribuição normal $(p \geq 0,05)$ em T1 e T2, exceto a medida de inclinação do incisivo lateral do lado não fissurado. Portanto, para este dente foi aplicado o teste de Wilcoxon e para todos os demais foi aplicado o teste t pareado de modo a checar o erro sistemático. O Erro Sistemático examina a reprodutibilidade ou replicabilidade das medidas executadas, ou seja, descreve se você, sistematicamente, obteve medidas diferentes nos dois tempos de medidas (T1 e T2).

Pelo teste $\mathrm{t}$ pareado, foi detectado que ocorreram algumas pequenas diferenças estatísticas entre a $1^{\underline{a}}$ e a $2^{\underline{a}}$ medidas, mas as diferenças, apesar de serem significantes estatisticamente, são muito pequenas sob o ponto de vista clínico. As medidas que apresentaram diferença estatisticamente significante foram: dimensão da coroa anatômica, coroa clínica e distância do ponto EV do incisivo central do lado não fissurado e angulação do dente 41.

O último teste estatístico aplicado foi o do erro casual, utilizando a fórmula de Dalberg. O erro casual é uma média das diferenças entre a primeira e a segunda 
medidas. Ele define qual a precisão do método. Define-se como "precisão", a capacidade do método de fazer uma leitura exata do fenômeno examinado.

A fórmula proposta para o erro casual é a que segue (Houston, 1983):

$$
S_{e}^{2}=\frac{\Sigma d^{2}}{2 n}
$$

$\mathrm{S}_{\mathrm{e}}=$ representa 0 erro de Dalberg

$\Sigma d^{2}=$ somatório dos quadrados das diferenças entre as primeiras e segundas medições

$2 \mathrm{n}=$ dobro do número dos casos em que foram repetidas as mensurações

Nos resultados desta pesquisa a precisão do método foi satisfatória, pois as diferenças médias (Dahlberg) foram pequenas, variando entre $0,1^{\circ}$ e $0,9^{\circ}$.

Todos os resultados encontrados e testes estatísticos para inclinação e angulação estão exemplificados nas tabelas abaixo. Os demais testes estão em anexo.

Tabela 5.1 - Testes estatísticos para inclinação no arco superior

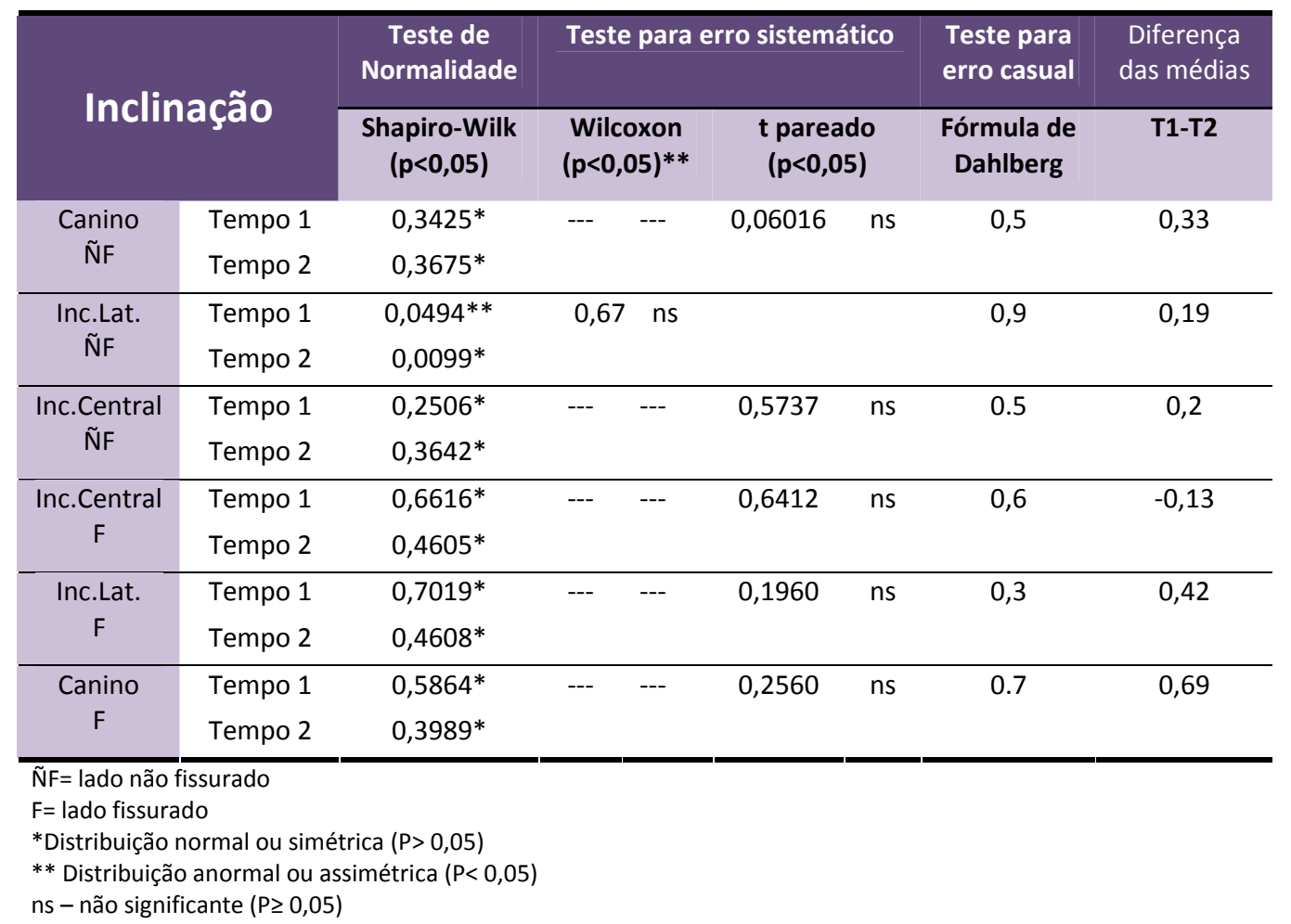


Tabela 5.2 - Testes estatísticos para angulação no arco superior

\begin{tabular}{|c|c|c|c|c|c|c|c|c|}
\hline \multirow{2}{*}{\multicolumn{2}{|c|}{ Angulação }} & \multirow{2}{*}{$\begin{array}{c}\text { Teste de } \\
\text { Normalidade } \\
\begin{array}{c}\text { Shapiro-Wilk } \\
(p<0,05)\end{array}\end{array}$} & \multicolumn{4}{|c|}{ Teste para erro sistemático } & \multirow{3}{*}{$\begin{array}{c}\begin{array}{c}\text { Teste para } \\
\text { erro casual }\end{array} \\
\begin{array}{c}\text { Fórmula de } \\
\text { Dahlberg }\end{array} \\
0.4\end{array}$} & \multirow{3}{*}{$\begin{array}{c}\begin{array}{c}\text { Diferença } \\
\text { das médias }\end{array} \\
\text { T1-T2 } \\
-0,02\end{array}$} \\
\hline & & & \multicolumn{2}{|c|}{$\begin{array}{l}\text { Wilcoxon } \\
(p<0,05)^{* *}\end{array}$} & \multicolumn{2}{|c|}{$\begin{array}{c}\text { t pareado } \\
(p<0,05)\end{array}$} & & \\
\hline \multirow{2}{*}{$\begin{array}{l}\text { Canino } \\
\tilde{N} F\end{array}$} & Tempo 1 & $0,4959 *$ & --- & --- & 0,4433 & ns & & \\
\hline & Tempo 2 & $0,5387^{*}$ & & & & & & \\
\hline \multirow{2}{*}{$\begin{array}{l}\text { Inc.Lat. } \\
\tilde{N} F\end{array}$} & Tempo 1 & $0,9392 *$ & --- & --- & 0,1679 & ns & 0.4 & $-0,22$ \\
\hline & Tempo 2 & $0,9661 *$ & & & & & & \\
\hline \multirow{2}{*}{$\begin{array}{c}\text { Inc.Central } \\
\tilde{N} F\end{array}$} & Tempo 1 & $0,9427 *$ & --- & --- & 0,1565 & ns & 0.7 & $-0,23$ \\
\hline & Tempo 2 & $0,7617^{*}$ & & & & & & \\
\hline \multirow{2}{*}{$\begin{array}{c}\text { Inc.Central } \\
\mathrm{F}\end{array}$} & Tempo 1 & $0,9568^{*}$ & --- & --- & 0,5121 & ns & 0.5 & $-0,16$ \\
\hline & Tempo 2 & 0,9900* & & & & & & \\
\hline \multirow{2}{*}{$\begin{array}{c}\text { Inc. Lat. } \\
\text { F }\end{array}$} & Tempo 1 & $0,3861 *$ & --- & --- & 0,8074 & ns & 0.3 & $-0,08$ \\
\hline & Tempo 2 & $0,3253^{*}$ & & & & & & \\
\hline \multirow{2}{*}{$\begin{array}{c}\text { Canino } \\
\mathrm{F}\end{array}$} & Tempo 1 & $0,4162 *$ & --- & --- & 0,4296 & ns & 0.5 & 0,06 \\
\hline & Tempo 2 & $0,2879 *$ & & & & & & \\
\hline
\end{tabular}

$\tilde{\mathrm{N}} \mathrm{F}=$ lado não fissurado

$\mathrm{F}=$ lado fissurado

*Distribuição normal ou simétrica $(P>0,05)$

** Distribuição anormal ou assimétrica $(P<0,05)$

ns - não significante $(P \geq 0,05)$

Tabela 5.3 - Testes estatísticos para inclinação no arco inferior

\begin{tabular}{|c|c|c|c|c|c|c|c|c|}
\hline \multirow{2}{*}{\multicolumn{2}{|c|}{ Inclinação }} & Teste de & \multicolumn{4}{|c|}{ Teste para erro sistemático } & \multirow{4}{*}{ 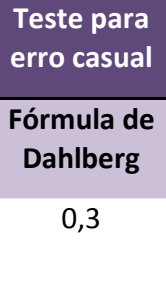 } & \multirow{4}{*}{$\begin{array}{c}\begin{array}{c}\text { Diferença } \\
\text { das médias }\end{array} \\
\text { T1-T2 } \\
-0,01\end{array}$} \\
\hline & & $\begin{array}{c}\text { Shapiro-Wilk } \\
(p<0,05)\end{array}$ & \multicolumn{2}{|c|}{$\begin{array}{l}\text { Wilcoxon } \\
(p<0,05)^{* *}\end{array}$} & \multicolumn{2}{|c|}{$\begin{array}{l}\text { t pareado } \\
(p<0,05)\end{array}$} & & \\
\hline \multirow[t]{2}{*}{ Dente 33} & Tempo 1 & $0,1473 *$ & --- & --- & 0,9409 & ns & & \\
\hline & Tempo 2 & $0,2288^{*}$ & & & & & & \\
\hline \multirow[t]{2}{*}{ Dente 32} & Tempo 1 & $0,291^{*}$ & --- & --- & 0,5871 & ns & 0,3 & 0,08 \\
\hline & Tempo 2 & $0,3295^{*}$ & & & & & & \\
\hline \multirow[t]{2}{*}{ Dente 31} & Tempo 1 & $0,7836^{*}$ & --- & --- & 0,4014 & ns & 0.5 & 0,19 \\
\hline & Tempo 2 & $0,8471 *$ & & & & & & \\
\hline \multirow[t]{2}{*}{ Dente 41} & Tempo 1 & $0,6098^{*}$ & --- & --- & 0,2453 & ns & 0,6 & 0,32 \\
\hline & Tempo 2 & $0,7471^{*}$ & & & & & & \\
\hline \multirow[t]{2}{*}{ Dente 42} & Tempo 1 & $0,7863^{*}$ & --- & --- & 0,5402 & ns & 0,6 & 0,16 \\
\hline & Tempo 2 & $0,9634 *$ & & & & & & \\
\hline \multirow[t]{2}{*}{ Dente 43} & Tempo 1 & $0,1915^{*}$ & --- & --- & 0,4256 & ns & 0.9 & $-0,29$ \\
\hline & Tempo 2 & $0,6093^{*}$ & & & & & & \\
\hline
\end{tabular}

*Distribuição normal ou simétrica $(P>0,05)$

** Distribuição anormal ou assimétrica $(P<0,05)$

ns - não significante $(P \geq 0,05)$ 
Tabela 5.4 - Testes estatísticos para angulação no arco inferior

\begin{tabular}{|c|c|c|c|c|c|c|c|c|}
\hline \multirow{2}{*}{\multicolumn{2}{|c|}{ Angulação }} & \multirow{3}{*}{$\begin{array}{c}\begin{array}{c}\text { Teste de } \\
\text { Normalidade }\end{array} \\
\begin{array}{c}\text { Shapiro-Wilk } \\
(p<0,05)\end{array} \\
0,99^{*}\end{array}$} & \multicolumn{4}{|c|}{ Teste para erro sistemático } & \multirow{2}{*}{$\begin{array}{c}\begin{array}{c}\text { Teste para } \\
\text { erro casual }\end{array} \\
\begin{array}{c}\text { Fórmula } \\
\text { de } \\
\text { Dahlberg }\end{array}\end{array}$} & \multirow{3}{*}{$\begin{array}{c}\begin{array}{c}\text { Diferença } \\
\text { das médias }\end{array} \\
\text { T1-T2 }\end{array}$} \\
\hline & & & \multicolumn{2}{|c|}{$\begin{array}{l}\text { Wilcoxon } \\
(p<0,05)^{* *}\end{array}$} & \multicolumn{2}{|c|}{$\begin{array}{c}\text { t pareado } \\
(p<0,05)\end{array}$} & & \\
\hline \multirow{2}{*}{ Dente 33} & Tempo 1 & & --- & --- & 00751 & ns & 04 & \\
\hline & Tempo 2 & $0,9709 *$ & & & & & & \\
\hline \multirow[t]{2}{*}{ Dente 32} & Tempo 1 & $0,7508^{*}$ & --- & --- & 0,06 & ns & 0.7 & $-0,47$ \\
\hline & Tempo 2 & $0,8305^{*}$ & & & & & & \\
\hline \multirow[t]{2}{*}{ Dente 31} & Tempo 1 & $0,3894 *$ & --- & --- & 0,671 & ns & 0.7 & 0,11 \\
\hline & Tempo 2 & $0,2639 *$ & & & & & & \\
\hline \multirow[t]{2}{*}{ Dente 41} & Tempo 1 & $0,175^{*}$ & --- & --- & 0,0022 & $* * s$ & 0.8 & 0,77 \\
\hline & Tempo 2 & $0,1944^{*}$ & & & & & & \\
\hline \multirow[t]{2}{*}{ Dente 42} & Tempo 1 & $0,97^{*}$ & --- & --- & 0,5683 & ns & 0.5 & 0,12 \\
\hline & Tempo 2 & 0,9893* & & & & & & \\
\hline \multirow[t]{2}{*}{ Dente 43} & Tempo 1 & $0,0975^{*}$ & --- & --- & 0,273 & ns & 0.9 & 0,38 \\
\hline & Tempo 2 & $0,2832^{*}$ & & & & & & \\
\hline
\end{tabular}

*Distribuição normal ou simétrica $(P>0,05)$

** Distribuição anormal ou assimétrica $(P<0,05)$

ns - não significante $(P \geq 0,05)$

$* * s$ - significante $(P \leq 0,05)$ 

DISCUSSÃO 



\section{DISCUSSÃO}

$\mathrm{Na}$ incansável tentativa de encontrar o melhor método de tratamento para as fissuras labiopalatinas, os pesquisadores têm desenvolvido infindáveis investigações científicas, buscando sempre alcançar métodos diagnósticos mais seguros e respostas terapêuticas ideais para devolver ao paciente uma morfologia, função e estética facial satisfatórias (Silva Filho et al, 1995).

A fissura transforame incisivo unilateral, a mais comum dentre as fissuras labiopalatinas, rompe toda a maxila, desde o lábio até a úvula, atravessando o rebordo alveolar. Devido à ruptura dos tecidos duros e moles, a fissura acarreta alterações dentárias e faciais, que alteram toda a seqüência normal de desenvolvimento e crescimento craniofacial e dentário (Silva Filho, 2007).

O defeito ósseo imposto pela fissura causa deficiência na largura, altura e espessura do osso alveolar, que por conseqüência compromete a condição periodontal dos dentes adjacentes. O defeito no rebordo pode ser eliminado através da realização do enxerto ósseo alveolar, que resgata a sua continuidade (Silva Filho et al, 1995). A segmentação do rebordo alveolar também provoca alterações dentárias, tais como agenesias, supranumerários, incisivos laterais dismórficos e caninos impactados após enxerto ósseo, tornando a reabilitação deste paciente muito mais complexa (Silva Filho e Cavassan, 2007). Diante deste panorama, a imaginologia digital em três dimensões pode ser um grande aliado no diagnóstico e correto plano de tratamento desses pacientes (Wörtche et al, 2006).

Antes do surgimento da tomografia o único método de avaliação que possuíamos eram as radiografias bidimensionais. Na avaliação da cefalometria, através da radiografia lateral da face, a imagem dos dentes anteriores era 
sobreposta e as medidas realizadas nos incisivos superiores e inferiores eram aproximadas e obtidas por inferência. (Macchi et al 2006, Müssig, Wörtche e Lux, 2005, Mah et al 2003 e Capelozza Filho et al 2008). As pesquisas realizadas com radiografias panorâmicas também apresentaram como desvantagem a presença de algumas distorções na imagem. Foi identificado que o ângulo formado entre o plano oclusal e plano paralelo ao solo influenciam na imagem, isto é, quanto mais inclinado é o plano oclusal, maior a convergência das raízes superiores, e maior a divergência das raízes dos dentes inferiores a partir do plano oclusal. Desta forma, pacientes dolicocéfalos (plano oclusal mais divergente) parecem mostrar uma imagem mais distorcida na panorâmica do que os pacientes braquicéfalos (plano oclusal paralelo ao solo) (Capelozza Filho et al 1994 e Ursi et al 1990). Conseqüentemente, as angulações dentárias também serão alteradas conforme o padrão facial do paciente, podendo levar a interpretações errôneas destas medidas.

Com o avanço da imaginologia, a Ortodontia pela primeira vez possui uma imagem que disponibiliza a avaliação real da coroa e raiz dentária em todos os planos do espaço, mostrando a relação que as raízes dentárias mantêm com o osso alveolar e periodonto e a relação que as raízes mantêm entre si. Por permitir cortes de espessura extremamente finas e em diversos planos, é de grande valia para avaliação de dentes impactados, acompanhamento de reabsorções radiculares, acompanhamento do efeito do tratamento ortopédico, posicionamento dentário, relação entre osso alveolar e raiz dentária, principalmente através do corte transaxial, entre outros.

Neste trabalho foi avaliada a acurácia e reprodutibilidade do método de medição, através do exame tomográfico, das angulações e inclinações dentárias dos dentes anteriores em pacientes com fissura transforame incisivo unilateral, e 
analisada a condição óssea e alveolar na região dos dentes anteriores superiores e inferiores. Algumas características encontradas na literatura se assemelham aos resultados aqui encontrados e serão comparadas com o intuito de encontrar suporte ou assumir as divergências. Não foi encontrado na literatura trabalho semelhante de avaliação das angulações e inclinações dentárias por meio de tomografia computadorizada em pacientes com fissura transforame incisivo unilateral.

Para facilitar a discussão dos dados obtidos nesta pesquisa, o método e os resultados serão discutidos separadamente.

\subsection{METODOLOGIA}

Foi realizado o teste de erro intra-examinador para aferir a reprodutibilidade dos valores medidos. Foram realizadas duas mensurações (T1 e T2) em toda a amostra, e empregaram-se testes estatísticos para a avaliação do erro sistemático e do erro casual, conforme descrito nos Resultados. A comparação intra-examinador foi considerada de extrema importância nesta pesquisa, para que houvesse confiabilidade dos resultados, e conseqüentemente, que outros pesquisadores possam utilizar esta metodologia com segurança.

Nos resultados apresentados em relação ao erro sistemático, determinado pela aplicação do teste de Wilcoxon, para a medida de inclinação do incisivo lateral do lado não fissurado, e do teste t de Student para amostras pareadas, foi detectado que ocorreram algumas pequenas diferenças estatísticas entre a $1^{\underline{a}}$ e a $2^{\underline{a}}$ medidas, mas as diferenças, apesar de serem significantes estatisticamente, são muito pequenas sob o ponto de vista clínico. Isso é comum quando o teste t pareado é utilizado, pois é um método muito sensível. As medidas que apresentaram diferença estatisticamente significante foram: dimensão da coroa anatômica, dimensão da 
coroa clínica e distância do ponto EV do incisivo central do lado não fissurado e angulação do dente 41. Isso provavelmente se deve a dificuldade na visualização de determinadas áreas nas imagens tomográficas e, portanto, possíveis erros na demarcação dos pontos. Mas a diferença na angulação do dente 41 foi ao acaso, não há nenhum fator que a justifique.

Em relação ao erro casual, determinado pela fórmula de Dahlberg, conclui-se que o método é preciso, pois as diferenças médias foram pequenas.

Com base nestas análises, sugere-se que esta metodologia pode ser empregada com confiabilidade para a pesquisa das inclinações e angulações dentárias. Entretanto, considera-se que novas pesquisas utilizando esta metodologia devam ser realizadas para consolidá-la, incluindo erro inter-examinadores.

\subsection{AVALIAÇÃO DAS INCLINAÇÕES E ANGULAÇÕES DENTÁRIAS}

As medidas realizadas para avaliar a dimensão vertical da coroa clínica, dimensão vertical da coroa anatômica e ponto EV foram utilizadas como meio de obtenção das medidas de angulação e inclinação e também como variáveis de modo a testar a efetividade do método, não havendo a intenção de compará-las com valores da literatura.

Devido à presença da fissura influenciar o posicionamento dos dentes adjacentes a ela, houve considerável variabilidade nos resultados para os hemiarcos da dentadura superior, tanto para inclinação como para angulação. Desta forma, os resultados serão discutidos separando os lados fissurado e não fissurado, dando ênfase às alterações presentes devido à presença da fissura.

Outro fator a ser considerado foi que em nossa amostra a medição das angulações foi realizada englobando as coroas e raízes dos dentes anteriores, 
diferentemente das inclinações, que foi medida somente a coroa clínica. A mensuração das angulações foi realizada desta maneira pois não era possível definir com nitidez, no corte da panorâmica, o ponto extremo cervical da coroa clínica, havendo muita variabilidade nos resultados.

Os resultados encontrados neste estudo para inclinação e angulação estão descritos nas tabelas abaixo. Esses valores serão comparados com valores encontrados na literatura para oclusão normal natural (Andrews 1989 e Zanelato 2003), no intuito de avaliar a correlação das medidas de normalidade para pacientes sem fissura e pacientes com fissura transforame incisivo unilateral que obtiveram finalização satisfatória. Também tivemos o interesse de comparar os valores encontrados neste estudo com as prescrições de braquetes utilizadas no Hospital de Reabilitação de Anomalias Craniofaciais (Capelozza Filho et al, 1999), visando aquilatar as individualizações propostas.

Tabela 6.1 - Valores de inclinação e angulação dos caninos superiores

\begin{tabular}{|c|c|c|c|c|c|}
\hline \multirow{2}{*}{\multicolumn{2}{|c|}{$\begin{array}{c}\text { CANINOS } \\
\text { SUPERIORES }\end{array}$}} & \multicolumn{2}{|c|}{ Lado NÃO Fissurado } & \multicolumn{2}{|c|}{ Lado Fissurado } \\
\hline & & \multirow{2}{*}{$\begin{array}{c}\text { Média } \\
6,34\end{array}$} & \multirow{2}{*}{$\begin{array}{c}\text { Desvio } \\
\text { Padrão }\end{array}$} & \multirow{2}{*}{$\begin{array}{c}\text { Média } \\
7,53\end{array}$} & \multirow{2}{*}{$\begin{array}{c}\text { Desvio } \\
\text { Padrãc } \\
6,60\end{array}$} \\
\hline 웅 & Tempo 1 & & & & \\
\hline ฮั & Tempo 2 & 6,01 & 3,26 & 6,84 & 5,90 \\
\hline 으 & $\begin{array}{l}\text { Média } \\
\text { T1 e T2 }\end{array}$ & 6,18 & 3,23 & 7,18 & 6,25 \\
\hline \multirow{3}{*}{ 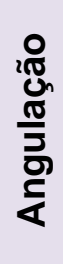 } & Tempo 1 & 13,08 & 3,79 & 12,68 & 4,54 \\
\hline & Tempo 2 & 13,10 & 4,01 & 12,61 & 4,11 \\
\hline & $\begin{array}{l}\text { Média } \\
\text { T1 e T2 }\end{array}$ & 13,09 & 3,90 & 12,64 & 4,33 \\
\hline
\end{tabular}


A média da inclinação para os caninos superiores do lado não fissurado foi de 6,18 e para os caninos superiores do lado fissurado foi de 7,18으 (Tabela 6.1). Com relação aos resultados obtidos na análise de pacientes com oclusão normal natural, descrito por Andrews (1989) e Zanelato (2003), nossos resultados são divergentes, pois os valores determinados neste estudo foram positivos, enquanto que para pacientes com oclusão normal foram negativos (Tabela 6.2).

Tabela 6.2 - Valores de inclinação dos caninos superiores em oclusão normal não tratada comparada a este estudo

\begin{tabular}{c|c|c|}
\cline { 2 - 3 } & \multicolumn{2}{c|}{$\begin{array}{r}\text { DENTES SUPERIORES } \\
\text { Caninos Superiores }\end{array}$} \\
\hline Andrews & $-7^{\circ} \stackrel{-0}{7^{\circ}}$ \\
\hline Zanelato & $-6,7^{\circ}$ & $-6,7^{\circ}$ \\
\hline Este estudo & $6,18^{\circ}(\mathrm{LñF})$ & $7,18^{\circ}(\mathrm{LF})$ \\
\hline
\end{tabular}

Em comparação com as prescrições de braquetes existentes (Capelozza Filho et al 1999 e Andrews 1989), todos eles possuem inclinações negativas. Capelozza Filho et al (1999) recomenda inclinação média de caninos superiores de $5^{\circ}$ para prescrição I e II e para prescrição III recomenda inclinação de $-2^{\circ}$ ou $+2^{\circ}$ para compensação máxima. Esse seria o valor correto para ser comparado com pacientes com fissura, que como sabemos tendem ao padrão III e geralmente recebem compensação máxima. Os valores encontrados para inclinação de caninos superiores também variaram bastante: entre $2,7^{\circ}$ e $13,0^{\circ}$ para o canino do lado não fissurado e entre $-2,1^{\circ}$ e $16,2^{\circ}$ para o canino do lado fissurado. Os resultados presentes neste estudo, com inclinação positiva dos caninos superiores, provavelmente ocorreram devido ao tipo de tratamento rotineiramente empregado para o paciente com fissura. Quase todos os pacientes que possuem a maxila 
totalmente rompida pela fissura irão apresentar atresia maxilar, com giro medial dos segmentos maior e menor na fissura unilateral completa, que geralmente resulta em mordida cruzada posterior e/ou anterior (Silva Filho, 2007).

Nessa circunstância, o tratamento de predileção é a expansão rápida da maxila. A quantidade de expansão varia de acordo com a severidade da má-oclusão e quanto maior a expansão, maior será o efeito de inclinação vestibular das coroas dentárias. Esse tratamento é altamente recidivante devido à ausência de tecido ósseo no palato e rebordo, exigindo compensação dentária, ou seja, inclinação vestibular. Essa condição é melhorada com a realização do enxerto ósseo na região da fissura, pois o rebordo fissurado é transformado em um arco contínuo (Silva Filho e Cavassan, 2007).

Outro fator a ser considerado é a finalização de muitos caninos superiores em classe II. Devido à agenesia do incisivo lateral do lado fissurado, em muitos tratamentos o canino foi mesializado para a região do incisivo lateral e o $1^{\circ}$ pré-molar para o lugar do canino. Desta forma, para as medidas nós consideramos o local em que o dente estava e não o dente em si. Por exemplo, dente 13 como 12, 14 como 13, e assim por diante. Provavelmente essa substituição também interfira nos valores de angulação e inclinação devido à variação na anatomia da coroa clínica.

A média de angulação para os caninos superiores do lado não fissurado foi de $13,09^{\circ}$ e para os caninos superiores do lado fissurado foi de $12,64^{\circ}$ (Tabela 6.1), mostrando relativa simetria entre os lados. Com relação aos resultados obtidos na análise de pacientes com oclusão normal natural, nossos resultados são mais próximos ao de Andrews (1989), porém maiores. Comparado aos valores encontrados por Zanelato (2003), os caninos desta amostra possuem angulação acentuadamente maior (Tabela 6.3) 
Tabela 6.3 - Valores de angulação dos caninos superiores em oclusão normal não tratada comparada a este estudo

\begin{tabular}{c|c|c|}
\cline { 2 - 3 } & \multicolumn{2}{|c|}{$\begin{array}{c}\text { DENTES SUPERIORES } \\
\text { Caninos Superiores }\end{array}$} \\
\hline Andrews & $11^{\circ}$ & $11^{\circ}$ \\
\hline Zanelato & $7,1^{\circ}$ & $7,1^{\circ}$ \\
\hline Este estudo & $13,09^{\circ}(\mathrm{LnF})$ & $12,64^{\circ}(\mathrm{LF})$ \\
\hline
\end{tabular}

Os valores encontrados nesta amostra se assemelham à prescrição III Capelozza que é de 11ำ (Capelozza Filho et al, 1999), e aos valores encontrados por Normando, com caninos superiores de classe III do lado direito de $9,97^{\circ}$ e caninos superiores do lado esquerdo de 10,1ำ (Normando, Azevedo e Torres, 2009), porém são relativamente maiores. Entretanto, os valores encontrados neste trabalho variaram bastante: entre $7,3^{\circ}$ e $18,5^{\circ}$ para o caninos do lado não fissurado e entre $4,3^{\circ}$ e $17,9^{\circ}$ para o caninos do lado fissurado. Essa alta variabilidade nas angulações provavelmente de dá pela presença da fissura, que altera o padrão de finalização.

Tabela 6.4 - Valores de angulação e inclinação dos incisivos superiores

\begin{tabular}{|c|c|c|c|c|c|c|c|c|c|}
\hline \multirow{3}{*}{\multicolumn{2}{|c|}{$\begin{array}{l}\text { INCISIVOS } \\
\text { SUPERIORES }\end{array}$}} & \multicolumn{4}{|c|}{ Lado NÃO Fissurado } & \multicolumn{4}{|c|}{ Lado Fissurado } \\
\hline & & \multicolumn{2}{|c|}{ Inc. Lateral } & \multicolumn{2}{|c|}{ Inc. Central } & \multicolumn{2}{|c|}{ Inc. Central } & \multicolumn{2}{|c|}{ Inc. Lateral } \\
\hline & & Média & $\begin{array}{l}\text { Desvio } \\
\text { Padrão }\end{array}$ & Média & $\begin{array}{l}\text { Desvio } \\
\text { Padrão }\end{array}$ & Média & $\begin{array}{l}\text { Desvio } \\
\text { Padrão }\end{array}$ & Média & $\begin{array}{l}\text { Desvio } \\
\text { Padrão }\end{array}$ \\
\hline \multirow{3}{*}{ 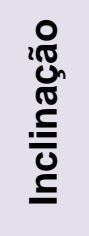 } & Tempo 1 & 7,81 & 3,56 & 5,95 & 3,93 & 5,06 & 5,15 & 6,63 & 3,59 \\
\hline & Tempo 2 & 7,62 & 3,35 & 5,8 & 3,59 & 5,2 & 5,02 & 6,3667 & 3,44 \\
\hline & $\begin{array}{c}\text { Média } \\
\text { T1 e T2 }\end{array}$ & 7,72 & 3,45 & 6,08 & 3,67 & 5,09 & 5,40 & 6,47 & 3,93 \\
\hline \multirow{3}{*}{ 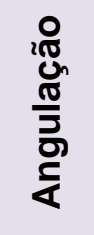 } & Tempo 1 & 9,81 & 4,49 & 6,63 & 5,24 & 1,5 & 8,11 & 14,80 & 8,24 \\
\hline & Tempo 2 & 10,03 & 4,68 & 6,9 & 5,14 & 1,7 & 8,19 & 14,86 & 8,15 \\
\hline & $\begin{array}{c}\text { Média } \\
\text { T1 e T2 }\end{array}$ & 9,92 & 4,48 & 6,83 & 5,32 & 0,12 & 7,10 & 15,10 & 9,14 \\
\hline
\end{tabular}


Nos valores de inclinação dos incisivos laterais superiores, para o incisivo lateral do lado não fissurado a média foi de $7,72^{\circ}$ (variando entre $3^{\circ}$ e $16,4^{\circ}$ ) e para o incisivo lateral lado fissurado foi de $6,4^{\circ}$ (variando entre $2,3^{\circ}$ e $12,4^{\circ}$ ) (Tabela 6.4). A inclinação encontrada por Andrews (1989) e Zanelato (2003) para oclusão normal está descrita na tabela abaixo (Tabela 6.5). Os valores encontrados em nossa amostra se apresentam mais inclinados do que os dados da literatura revelam.

Tabela 6.5 - Valores médios da inclinação dos dentes superiores deste trabalho comparados com o padrão de normalidade

\begin{tabular}{|c|c|c|c|c|}
\hline \multirow[b]{3}{*}{ Andrews } & \multicolumn{4}{|c|}{ DENTES SUPERIORES } \\
\hline & \multicolumn{2}{|c|}{ Incisivos Laterais } & \multicolumn{2}{|c|}{ Incisivos Centrais } \\
\hline & $3^{\circ}$ & $3^{\circ}$ & $7^{\circ}$ & $7^{\circ}$ \\
\hline Zanelato & $5^{0}$ & $5^{0}$ & $5,3^{\circ}$ & $5,3^{\circ}$ \\
\hline Este estudo & 7,72으 (LñF) & $6,47^{\circ}$ (LF) & $6,08^{\circ}(\mathrm{Ln} F)$ & $5,09^{\circ}(\mathrm{LF})$ \\
\hline
\end{tabular}

Comparados aos dados descritos por Capelozza Filho et al (1999), nossos resultados são mais próximos as prescrições I e II, que determinam o valor de $3^{\circ}$ para incisivos laterais. Na prescrição III a inclinação é de $10^{\circ}$ para incisivos laterais, só adotados para indivíduos negros, amarelos ou extrema compensação para brancos.

Nos valores de inclinação dos incisivos centrais superiores, para o incisivo central do lado não fissurado a média foi de 6,08을 (variando entre $-2,1^{\circ}$ e $10,2^{\circ}$ ) e para o incisivo central do lado fissurado a média foi de $5,09^{\circ}$ (variando entre $-3,9^{\circ}$ e $12,7^{\circ}$ ) (Tabela 6.4). Os nossos resultados, para os incisivos centrais, são menores que os de Andrews e maiores que os de Zanelato (Tabela 6.5).

Comparados aos dados descritos por Capelozza Filho et al (1999), nossos resultados são mais próximos as prescrições I e II, que determinam os valores de 7ํㅜ 
para os incisivos centrais superiores. Na prescrição III de Capelozza Filho a inclinação para os incisivos centrais superiores é de 14ำ também adotados somente para negros, amarelos e brancos para compensação máxima.

Nos valores de angulação dos incisivos laterais superiores, a média para o incisivo lateral do lado não fissurado foi de $9,92^{\circ}$ (variando entre $2^{\circ}$ e $17,6^{\circ}$ ) e para o incisivo lateral do lado fissurado foi de $15,10^{\circ}$ (variando entre $0^{\circ}$ e $23,9^{\circ}$ ). Já para os valores de angulação dos incisivos centrais superiores, para o incisivo central do lado não fissurado a média foi de $6,83^{\circ}$ (variando entre $-2,7^{\circ}$ e $14,5^{\circ}$ ) e para 0 incisivo central do lado fissurado a média foi de $\mathbf{0 , 1 2 ^ { \circ }}$ (variando entre $-11,4^{\circ}$ e $15,1^{\circ}$ ). Estes são os resultados, como seria lícito esperar, que mais denotam a influência da fissura. Enquanto as medidas do lado não fissurado se aproximam aos dados da literatura, como Andrews (1989) e Zanelato (2003) (Tabela 6.6), os incisivos centrais do lado da fissura ficam com a raiz praticamente verticalizada e para os incisivos laterais, como geralmente estão ausentes, o canino é mesializado para ocupar sua posição, permanecendo com uma angulação acentuada de sua raiz.

Com relação à comparação com a prescrição de braquetes, Capelozza Filho et al (1999) determinaram os valores de angulação de 9ำ para o IL e 5ํㅜ para o dente IC, similares aos resultados para o lado não fissurado.

Tabela 6.6 - Valores médios da angulação dos dentes superiores deste trabalho comparados com o padrão de normalidade

\section{DENTES SUPERIORES}

\section{Incisivos Laterais}

Incisivos Centrais

\begin{tabular}{c|c|c|c|c}
\hline Andrews & $9^{\circ}$ & $9^{\circ}$ & $5^{\circ}$ & $5^{\circ}$ \\
\hline Zanelato & $6,2^{\circ}$ & $6,2^{\circ}$ & $2^{\circ} 2^{\circ}$ & $2,2^{\circ}$ \\
\hline Este estudo & $9,92^{\circ}(\mathrm{Ln} F)$ & $15,10^{\circ}(\mathrm{LF})$ & $6,83^{\circ}(\mathrm{Ln} \mathrm{n})$ & $0,12^{\circ}(\mathrm{LF})$ \\
\hline
\end{tabular}


Os resultados dos valores de angulação para os incisivos superiores mostraram diferenças significantes entre os lados com e sem fissura. A agenesia dos incisivos laterais é bastante freqüente nestes pacientes, uma vez que a fissura rompe o rebordo na altura de seu germe dentário. Quando presentes geralmente apresentam as mais variadas formas, tamanhos e posições. Outra característica comum que é encontrada são os pré-caninos, dentes com formato conóide presentes à frente dos caninos do lado fissurado. Podem ser aproveitados para substituir o incisivo lateral ausente quando possuem estrutura radicular e osso alveolar adequados que permita mantê-los. Já os incisivos centrais do lado fissurado apresentam a raiz contra-angulada, devido à ausência osso alveolar na região da fissura, antes da cirurgia de enxerto ósseo alveolar e muitas vezes após a cirurgia, por ocorrer graus variados de reabsorção do osso enxertado.

Tabela 6.7 - Valores de angulação e inclinação dos caninos inferiores

\begin{tabular}{|c|c|c|c|c|c|}
\hline \multirow{2}{*}{\multicolumn{2}{|c|}{$\begin{array}{l}\text { CANINOS } \\
\text { INFERIORES }\end{array}$}} & \multicolumn{2}{|c|}{ Dente 33} & \multicolumn{2}{|c|}{ Dente 43} \\
\hline & & \multirow{2}{*}{$\begin{array}{c}\text { Média } \\
-4,98\end{array}$} & \multirow{2}{*}{$\begin{array}{c}\begin{array}{c}\text { Desvio } \\
\text { Padrão }\end{array} \\
6,9681\end{array}$} & \multirow{2}{*}{$\begin{array}{c}\text { Média } \\
-5,05\end{array}$} & \multirow{2}{*}{$\begin{array}{l}\text { Desvio } \\
\text { Padrão }\end{array}$} \\
\hline 우 & Tempo 1 & & & & \\
\hline 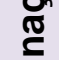 & Tempo 2 & $-4,97$ & 6,9033 & $-4,76$ & 4,4757 \\
\hline$\underline{\underline{0}}$ & $\begin{array}{l}\text { Média } \\
\text { T1 e T2 }\end{array}$ & $-4,98$ & 6,9357 & $-4,91$ & 4,6451 \\
\hline \multirow{3}{*}{ 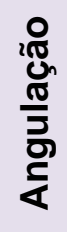 } & Tempo 1 & 11,12 & 5,6525 & 11,85 & 6,958 \\
\hline & Tempo 2 & 11,44 & 6,0749 & 11,47 & 6,1653 \\
\hline & $\begin{array}{l}\text { Média } \\
\text { T1 e T2 }\end{array}$ & 11,28 & 5,8637 & 11,66 & 6,5617 \\
\hline
\end{tabular}

Considerando os valores obtidos de inclinação dos caninos inferiores, eles também foram negativos como a maioria dos dados da literatura nos mostra, com média de -4,98을 para o canino inferior esquerdo (dente 33 ) e $-4,91^{\circ}$ para o canino inferior direito (dente 43) (Tabela 6.7). Comparando aos resultados obtidos na 
análise de pacientes com oclusão normal natural, descritos por Andrews (1989) e Zanelato (2003), os caninos desta amostra possuem inclinação menos negativa (Tabela 6.8)

Tabela 6.8 - Valores de inclinação dos caninos inferiores em oclusão normal não tratada comparada a este estudo

\begin{tabular}{|c|c|c|}
\cline { 2 - 3 } & \multicolumn{2}{|c|}{ DENTES INFERIORES } \\
\hline Andrews & $-11^{\circ}$ & Dente 43 \\
\hline Zanelato & $-10,1^{\circ}$ & $-11^{\circ}$ \\
\hline Este estudo & $-4,98^{\circ}$ & $-10,1^{\circ}$ \\
\hline
\end{tabular}

Comparados aos valores propostos por Capelozza Filho et al (1999), com inclinação de $-11^{\circ}$, a inclinação dos caninos desta amostra também se apresentaram mais suaves. Provavelmente isso ocorreu devido a relação sagital tendendo ao padrão III, com uma tendência a aumento na distância intercaninos inferiores a custa de uma menor inclinação para lingual. Os valores encontrados para essa medida também variaram bastante: entre $-15,3^{\circ}$ e $3,2^{\circ}$ para o dente 33 e entre $-16,5^{\circ}$ e $2,2^{\circ}$ para o dente 43.

Com relação às medidas de angulação dos caninos inferiores, o valor médio para os caninos do lado esquerdo (dente 33 ) foi de $11,28^{\circ}$ e para os caninos do lado direito (dente 43) foi de 11,66, mostrando simetria entre os lados. Comparando aos resultados obtidos na análise de pacientes com oclusão normal natural, descritos por Andrews (1989) e Zanelato (2003), os caninos desta amostra possuem angulação acentuadamente maior do que os descritos na literatura (Tabela 6.9). Esta acentuada divergência demonstra claramente que angulação de coroa não pode ser comparada com angulação total (coroa+raiz). 
Tabela 6.9 - Valores de angulação dos caninos inferiores em oclusão normal não tratada comparada a este estudo

\begin{tabular}{|c|c|c|}
\cline { 2 - 3 } & \multicolumn{2}{|c|}{ DENTES INFERIORES } \\
\hline Andrews & $5^{\circ}$ & Dente 43 \\
\hline Zanelato & $2,4^{\circ}$ & $5^{\circ}$ \\
\hline Este estudo & $11,28^{\circ}$ & $2,4^{\circ}$ \\
\hline
\end{tabular}

Esses valores também são maiores do que os determinados por Capelozza Filho et al (1999), com angulação média de $5^{0}$ para prescrição I e II e $0^{\circ}$ para prescrição III, que seria o aplicado para os pacientes desta amostra . Normando et al (2008) encontrou valores de angulação de $6,99^{\circ}$ para o dente 33 e de $7,87^{\circ}$ para o dente 43 em indivíduos com relação oclusal de classe I, que se aproximam mais dos nossos resultados. Já seus valores de angulação para relação oclusal de classe III, que foi de $-2,78^{0}$ para o dente 33 e $-1,67^{0}$ para o dente 43 , divergem dos valores aqui encontrados. Entretanto houve grande variação nas medidas, com os valores míninos e máximos entre $1,3^{\circ}$ e $15,9^{\circ}$ para o dente 33 e entre $4,7^{\circ}$ e $24,5^{\circ}$ para o dente 43.

Os valores de angulação para os caninos inferiores em nossa amostra foram similares aos resultados obtidos para tratamento compensatório de classe II, ao invés de corresponder ao tratamento compensatório de classe III como seria o esperado para este tipo de paciente. Contudo, como a amostra foi heterogênea e 3 dos 10 pacientes foram submetidos ao tratamento descompensatório para cirurgia ortognática, os valores de angulação são alterados. De qualquer modo, não parece lícito comparar angulação total com angulação somente da coroa clínica. Assim, esse método não é satisfatório para avaliar angulação com objetivo de prescrição para braquetes. 
Tabela 6.10 - Valores de angulação e inclinação dos incisivos inferiores

\begin{tabular}{|c|c|c|c|c|c|c|c|c|c|}
\hline \multirow{2}{*}{\multicolumn{2}{|c|}{$\begin{array}{l}\text { INCISIVOS } \\
\text { INFERIORES }\end{array}$}} & \multicolumn{2}{|c|}{ Dente 32} & \multicolumn{2}{|c|}{ Dente 31} & \multicolumn{2}{|c|}{ Dente 41} & \multicolumn{2}{|c|}{ Dente 42} \\
\hline & & \multirow{2}{*}{$\begin{array}{c}\text { Média } \\
-3,2\end{array}$} & \multirow{2}{*}{$\begin{array}{c}\begin{array}{r}\text { Desvio } \\
\text { Padrão }\end{array} \\
6,597\end{array}$} & \multirow{2}{*}{$\begin{array}{c}\text { Média } \\
-2,14\end{array}$} & \multirow{2}{*}{$\begin{array}{l}\text { Desvio } \\
\text { Padrão }\end{array}$} & \multirow{2}{*}{$\begin{array}{l}\text { Média } \\
-1,189\end{array}$} & \multirow{2}{*}{$\begin{array}{l}\text { Desvio } \\
\text { Padrão }\end{array}$} & \multirow{2}{*}{$\begin{array}{c}\text { Média } \\
-3,27\end{array}$} & \multirow{2}{*}{$\begin{array}{l}\text { Desvio } \\
\text { Padrão }\end{array}$} \\
\hline 웅 & Tempo 1 & & & & & & & & \\
\hline \multirow{2}{*}{ 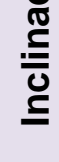 } & Tempo 2 & $-3,28$ & 6,7171 & $-2,33$ & 7,0314 & $-1,511$ & 5,9276 & $-3,43$ & 5,7925 \\
\hline & $\begin{array}{l}\text { Média } \\
\text { T1 e T2 }\end{array}$ & $-3,24$ & 6,657 & $-2,24$ & 6,9702 & $-1,35$ & 5,8734 & $-3,35$ & 5,8637 \\
\hline \multirow{3}{*}{ 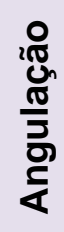 } & Tempo 1 & 4 & 2,971 & 2,67 & 5,2846 & $-0,444$ & 5,3524 & 4,37 & 4,1363 \\
\hline & Tempo 2 & 4,47 & 2,9318 & 2,56 & 5,1876 & $-1,211$ & 5,1038 & 4,25 & 4,2209 \\
\hline & $\begin{array}{l}\text { Média } \\
\text { T1 e T2 }\end{array}$ & 4,24 & 2,9514 & 2,62 & 5,2361 & $-0,83$ & 5,2281 & 4,31 & 4,1786 \\
\hline
\end{tabular}

Os valores de inclinação dos incisivos laterais inferiores desta amostra foram: -3,24 (variando entre $-11,5^{\circ}$ e $8,4^{\circ}$ ) para o incisivo lateral esquerdo (dente 32) e $-3,35^{\circ}$ (variando entre $-12^{\circ}$ e $6,4^{\circ}$ ) para 0 incisivo lateral direito (dente 42) (Tabela 6.10). Para os incisivos centrais inferiores os valores médios de inclinação foram: -2,24ำ (variando entre -12,6ㅇ e $11,2^{\circ}$ ) para o incisivo central esquerdo (dente 31), $-1,35^{\circ}$ (variando entre $-10,9^{\circ}$ e $6,8^{\circ}$ ) para o incisivo central direito (dente 41). A inclinação média dos incisivos inferiores foi negativa, isto é, inclinação lingual, correspondendo aos dados encontrados por Andrews (1989) e próximos ao de Zanelato (2003) (Figura 6.11).

Tabela 6.11 - Valores médios da inclinação dos dentes inferiores deste trabalho comparados com o padrão de normalidade

\begin{tabular}{|c|c|c|c|c|}
\cline { 2 - 5 } & \multicolumn{4}{c}{ DENTES INFERIORES } \\
\hline Andrews & $-1^{\circ}$ & $-1^{\circ}$ & $-1^{\circ}$ & $-1^{\circ}$ \\
\hline Zanelato & $-2^{\circ}$ & $0,1^{\circ}$ & $0,1^{\circ}$ & $-2^{\circ}$ \\
\hline Este estudo & $-3,24^{\circ}$ & $-2,24^{\circ}$ & $-1,35^{\circ}$ & $-3,35^{\circ}$ \\
\hline
\end{tabular}


Capelozza Filho et al (1999) determinou valores de -1ำ para prescrição I e -6ำ para prescrição III, ficando nossos valores entre as duas prescrições. Os pacientes com fissura, por geralmente apresentarem discrepâncias sagitais durante o crescimento, têm maior indicação para tratamento compensatório, sendo os valores de inclinação mais compatíveis com a prescrição III.

Quanto à angulação dos incisivos inferiores, por não serem afetados pela fissura, não apresentaram tantas alterações quanto os superiores. Os valores médios encontrados para os incisivos laterais foram: $4,24^{\circ}$ (variando entre $-0,8^{\circ} \mathrm{e}$ $8,8^{\circ}$ ) para o incisivo lateral esquerdo (dente 32 ) e 4,31으 (variando entre $-2,7^{\circ}$ e $11,9^{\circ}$ ) para o incisivo lateral direito (dente 42). Já os valores médios encontrados para os incisivos centrais foram: $2,6^{\circ}$ (variando entre $-4,6^{\circ}$ e 10,6ํ) para o incisivo central esquerdo (dente 31 ), $-\mathbf{- 0 , 8 3 ^ { \circ }}$ (variando entre $-5^{\circ}$ e $10,7^{\circ}$ ) para o incisivo central direito (dente 41). Os incisivos inferiores de nossa amostra, exceto o dente 41, se mostraram com valores de angulação maiores do que os descritos por Andrews (1989) e Zanelato (2003) (Tabela 6.12). A larga variação dificulta a compreensão de uma tendência.

O valores de inclinação dos incisivos inferiores desta amostra são compatíveis com os braquetes prescrição I, Capelozza Filho et al (1999), que apresentam $2^{\circ}$ de angulação.

Tabela 6.12 - Valores médios da angulação dos dentes inferiores deste trabalho comparados com o padrão de normalidade

DENTES INFERIORES

Dente 32

Dente 31

Dente 41

Dente 42

\begin{tabular}{|c|c|c|c|c}
\hline Andrews & $2^{\circ}$ & $2^{\circ}$ & $2^{\circ}$ & $2^{\circ}$ \\
\hline Zanelato & $-0,6^{\circ}$ & $0^{\circ}$ & $0^{\circ}$ & $-0,6^{\circ}$ \\
\hline Este estudo & $4,24^{\circ}$ & $2,62^{\circ}$ & $-0,83^{\circ}$ & $4,31^{\circ}$ \\
\hline
\end{tabular}


Em resumo, os dados encontrados nesta pesquisa foram:

- caninos superiores com angulação aumentada e inclinação muito aumentada, correspondendo as características dos padrão III;

- incisivos centrais e laterais superiores com valores de inclinação próximos aos valores de normalidade descritos na literatura, e relativamente simétricos entre os lados com e sem fissura. Entretanto, os valores de angulação apresentaram diferença significativa entre os lados com e sem fissura, sendo o lado não fissurado compatível com os valores de normalidade e no lado fissurado o incisivo central permaneceu verticalizado e o lateral com angulação muito acentuada;

- caninos inferiores com inclinação lingual mais suave quando comparados aos valores de normalidade e com angulação acentuadamente aumentada;

- incisivos centrais e laterais inferiores com inclinação negativa característica do padrão III e angulação um pouco maior do que os padrões de normalidade, exceto para o dente 41.

Os valores de angulação e inclinação encontrados no trabalho de Ribas (2003) não puderam ser comparados aos nossos achados pois, além da diferença na metodologia para mensuração, que utilizou modelos de estudo, a amostra utilizada no outro estudo era de pacientes sem tratamento ortodôntico prévio.

A variabilidade dos resultados para angulação e inclinação provavelmente ocorreu devido à heterogeneidade da amostra, ao pequeno número de pacientes avaliados e as características inerentes à fissura. As metas terapêuticas devem ser definidas levando em consideração as limitações reais impostas pela fissura, como alteração no posicionamento dos dentes vizinhos a fissura e a compensação que é 
inexorável e atinge todos os dentes. Isso ajudaria a definir o plano de tratamento, incluindo braquetes. Na técnica de Straight-Wire os braquetes, por conterem em suas canaletas informações que contribuem para posicionar os dentes, podem agregar valor à movimentação ortodôntica, desde que corretamente escolhidos, de acordo com informações que determinem possibilidades e limitações para a movimentação dos elementos dentários. Isso significa individualização do tratamento, conduta que tende a ser rotina também no tratamento de pacientes com fissura, mas que exigem informações mais acuradas, agora possíveis de serem diponibilizadas com a ferramenta tomografia computadorizada.

As variáveis analisadas como tamanho da coroa anatômica, tamanho da coroa clínica, ponto EV, angulação e inclinação mostraram resultados bastante semelhante em T1 e T2 para todos os testes aplicados. Desta forma podemos sugerir que o método inter-examinadores utilizado é preciso, eficaz e reproduzível.

\subsection{AVALIAÇÃO DAS REGIÕES ÓSSEAS E RADICULARES}

Outra variável analisada neste estudo foram as características das regiões ósseas e radiculares após finalização do tratamento ortodôntico.

Foi constatado que praticamente todos os dentes superiores apresentaram uma tábua óssea vestibular extremamente fina ou muitas vezes presente somente no terço apical das raízes (Figs. 6.1 e 6.2). 


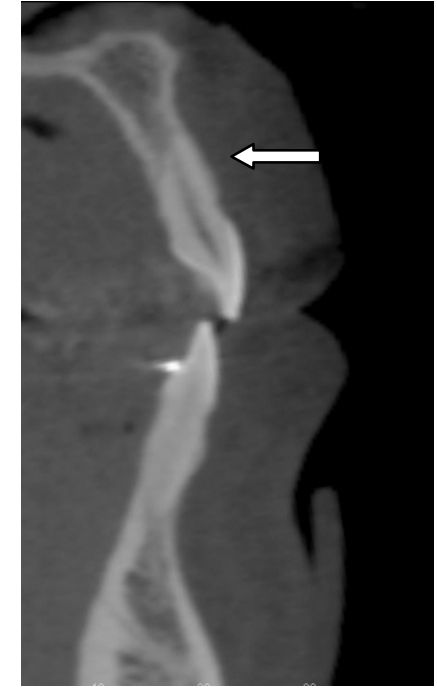

Figura 6.1 - Tábua óssea vestibular muito fina

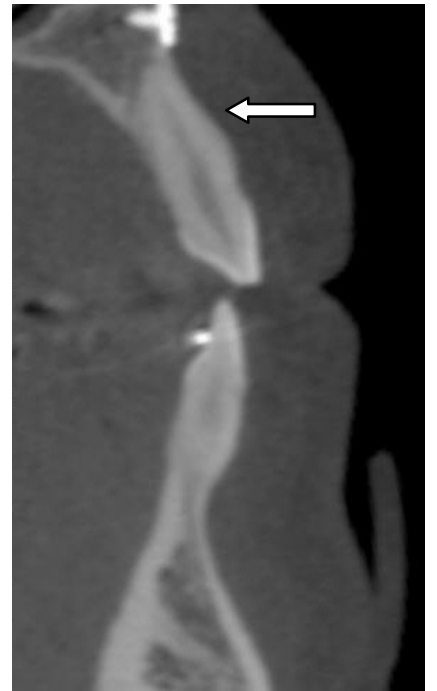

Figura 6.2 - Tábua óssea vestibular praticamente inexistente

Já a tábua óssea palatina deste dentes apresentava uma quantidade um pouco maior de osso, porém em alguns dentes ela também estava presente somente no terço apical das raízes (Fig. 6.3). Alguns dentes, entretanto, estavam praticamente recobertos somente por tecido gengival na vestibular e lingual, com osso presente somente no ápice (Fig. 6.4).

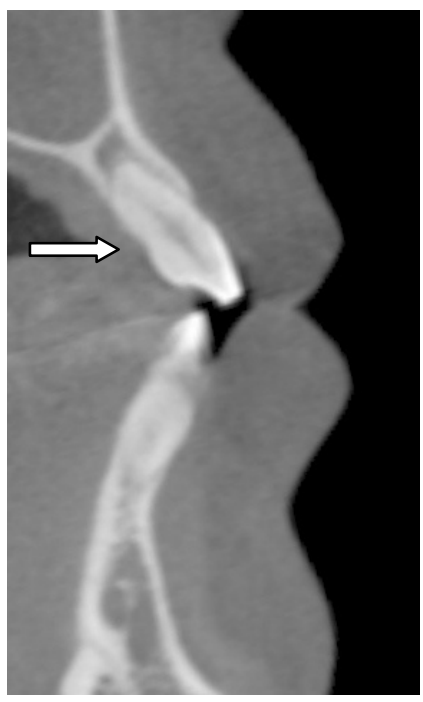

Figura 6.3 - Tábua óssea palatina somente no terço apical

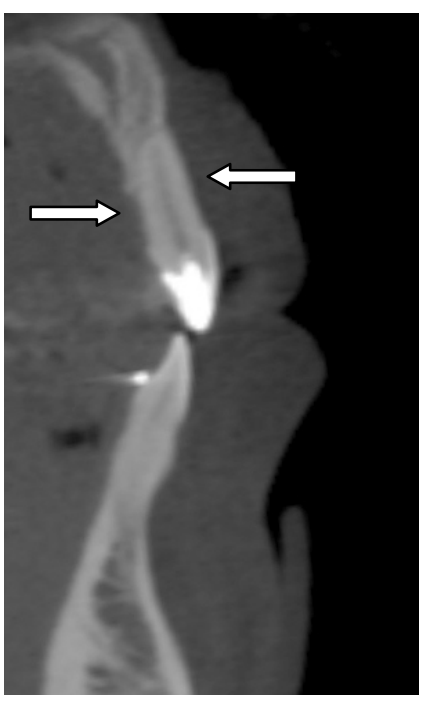

Figura 6.4 - Presença de tecido ósseo somente na região apical 
Os resultados encontrados nos dentes inferiores são ainda mais assustadores. A grande maioria dos dentes possuía pequena (Fig. 6.5) ou nenhuma tábua óssea recobrindo as faces vestibulares e linguais (Fig. 6.6). Alguns dentes estavam "praticamente" flutuando.

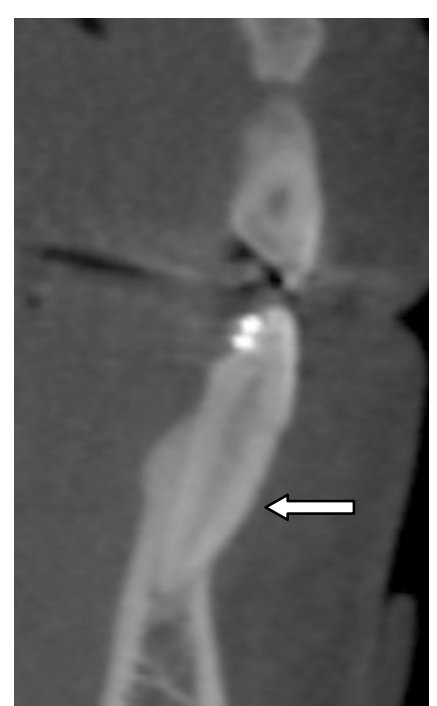

Figura 6.5 - Tábua óssea vestibular somente no terço apical

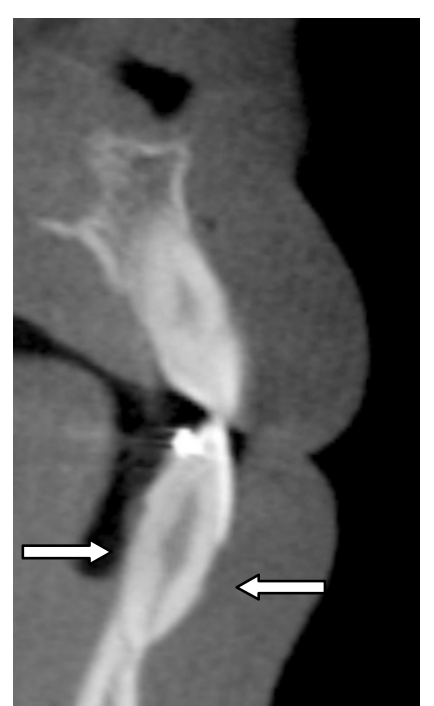

Figura 6.6 - Osso presente somente na região apical

Outro dado observado foi a presença de reabsorção radicular em alguns dentes. Alguns pacientes apresentaram grau moderado de reabsorção na região dos incisivos superiores (Fig. 6.7). Outros, contudo, apresentaram reabsorção radicular mais acentuada nesta região após finalização do tratamento ortodôntico (Fig. 6.8).

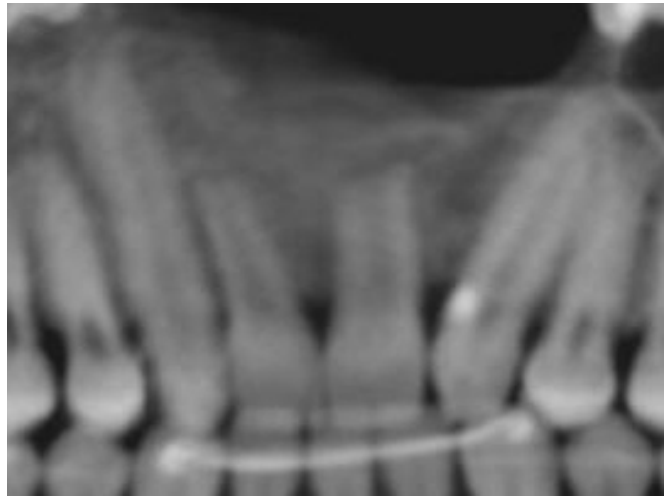

Figura 6.7 - Reabsorção radicular moderada nos incisivos (remodelação apical)

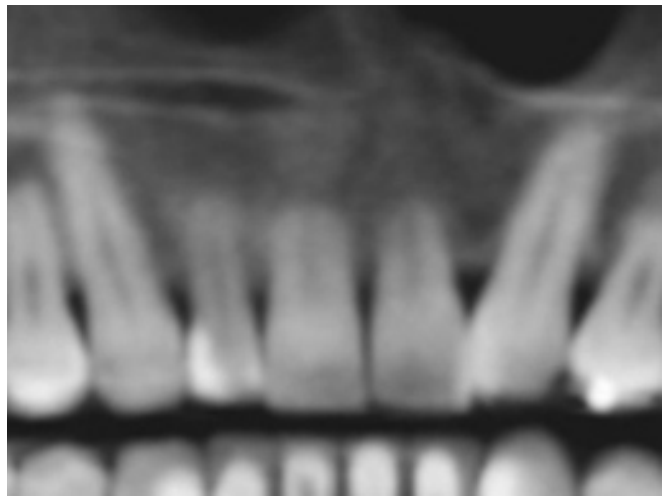

Figura 6.8 - Reabsorção radicular mais acentuada nos incisivos 
Com relação à reabsorção óssea horizontal, nenhum paciente desta amostra mostrou valor significativo deste tipo de reabsorção. Encontramos em três pacientes uma leve reabsorção vertical na área do enxerto (Fig. 6.9) e em um paciente havia uma significativa reabsorção do enxerto ósseo alveolar (Fig. 6.10).

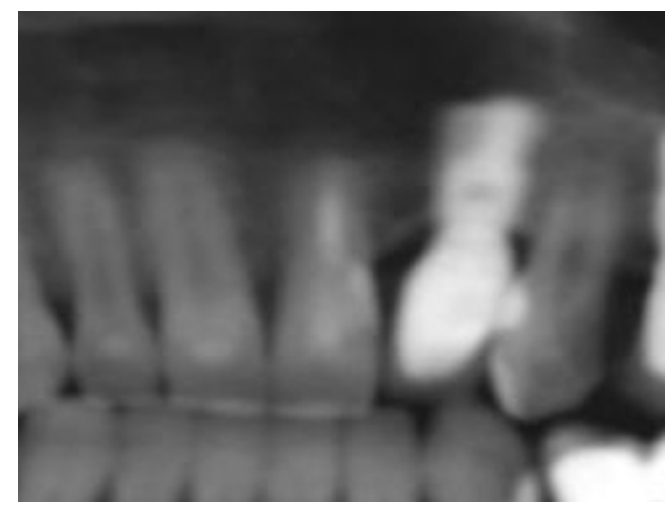

Figura 6.9 - Reabsorção óssea vertical leve na região do enxerto (implante)

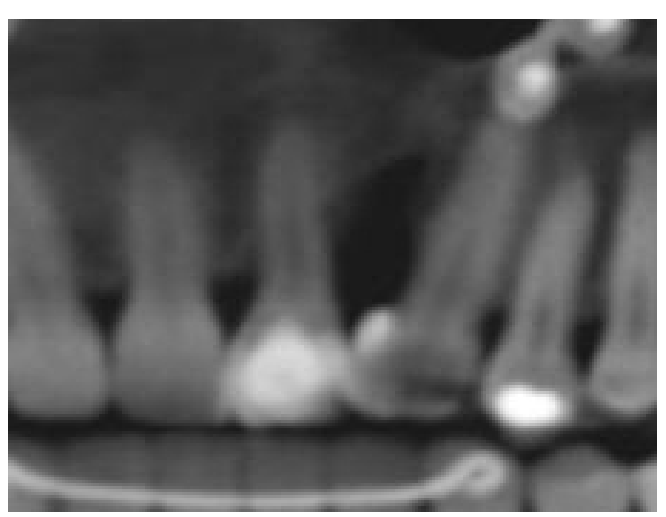

Figura 6.10 - Reabsorção óssea vertical acentuada na região da fissura

As características descritas acima são consideradas como uma das grandes vantagens da tomografia computadorizada. A maioria destes detalhes era impossível de ser visualizado nas imagens bidimensionais. A grande contribuição deste exame são os cortes parassagitais, que nos mostra detalhes que antes eram somente suposições, como, por exemplo, a escassez de osso nas tábuas vestibulares e linguais dos dentes anteriores.

Reconhecendo isto, por que medir?

A justificativa seria permitir análises de grupos amplos de casos, com abordagem estatística para tentar criar valores de angulação e inclinação dentárias que possam ser usados como metas terapêuticas viáveis no planejamento destes pacientes, prevendo as posições dentárias prováveisao final do tratamento. 
CONCLUSÕES 



\section{CONCLUSÕES}

Pudemos concluir que:

- A metodologia proposta mostrou-se relativamente precisa e reproduzível intraexaminadores para mensuração das inclinações e angulações dentárias.

- A utilização do exame tomográfico, através dos cortes parassagitais, nos permite a mensuração da inclinação real do dente, e também nos proporcionada uma imagem panorâmica para mensuração da angulação livre de distorções, que muitas vezes estão presentes na panorâmica convencional.

- Houve grande variabilidade nas medidas de angulação e inclinação, principalmente do lado fissura no arco superior, reafirmando que a ruptura de continuidade do rebordo altera toda a seqüência normal de desenvolvimento dentário, mesmo após a reabilitação com enxerto ósseo alveolar e, em alguns casos, cirurgia ortognática.

- O arco inferior apresentou resultados mais simétricos, e demonstrou que sofre uma menor interferência da fissura.

- Foi possível a visualização das limitações para o tratamento ortodôntico através do posicionamento das raízes dentárias e no osso alveolar adjacente. Nos cortes tomográficos fica nítida a escassez de osso alveolar nas tábuas ósseas lingual e vestibulares, principalmente no arco inferior.

- A amostra foi bastante heterogênea, justificando também a alta variabilidade nos resultados com relação às angulações e inclinações dentárias. Para comparação e definição de condutas terapêuticas com relação ao posicionamento dentário final e a prescrições de braquetes, é necessária uma 
pesquisa com uma amostra mais ampla e mais homogênea. Este exame permitiu a visualização real da relação entre as raízes dentárias com o osso alveolar que as suportam. 
REFERÊNCIAS 



\section{REFERÊNCIAS}

Almeida RR. Estudo ortopantomográfico das inclinações axiais dos dentes anteriores, comparando pacientes tratados ortodonticamente e jovens com oclusão normal [dissertação]. Bauru: Faculdade de Odontologia, Universidade de São Paulo; 1999.

Andrews LF. Straight wire: o conceito e o aparelho. San Diego: L. A. Wells, 1989.

Andrews LF. The sixs keys to normal occlusion. Am J Orthod. 1972;62:296-309.

Bastia, FMM. Estudo das angulações e inclinações dentárias obtidas no tratamento ortodôntico com a utilização da prescrição MBT TM [dissertação]. São Bernardo do Campo: Faculdade de Odontologia, Universidade Metodista de São Paulo; 2005.

Bennett JC, McLaughlin RP. As mecânicas de tratamento ortodôntico e o aparelho pré-ajustado. São Paulo: Artes Médicas, 1994.

Capelozza Filho L. Diagnóstico em Ortodontia. Maringá: Dental Press Editora, 2004.

Capelozza Filho L, Fattori L, Cordeiro A, Maltagliati LA. Avaliação da inclinação do incisivo inferior através da tomografia computadorizada. $\mathrm{R}$ Dental Press Ortodon Ortop Facial. 2008;13(6):108-117.

Capelozza Filho L, Fattori L, Maltagliati LA. Um novo método para avaliar as inclinações dentárias utilizando a tomografia computadorizada. $\mathrm{R}$ Dental Press Ortodon Ortop Maxilar. 2005;10:23-9.

Capelozza Filho L, Machado GB, Okada T, Trevisi HJ. Angulação dentária após o tratamento ortodôntico pela Técnica de Andrews e Edgewise: avaliação pela ortopantomografia. Ortodontia. 1994;27(2):60-66.

Capelozza Filho L, Normando ADC, Silva Filho OG. Isolated influences of lip and palate surgery on facial growth: comparison of operated and unoperated male adults with UCLP. Cleft Palate Craniofacial J. 1996;33:51-6.

Capelozza Filho L, Silva Filho OG. Fissuras lábio-palatais. In: Petrelli E. Ortodontia para fonoaudiologia. Curitiba:Lovise. 1992;197-239. 
Capelozza Filho L, Silva Filho OG, Ozawa TO, Cavassan AO. Individualização de bráquetes na técnica straight-wire: revisão de conceitos e sugestão de indicações para uso. R Dental Press Ortodon Ortop Maxilar. 1999;4:87-106.

Capelozza Filho L, Taniguchi SM, Silva Filho OG. Craniofacial morphology of adult unoperated complete unilateral cleft lip and palate patients. Cleft Palate Craniofac J. 1993;30:376-381.

Cavalcanti MGP, Sales MAO. Tomografia Computadorizada. In: Cavalcanti MGP. Diagnóstico por Imagem da Face. São Paulo: Santos; 2008. p.3-43.

Cerqueira MN, Teixeira SC, Naressi SCM, Ferreira, APP. Ocorrência de fissuras labiopalatais na cidade de Sõ José dos Campos-SP. Ver Bras Epidemiol. 2005;8(2): 161-6.

Cohnen M, Kemper J, Mobes O, Pawelzik J, Modder U. Radiation doses in dental radiology. Eur Radiol. 2002;12:634-7.

Creekmoore, TD, Kunik, RL. Straight Wire: The next generation. Am J Orthod Dentofacial Orthop. 1993;104:8-20.

Diewert VM. A morphometric analysis of craniofacial growth and changes in spacial relations during secondary palatal development in human embryos and fetuses. Am J Anat. 1983;167:495-522.

Dolphin Imaging \& Manegement Solutions [homepage na internet]. USA; [acesso em 12 março 2009]. Disponível: http://www.dolphinimaging.com/3d.html.

Enciso R, Memon A, MahJ. Three-dimensional visualization of the craniofacial patient: volume segmentation, data integration and animation. Orthod Craniofacial Res. 2003;6(Suppl.1):66-71.

Farman AG. Fundamentals of image acquisition and processing in the digital era. Orthod Craniofacial Res. 2003;6(Suppl.1):17-22.

Fattori L. Avaliação das inclinações dentárias obtidas pela técnica Straight-Wire Prescrição Capelozza Classe II [dissertação]. São Bernardo do Campo: Faculdade de Odontologia, Universidade Metodista de São Paulo; 2006.

Firoosnia H, Golimbu CN, Rafii M, Rauschning W, Weinreb JC. MRI and CT of the musculoskeletal system. St. Louis: Mosby Year Book;1992. 
Garib DG, Raymundo Júnior R, Raymundo MV, Raymundo DV, Ferreira SN. Tomografia computadorizada de feixe cônico (cone beam): entendendo este novo método de diagnóstico por imagem com promissora aplicabilidade na Ortodontia. $\mathrm{R}$ Dental Press Ortodon Ortop Facial. 2007;12:139-156.

Geraedts C TM, Borstap WA, Groenewoud JMM, Stoenlinga PJW. Long-term evaluation of bilateral cleft lip and palate patients after early secondary closure and premaxilla repositioning. Int. J. Oral Maxillofac. Surg. In press 2007.

Graber TM, Vanarsdall Junior RL. Ortodontia: princípios e técnicas atuais. 2 ed. Rio de Janeiro: Guanabara Koogan;1996.

Greene JC. Epidemiologic research - 1964 - 1967. J Am Dent Assoc. 1968;76:13506.

Hans MG, Kishiyama C, Parker SH, Wolf GR, Noachtar R. Cephalometric evaluation of two treatment strategies for deep overbite correction. Angle Orthod. 1994; Appleton, 4:255-276.

Hatcher M, Aboudara CL. Diagnosis goes digital. Am J Orthod Dentofacial Orthop. 2004;125:512-5.

Heiland M, Schulze D, Rother U, Schmelzle R. Midfacial imaging using digital volume tomography. Int Cong Ser. 2003;1256:1230-4.

Holdaway RA. Bracket angulation as applied to the edgewise appliance. Angle Orthod. Appleton. 1952;22(4):227-236.

Houston WJB. The analysis of errors in orthodontics measurements. Am J Orthod Dentofacial Orthop. 1983;83:382-90.

Imaging Sciences International. Manual de informações técnicas i-Cat [homepage na internet]. USA; [acesso em 25 setembro 2007]. Disponível: http://www.imagingsciences.com.

Jarabak JR. Development of a treatment plan in the light of one's concept of treatment objectives. Am J Orthod. 1960;46(7):481-514.

Korbmacher H, Barbel HN, Schollchen M, Heiland M. Value of Two Cone-beam Computed Tomography Systems from an Orthodontic Point of View. J Orofac Orthop. 2007;68:278-89. 
Lascala CA, Panella J, Marques MM. Analysis of the accuracy of linear measurements obtained by cone beam computed tomography (CBCT- NewTom). Dentomaxillof Radiol. 2004;33:291-4.

Ludlow JB, Davies-Ludlow LE, Brooks SL, Howerton WB. Dosimetry of 3 CBCT devices for oral and maxillofacial radiology: CB Mercuray, NewTom 3G and i-CAT. Dentomaxillofacial Radiology. 2006;35:219-226.

Macchi A, Carrafiello G, Cacciafesta V, Norcini A. Three-dimensional digital modeling and setup. Am J Orthod Dentofacial Orthop. 2006;129:605-610.

Machado FMC. Influência do calibre do fio na expressividade dos braquetes individualizados para más oclusões de Classe II e III [monografia]. Bauru - SP: Sociedade de Promoção do Fissurado Lábio-Palatal (PROFIS); 2001.

Mah JK, Danforth RA, Bumann A, Hatcher D. Radiation absorved in maxillofacial imaging with a new dental computed tomography device. Oral Surg Oral Med Oral Pathol Oral Radiol Endod. 2003;96:508-13.

Maki K, Inou N, Takanishi A, Miller AJ. Computer-assisted simulations in orthodontic diagnosis and the application of a new cone beam X-ray computed tomography. Orthod Craniofacial Res. 2003;6(Suppl. 1):95-101.

McLaughlin R, Bennett JC, Trevisi HJ. Mecânica sistematizada de tratamento ortodôntico. São Paulo: Artes Médicas, 2002.

Miller RJ, Kuo E, Choi W. Validation of Align Technology's Treat III ${ }^{\mathrm{TM}}$ digital model superimposition tool and its case application. Orthod Craniofacial Res. 2003;6(Suppl.1):143-149.

Müssig E, Wörtche R, Lux CJ. Indications for digital volume tomography in orthodontics. J Orofac Orthop. 2005;66:241-9.

Nagem Filho H, Morais N, Rocha RGF. Contribuição para o estudo da prevalência das malformações congênitas labiopalatinas na população escolar de Bauru. Rev Fac Odonto São Paulo. 1968;7:111-28.

Normando ADC, Quintão CCA, Almeida, MAO. Análise do Emprego do Cálculo Amostral e do Erro do Método em Pesquisas Científicas Publicadas na Literatura Ortodôntica Nacional e Internacional. R Dental Press Ortodon Ortop Facial. In press 2008. 
Normando ADC, Azevedo LR, Torres, TB. Angulação dos caninos em indivíduos portadores de má oclusão de classe I e classe III - Análise comparativa através de um novo método utilizando imagens digitalizadas [homepage na internet]. Brasil; [acesso em 04 abril 2009]. Disponível em: http://solutions.3m.com.br/wps/portal/3M/pt BR/Abzil/Home/DocumentosPublicacoes /ArtigosPublicacoes/.

Reis AC, Capelozza Filho L, Ozawa TO, Cavassan AO. Avaliação da angulação e inclinação dos elementos dentários em pacientes adultos jovens portadores de fissura transforame incisivo bilateral. $R$ Dental Press Ortodon Ortop Facial. 2008;13(1):113-123.

Ribas APCM. Avaliação e quantificação das angulações e inclinações dentárias em modelos de pacientes portadores de fissura transforame incisivo unilateral, no estágio da dentadura permanente [especialização]. Bauru: Hospital de Reabilitação de Anomalias Craniofaciais, Universidade de São Paulo; 2003.

Roth RH. The straight-wire appliance 17 years later. J Clin Orthod. 1987;21:632-642.

Rouas P, Bandon D, Nancy J, Delbos Y, Hauret L, Bar D. La tomographie volumétrique numérisée par le système NewTom : intérêt de ce nouvel examen d'imagerie médicale chez l'enfant. Archives de Pédiatrie. 2006;13:1169-77.

Scarfe WC, Farman, AG, Sukovic P. Clinical Applications of Cone-Beam Computed Tomography in Dental Practice. J Can Dent Assoc. 2006;72:75-80.

Schulze D, Heiland M, Schmelzle R., Rother UJ. Diagnostic possibilities of conebeam computed tomography in the facial skeleton. Int Cong Ser. 2004,1268:1179-83.

Silva Filho OG. Crescimento Facial. In: Trindade IEK, Silva Filho OG. Fissuras lábiopalatinas: uma abordagem interdisciplinar. 1를. São Paulo: Livraria Editora Santos; 2007: 173-198.

Silva Filho OG, Cavassan, AO. Abordagem Ortodôntica. In: Trindade IEK, Silva Filho OG. Fissuras lábiopalatinas: uma abordagem interdisciplinar. 1 ed. São Paulo: Livraria Editora Santos; 2007: 213-238.

Silva Filho OG, Ferrari Júnior FM, Capelozza Filho L, Albuquerque MVP. Enxerto ósseo alveolar em pacientes fissurados: realidade e perspectiva. Ortodontia. $1995 ; 28(1): 34-45$. 
Silva Filho OG, Ferrari Júnior FM, Rocha DL, Souza Freitas JA. Classificação das fissuras lábio-palatais: breve histórico, considerações clínicas e sugestão de modificação. Rev Bras Cirurg. 1992;82:59-65.

Silva Filho OG, Souza Freitas JA. Caracterização Morfológica e Origem Embriolágica. In: Trindade IEK, Silva Filho OG. Fissuras lábiopalatinas: uma abordagem interdisciplinar. 1 ed. São Paulo: Livraria Editora Santos; 2007:17-49

Silva Filho OG, Souza Freitas JA, Okada T. Fissuras labiopalatinas: diagnóstico e uma filosofia interdisciplinar de tratamento. In: Pinto VG. Saúde Bucal Coletiva. 4 Ed. São Paulo: Santos; 2000:481-527.

Silva Filho OG, Okada T, Souza Freitas JA. Fissuras lábio-palatais: diagnóstico e uma filosofia interdisciplinar de tratamento. In: Pinto VG. Saúde Bucal Coletica. 4eed. São Paulo:Santos; 2000:481-527.

Sperber GH. Craniofacial embriology. 4를. Ed. London:Wrigth;1989:7-57.

Spina V, Psillakis JM, Lapa FS, Ferreira MC. Classificação das fissuras lábiopalatinas: sugestão de modificação. Rev Hosp Clin Fac Med. 1972;27(1):5-6.

Sudovic P. Cone beam computed tomography in craniofacial imaging. Orthod Craniofacial Res. 2003;6(Suppl. 1):31-6.

Suri S, Utreja A, Khandelwal N, Mago SK. Craniofacial Computerized Tomography Analysis of the midface of patients with repaired complete unilateral cleft lip and palate. Am J Orthod Dentofacial Orthop. 2008;134(3):418-429.

Suzuki A, Watanabe C, Nakano M, Takahama Y. Maxillary lateral incisors of subjects with cleft lip and/or palate. II. Cleft Palate Craniofacial J. 1992;29:380-4.

Tavano O, Ursi WJS, Almeida RR, Henriques JFC. Determinação de linhas de referência para medições angulares em radiografias ortopantomográficas . Odontol. Mod. 1989,16(9):22-5.

Tsiklakis K, Donta C, Gavala S, Karayianni K, Kamenopoulou V, Hourdakis CJ. Dose reduction in maxillofacial imaging using low dose Cone Beam CT. Eur J Radiol. 2005;56:413-17.

Ursi WJ, Almeida RR, Tavano O, Henriques JFC. Assessment of mesiodistal axial inclination trough panoramic radiography. J Clin Orthod. 1990;24:166-173. 
Vannier MW. Craniofacial computed tomography scanning: technology, applications and future trends. Orthod Craniofacial Res. 2003;6(Suppl.1):17-22.

Vardimon A, Lambertz W. Statistical evaluation of torque angles in reference to straight-wire appliance (SWA) theories. Am J Orthod. 1986;89:56-66.

Wörtche R, Hassfeld S, Lux CJ, Müssig E, Hensley FW, Krempien R, Hofele C. Clinical application of cone beam digital volume tomography in children with cleft lip and palate. Dentomaxillofacial Radiology. 2006;35:88-94.

Yajima A, Otonari-Yamamoto M, Sano T, Hayakawa Y, Otonari T, Tanabe K, Wakoh M, Mizuta S, Yonezu H, Nakagawa K, Yajima Y. Cone-beam CT (CB Throne ${ }^{\circledR}$ ) Applied to Dentomaxillofacial Region. Bull Tokyo Dent Coll. 2006;47:133-141.

Yamamoto K, Ueno K, Seo K, Shinohara D. Development of dento-maxillofacial cone beam X-ray computed tomography system. Orthod Craniofacial Res. 2003;6(Suppl.1):160-162.

Zanelato ACT. Estudo das angulações e inclinações dentárias em brasileiros, leucodermas com oclusão normal natural [dissertação]. São Bernardo do Campo: Faculdade de Odontologia, Universidade Metodista de São Paulo; 2003.

Zanelato ACT, Maltagliati LA, Scanavini MA, Mandetta S. Método para mensuração das angulações e inclinações das coroas dentárias utilizando modelos de gesso. $R$ Dental Press Ortodon Ortop Facial. 2006;11(2):63-73. 

ANEXOS 



\section{ANEXOS}

\section{Anexo 1 - Tabelas estatísticas}

Tabela 1 - Resultados estatísticos para o canino superior lado não fissurado

\begin{tabular}{|c|c|c|c|c|c|c|c|c|c|c|}
\hline \multirow{2}{*}{$\begin{array}{c}\text { Canino } \\
\text { Lado ñ Fissurado }\end{array}$} & \multicolumn{4}{|c|}{$\mathrm{T} 1$} & \multirow[b]{2}{*}{ ANG } & \multirow[b]{2}{*}{ CA } & \multirow[b]{2}{*}{ CC } & \multicolumn{2}{|l|}{ T2 } & \multirow[b]{2}{*}{ ANG } \\
\hline & CA & CC & EV & INC & & & & EV & INC & \\
\hline PACIENTE 01 & 8,9 & 7,1 & 3,6 & 5,6 & 18,1 & 9,3 & 7,5 & 3,8 & 5,0 & 18,5 \\
\hline PACIENTE 02 & 7,5 & 5,7 & 2,9 & 2,7 & 7,4 & 7,8 & 6,0 & 3,0 & 2,3 & 7,3 \\
\hline PACIENTE 03 & 9,3 & 7,5 & 3,8 & 8,9 & 13,2 & 9,0 & 7,2 & 3,6 & 8,4 & 13,2 \\
\hline PACIENTE 04 & 9,1 & 7,3 & 3,7 & 4,0 & 13,1 & 9,2 & 7,4 & 3,7 & 2,8 & 13,1 \\
\hline PACIENTE 05 & 8,5 & 6,7 & 3,4 & 9,2 & 9,4 & 8,6 & 6,8 & 3,4 & 8,5 & 9,0 \\
\hline PACIENTE 06 & 10,4 & 8,6 & 4,3 & 4,4 & 15,7 & 10,6 & 8,8 & 4,4 & 4,5 & 15,3 \\
\hline PACIENTE 07 & 10,4 & 8,6 & 4,3 & 5,4 & 14,6 & 10,5 & 8,7 & 4,4 & 5,2 & 15,1 \\
\hline PACIENTE 08 & 11,7 & 9,9 & 5,0 & 6,5 & 12,7 & 11,6 & 9,8 & 4,9 & 7,0 & 12,4 \\
\hline PACIENTE 09 & 7,0 & 5,2 & 2,6 & 3,3 & 8,1 & 6,8 & 5,0 & 2,5 & 3,2 & 7,9 \\
\hline PACIENTE 10 & 9,9 & 8,1 & 4,1 & 13,0 & 17,7 & 9,9 & 8,1 & 4,1 & 12,9 & 17,4 \\
\hline Média & 9,27 & 7,47 & 3,77 & 6,30 & 13,00 & 9,33 & 7,53 & 3,78 & 5,98 & 12,92 \\
\hline $\mathrm{DP}$ & 1,41 & 1,41 & 0,71 & 3,20 & 3,75 & 1,41 & 1,41 & 0,71 & 3,27 & 3,86 \\
\hline Normalid. (Shapiro- Wilk) & 0,963 & 0,963 & 0,964 & 0,343 & 0,496 & 0,990 & 0,990 & 0,984 & 0,368 & 0,539 \\
\hline Diferença das Médias & & & & & & $-0,05$ & $-0,05$ & 0,00 & 0,33 & $-0,02$ \\
\hline Valor $\mathrm{P}$ (t pareado) & & & & & & 0,405 & 0,405 & 0,798 & 0,060 & 0,443 \\
\hline Significante T1 X T2? & & & & & & ns & ns & ns & ns & ns \\
\hline Erro Casual (Dahlberg) & & & & & & 0,2 & 0,2 & 0,1 & 0,6 & 0,3 \\
\hline
\end{tabular}

Tabela 2 - Resultados estatísticos para o incisivo lateral superior lado não fissurado

\begin{tabular}{|c|c|c|c|c|c|c|c|c|c|c|}
\hline \multirow{2}{*}{$\begin{array}{l}\text { Incisivo Lateral } \\
\text { Lado ñ Fissurado }\end{array}$} & \multicolumn{4}{|c|}{ T1 } & \multirow[b]{2}{*}{ ANG } & \multirow[b]{2}{*}{ CA } & \multirow[b]{2}{*}{$\mathrm{CC}$} & \multirow{2}{*}{$\begin{array}{l}\text { T2 } \\
\text { EV }\end{array}$} & \multirow[b]{2}{*}{ INC } & \multirow[b]{2}{*}{ ANG } \\
\hline & CA & $\mathrm{CC}$ & EV & INC & & & & & & \\
\hline PACIENTE 01 & 9,5 & 7,7 & 3,9 & 10,1 & 11,2 & 9,6 & 7,8 & 3,9 & 8,4 & 11,1 \\
\hline PACIENTE 02 & 7,6 & 5,8 & 2,9 & 4,6 & 17,1 & 8,0 & 6,2 & 3,1 & 3,0 & 17,6 \\
\hline PACIENTE 03 & 8,5 & 6,7 & 3,4 & 6,8 & 13,6 & 8,8 & 7,0 & 3,5 & 6,7 & 14,5 \\
\hline PACIENTE 04 & 11,6 & 9,8 & 4,9 & 9,4 & 12,3 & 11,3 & 9,5 & 4,8 & 7,7 & 12,7 \\
\hline PACIENTE 05 & 8,7 & 6,9 & 3,5 & 16,4 & 8,2 & 8,6 & 6,8 & 3,4 & 16,1 & 7,7 \\
\hline PACIENTE 06 & 7,0 & 5,2 & 2,6 & 7,5 & 6,6 & 7,0 & 5,2 & 2,6 & 7,5 & 6,5 \\
\hline PACIENTE 07 & 9,5 & 7,7 & 3,9 & 6,4 & 13,5 & 9,8 & 8,0 & 4,0 & 6,9 & 13,5 \\
\hline PACIENTE 08 & 10,5 & 8,7 & 4,4 & 7,3 & 5,7 & 10,3 & 8,5 & 4,3 & 7,6 & 6,2 \\
\hline PACIENTE 09 & 9,7 & 7,9 & 4,0 & 5,3 & 2,2 & 9,5 & 7,7 & 3,9 & 5,3 & 2,0 \\
\hline PACIENTE 10 & 9,6 & 7,8 & 3,9 & 4,3 & 7,7 & 9,7 & 7,9 & 4,0 & 7,0 & 8,5 \\
\hline Média & 9,22 & 7,42 & 3,74 & 7,81 & 9,81 & 9,26 & 7,46 & 3,75 & 7,62 & 10,03 \\
\hline $\mathrm{DP}$ & 1,34 & 1,34 & 0,68 & 3,56 & 4,49 & 1,21 & 1,21 & 0,62 & 3,35 & 4,68 \\
\hline Normalid. (Shapiro- Wilk) & 0,878 & 0,878 & 0,829 & 0,049 & 0,939 & 0,936 & 0,936 & 0,912 & 0,010 & 0,966 \\
\hline Diferença das Médias & & & & & & $-0,04$ & $-0,04$ & $-0,01$ & 0,19 & $-0,22$ \\
\hline \multirow[t]{2}{*}{ Valor $\mathrm{P}$ (t pareado) } & & & & & & 0,613 & 0,613 & 0,780 & 0,670 & 0,168 \\
\hline & & & & & & & & \multicolumn{3}{|c|}{ Wilcoxon } \\
\hline Significante T1 X T2? & & & & & & ns & ns & Ns & $\mathrm{ns}$ & ns \\
\hline Erro Casual (Dahlberg) & & & & & & 0,2 & 0,2 & 0,1 & 0,8 & 0,4 \\
\hline
\end{tabular}


Tabela 3 - Resultados estatísticos para o incisivo central superior lado não fissurado

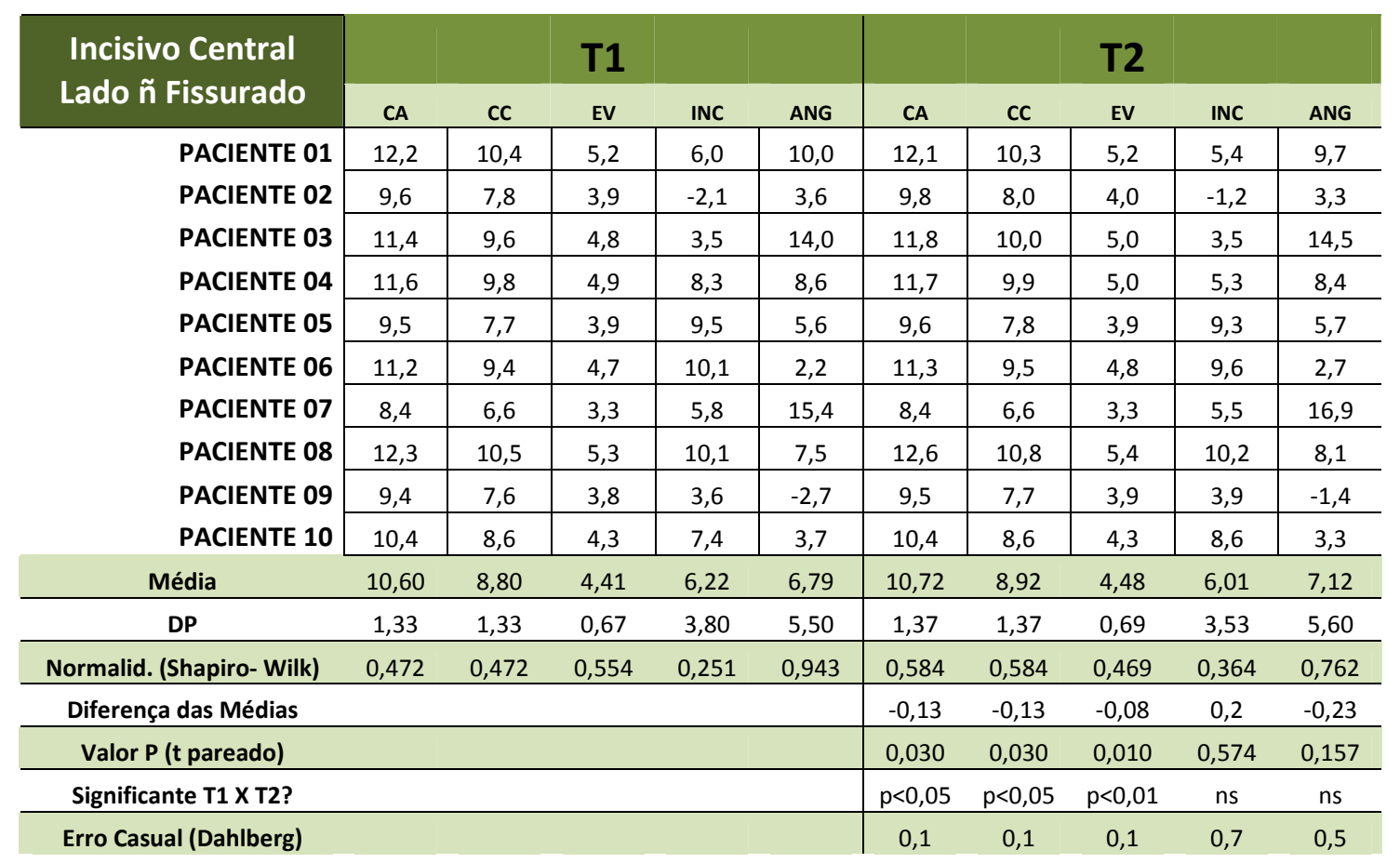

Tabela 4 - Resultados estatísticos para o incisivo central superior lado fissurado

\begin{tabular}{|c|c|c|c|c|c|c|c|c|c|c|}
\hline \multirow{2}{*}{$\begin{array}{l}\text { Incisivo Central } \\
\text { Lado Fissurado }\end{array}$} & & & T1 & & & & \multicolumn{3}{|c|}{ T2 } & \multirow[b]{2}{*}{ ANG } \\
\hline & CA & $\mathrm{cc}$ & EV & INC & ANG & CA & $\mathrm{CC}$ & EV & INC & \\
\hline PACIENTE 01 & 12,3 & 10,5 & 5,3 & 5,6 & 3,2 & 12,5 & 10,7 & 5,4 & 5,1 & 3,3 \\
\hline PACIENTE 02 & 9,7 & 7,9 & 4,0 & $-3,9$ & $-1,4$ & 9,9 & 8,1 & 4,1 & $-3,9$ & $-1,4$ \\
\hline PACIENTE 03 & 11,4 & 9,6 & 4,8 & $-2,2$ & 0,6 & 11,7 & 9,9 & 5,0 & $-1,7$ & 0,5 \\
\hline PACIENTE 04 & 11,7 & 9,9 & 5,0 & 5,6 & 13,1 & 11,8 & 10,0 & 5,0 & 4,4 & 12,7 \\
\hline PACIENTE 05 & 9,9 & 8,1 & 4,1 & 4,8 & $-7,4$ & 10,1 & 8,3 & 4,2 & 5,4 & $-7,7$ \\
\hline PACIENTE 06 & 12,0 & 10,2 & 5,1 & 10,4 & $-2,6$ & 12,2 & 10,4 & 5,2 & 10,7 & $-3,4$ \\
\hline PACIENTE 07 & & & & & & & & & & \\
\hline PACIENTE 08 & 12,2 & 10,4 & 5,2 & 9,0 & 1,3 & 12,0 & 10,2 & 5,1 & 9,3 & 2,5 \\
\hline PACIENTE 09 & 8,7 & 6,9 & 3,5 & 12,7 & 5,0 & 8,6 & 6,8 & 3,4 & 12,2 & 6,1 \\
\hline PACIENTE 10 & 11,0 & 9,2 & 4,6 & 3,2 & $-11,4$ & 11,0 & 9,2 & 4,6 & 4,9 & $-10,8$ \\
\hline Média & 10,99 & 9,19 & 4,62 & 5,02 & 0,04 & 11,09 & 9,29 & 4,67 & 5,16 & 0,20 \\
\hline $\mathrm{DP}$ & 1,27 & 1,27 & 0,62 & 5,47 & 7,09 & 1,30 & 1,30 & 0,65 & 5,33 & 7,11 \\
\hline Normalid. (Shapiro- Wilk) & 0,303 & 0,303 & 0,373 & 0,662 & 0,957 & 0,327 & 0,327 & 0,349 & 0,461 & 0,990 \\
\hline Diferença das Médias & & & & & & $-0,1$ & $-0,1$ & $-0,04$ & $-0,13$ & $-0,16$ \\
\hline Valor $\mathrm{P}$ (t pareado) & & & & & & 0,108 & 0,108 & 0,225 & 0,641 & 0,512 \\
\hline Significante $\mathrm{T} 1 \mathrm{X} \mathrm{T} 2$ ? & & & & & & ns & ns & ns & ns & ns \\
\hline Erro Casual (Dahlberg) & & & & & & 0,2 & 0,2 & 0,1 & 0,6 & 0,5 \\
\hline
\end{tabular}


Tabela 5 - Resultados estatísticos para o incisivo lateral superior lado fissurado

\begin{tabular}{|c|c|c|c|c|c|c|c|c|c|c|}
\hline \multirow{2}{*}{$\begin{array}{l}\text { Incisivo Lateral } \\
\text { Lado ñ Fissurado }\end{array}$} & \multicolumn{5}{|c|}{ T1 } & \multicolumn{4}{|c|}{ T2 } & \multirow[b]{2}{*}{ ANG } \\
\hline & CA & $\mathrm{CC}$ & EV & INC & ANG & CA & $\mathrm{CC}$ & EV & INC & \\
\hline \multicolumn{11}{|l|}{ PACIENTE 01} \\
\hline PACIENTE 02 & 8,0 & 6,2 & 3,1 & 2,3 & 20,6 & 8,5 & 6,7 & 3,4 & 2,4 & 21,7 \\
\hline PACIENTE 03 & 11,9 & 10,1 & 5,1 & 9,0 & 23,9 & 12,1 & 10,3 & 5,2 & 8,4 & 23,3 \\
\hline PACIENTE 04 & 10,8 & 9,0 & 4,5 & 4,3 & 14,5 & 10,9 & 9,1 & 4,6 & 4,5 & 14,6 \\
\hline \multicolumn{11}{|l|}{ PACIENTE 05} \\
\hline PACIENTE 06 & 11,3 & 9,5 & 4,8 & 12,4 & 16,3 & 11,6 & 9,8 & 4,9 & 11,9 & 15,8 \\
\hline \multicolumn{11}{|l|}{ PACIENTE 07} \\
\hline \multicolumn{11}{|l|}{ PACIENTE 08} \\
\hline \multicolumn{11}{|l|}{ PACIENTE 09} \\
\hline PACIENTE 10 & 10,2 & 8,4 & 4,2 & 5,4 & 0,0 & 10,1 & 8,3 & 4,2 & 4,1 & 0,3 \\
\hline Média & 10,44 & 8,64 & 4,34 & 6,68 & 15,06 & 10,64 & 8,84 & 4,46 & 6,26 & 15,14 \\
\hline DP & 1,50 & 1,50 & 0,77 & 4,02 & 9,19 & 1,41 & 1,41 & 0,70 & 3,84 & 9,09 \\
\hline Normalid. (Shapiro- Wilk) & 0,431 & 0,431 & 0,463 & 0,702 & 0,386 & 0,672 & 0,672 & 0,714 & 0,461 & 0,325 \\
\hline Diferença das Médias & & & & & & $-0,2$ & $-0,2$ & $-0,12$ & 0,42 & $-0,08$ \\
\hline Valor $\mathrm{P}$ (t pareado) & & & & & & 0,116 & 0,116 & 0,070 & 0,196 & 0,807 \\
\hline Significante $\mathrm{T} 1 \mathrm{X} \mathrm{T} 2$ ? & & & & & & ns & ns & ns & ns & ns \\
\hline Erro Casual (Dahlberg) & & & & & & 0,2 & 0,2 & 0,1 & 0,4 & 0,3 \\
\hline
\end{tabular}

Tabela 6 - Resultados estatísticos para o canino superior lado fissurado

\begin{tabular}{|c|c|c|c|c|c|c|c|c|c|c|}
\hline \multirow{2}{*}{$\begin{array}{c}\text { Canino } \\
\text { Lado Fissurado }\end{array}$} & \multicolumn{5}{|c|}{ T1 } & \multicolumn{4}{|c|}{ T2 } & \multirow[b]{2}{*}{ ANG } \\
\hline & CA & $\mathrm{CC}$ & EV & INC & ANG & CA & $\mathrm{CC}$ & EV & INC & \\
\hline PACIENTE 01 & 10,5 & 8,7 & 4,4 & 6,5 & 14,6 & 11,1 & 9,3 & 4,7 & 6,1 & 14,3 \\
\hline PACIENTE 02 & 8,0 & 6,2 & 3,1 & 2,5 & 11,4 & 7,8 & 6,0 & 3,0 & 2,8 & 11,9 \\
\hline PACIENTE 03 & 8,7 & 6,9 & 3,5 & 7,3 & 15,9 & 8,8 & 7,0 & 3,5 & 6,8 & 16,2 \\
\hline PACIENTE 04 & 9,4 & 7,6 & 3,8 & 2,4 & 8,0 & 9,3 & 7,5 & 3,8 & 1,5 & 8,7 \\
\hline PACIENTE 05 & 9,3 & 7,5 & 3,8 & 11,7 & 13,8 & 9,4 & 7,6 & 3,8 & 10,2 & 14,1 \\
\hline PACIENTE 06 & 7,5 & 5,7 & 2,9 & 15,7 & 17,9 & 7,8 & 6,0 & 3,0 & 14,5 & 17,4 \\
\hline PACIENTE 07 & & & & & & & & & & \\
\hline PACIENTE 08 & 10,7 & 8,9 & 4,5 & $-2,1$ & 4,3 & 10,8 & 9,0 & 4,5 & $-1,6$ & 4,8 \\
\hline PACIENTE 09 & & & & & & & & & & \\
\hline PACIENTE 10 & 9,8 & 8,0 & 4,0 & 16,2 & 15,5 & 10,0 & 8,2 & 4,1 & 14,4 & 13,5 \\
\hline Média & 9,24 & 7,44 & 3,75 & 7,53 & 12,68 & 9,38 & 7,58 & 3,80 & 6,84 & 12,61 \\
\hline DP & 1,13 & 1,13 & 0,57 & 6,60 & 4,54 & 1,24 & 1,24 & 0,63 & 5,90 & 4,11 \\
\hline Normalid. (Shapiro- Wilk) & 0,773 & 0,773 & 0,700 & 0,586 & 0,416 & 0,383 & 0,383 & 0,415 & 0,399 & 0,288 \\
\hline Diferença das Médias & & & & & & $-0,14$ & $-0,14$ & $-0,05$ & 0,69 & 0,06 \\
\hline Valor $\mathrm{P}$ (t pareado) & & & & & & 0,131 & 0,131 & 0,200 & 0,256 & 0,430 \\
\hline Significante $\mathrm{T} 1 \mathrm{X} T 2$ ? & & & & & & ns & ns & $\mathrm{ns}$ & ns & ns \\
\hline Erro Casual (Dahlberg) & & & & & & 0,2 & 0,2 & 0,1 & 0,7 & 0,7 \\
\hline
\end{tabular}


Tabela 7 - Resultados estatísticos para o dente 33

\begin{tabular}{|c|c|c|c|c|c|c|c|c|c|c|}
\hline \multirow{2}{*}{ DENTE 33} & \multicolumn{5}{|c|}{ T1 } & \multicolumn{4}{|c|}{ T2 } & \multirow[b]{2}{*}{ ANG } \\
\hline & CA & $\mathrm{cc}$ & EV & INC & ANG & CA & CC & EV & INC & \\
\hline PACIENTE 01 & 11,9 & 10,1 & 5,1 & $-1,0$ & 11,6 & 11,9 & 10,1 & 5,1 & $-0,7$ & 12,0 \\
\hline PACIENTE 02 & 9,1 & 7,3 & 3,7 & 2,0 & 13,1 & 9,3 & 7,5 & 3,8 & 1,9 & 13,7 \\
\hline PACIENTE 03 & 12,4 & 10,6 & 5,3 & $-11,3$ & 14,5 & 12,0 & 10,2 & 5,1 & $-10,4$ & 14,8 \\
\hline PACIENTE 04 & 12,5 & 10,7 & 5,4 & $-4,2$ & 8,3 & 12,7 & 10,9 & 5,5 & $-4,0$ & 8,4 \\
\hline PACIENTE 05 & 10,4 & 8,6 & 4,3 & 3,1 & 21,6 & 10,6 & 8,8 & 4,4 & 3,2 & 23,1 \\
\hline PACIENTE 06 & 12,3 & 10,5 & 5,3 & $-12,7$ & 1,3 & 12,5 & 10,7 & 5,4 & $-13,0$ & 1,4 \\
\hline PACIENTE 07 & 9,8 & 8,0 & 4,0 & $-15,3$ & 5,4 & 9,9 & 8,1 & 4,1 & $-15,2$ & 5,0 \\
\hline PACIENTE 08 & 12,3 & 10,5 & 5,3 & $-11,2$ & 8,7 & 12,5 & 10,7 & 5,4 & $-11,5$ & 8,6 \\
\hline PACIENTE 09 & 10,8 & 9,0 & 4,5 & $-1,0$ & 11,2 & 10,6 & 8,8 & 4,4 & $-1,6$ & 11,5 \\
\hline PACIENTE 10 & 11,7 & 9,9 & 5,0 & 1,8 & 15,5 & 11,4 & 9,6 & 4,8 & 1,6 & 15,9 \\
\hline Média & 11,32 & 9,52 & 4,785 & $-4,98$ & 11,12 & 11,34 & 9,54 & 4,8 & $-4,97$ & 11,44 \\
\hline $\mathrm{DP}$ & 1,216 & 1,216 & 0,612 & 6,968 & 5,652 & 1,184 & 1,184 & 0,596 & 6,903 & 6,075 \\
\hline Normalid. (Shapiro- Wilk) & 0,111 & 0,111 & 0,062 & 0,147 & 0,99 & 0,387 & 0,387 & 0,392 & 0,229 & 0,971 \\
\hline Diferença das Médias & & & & & & $-0,02$ & $-0,02$ & $-0,01$ & $-0,01$ & $-0,32$ \\
\hline Valor $\mathrm{P}$ (t pareado) & & & & & & 0,794 & 0,794 & 0,73 & 0,941 & 0,075 \\
\hline Significante $\mathrm{T} 1 \mathrm{X} \mathrm{T} 2$ ? & & & & & & ns & ns & ns & ns & ns \\
\hline Erro Casual (Dahlberg) & & & & & & 0,2 & 0,2 & 0,1 & 0,3 & 0,4 \\
\hline
\end{tabular}

Tabela 8 - Resultados estatísticos para o dente 32

\begin{tabular}{|c|c|c|c|c|c|c|c|c|c|c|}
\hline \multirow{2}{*}{ DENTE 32} & \multicolumn{5}{|c|}{ T1 } & \multicolumn{4}{|c|}{ T2 } & \multirow[b]{2}{*}{ ANG } \\
\hline & CA & CC & EV & INC & ANG & CA & $\mathrm{CC}$ & EV & INC & \\
\hline PACIENTE 01 & 10,8 & 9,0 & 4,5 & 8,4 & 0,6 & 10,9 & 9,1 & 4,5 & 8,3 & 0,7 \\
\hline PACIENTE 02 & 8,7 & 6,9 & 3,5 & $-4,3$ & 3,2 & 8,8 & 7,0 & 3,5 & $-4,2$ & 3,7 \\
\hline PACIENTE 03 & 10,3 & 8,5 & 4,3 & $-10,4$ & 8,4 & 10,4 & 8,6 & 4,3 & $-9,7$ & 8,8 \\
\hline PACIENTE 04 & 11,1 & 9,3 & 4,7 & $-2,7$ & 6,1 & 11,1 & 9,3 & 4,7 & $-3,0$ & 6,8 \\
\hline PACIENTE 05 & 8,8 & 7,0 & 3,5 & 6,6 & 4,2 & 9,0 & 7,2 & 3,6 & 6,9 & 5,3 \\
\hline PACIENTE 06 & 9,9 & 8,1 & 4,1 & $-4,6$ & $-0,8$ & 9,9 & 8,1 & 4,1 & $-4,6$ & $-0,5$ \\
\hline PACIENTE 07 & 9,0 & 7,2 & 3,6 & $-9,3$ & 5,9 & 8,8 & 7,0 & 3,5 & $-9,9$ & 6,3 \\
\hline PACIENTE 08 & 10,4 & 8,6 & 4,3 & $-10,6$ & 6,7 & 10,4 & 8,6 & 4,3 & $-11,5$ & 7,0 \\
\hline PACIENTE 09 & 9,8 & 8,0 & 4,0 & $-5,1$ & 4,7 & 9,6 & 7,8 & 3,9 & $-5,0$ & 3,8 \\
\hline PACIENTE 10 & 10,1 & 8,3 & 4,2 & 0,0 & 1,0 & 9,9 & 8,1 & 4,1 & $-0,1$ & 2,8 \\
\hline Média & 9,89 & 8,09 & 4,07 & $-3,2$ & 4 & 9,88 & 8,08 & 4,05 & $-3,28$ & 4,47 \\
\hline DP & 0,828 & 0,828 & 0,419 & 6,597 & 2,971 & 0,834 & 0,834 & 0,42 & 6,717 & 2,932 \\
\hline Normalid. (Shapiro- Wilk) & 0,495 & 0,495 & 0,416 & 0,291 & 0,751 & 0,439 & 0,439 & 0,476 & 0,33 & 0,831 \\
\hline Diferença das Médias & & & & & & 0,01 & 0,01 & 0,02 & 0,08 & $-0,47$ \\
\hline Valor $\mathrm{P}$ (t pareado) & & & & & & 0,832 & 0,832 & 0,343 & 0,587 & 0,06 \\
\hline Significante $\mathrm{T} 1 \mathrm{X} \mathrm{T} 2$ ? & & & & & & ns & ns & ns & ns & ns \\
\hline Erro Casual (Dahlberg) & & & & & & 0,1 & 0,1 & 0,0 & 0,3 & 0,7 \\
\hline
\end{tabular}


Tabela 9 - Resultados estatísticos para o dente 31

\begin{tabular}{|c|c|c|c|c|c|c|c|c|c|c|}
\hline \multirow[t]{2}{*}{ DENTE 31} & \multicolumn{4}{|c|}{ T1 } & \multirow[b]{2}{*}{ ANG } & \multirow[b]{2}{*}{ CA } & \multirow[b]{2}{*}{$\mathrm{cC}$} & \multirow{2}{*}{$\begin{array}{c}\text { T2 } \\
\text { EV }\end{array}$} & \multirow[b]{2}{*}{ INC } & \multirow[b]{2}{*}{ ANG } \\
\hline & CA & $\mathrm{CC}$ & EV & INC & & & & & & \\
\hline PACIENTE 01 & 10,2 & 8,4 & 4,2 & 6,0 & $-4,2$ & 10,2 & 8,4 & 4,2 & 6,1 & $-4,6$ \\
\hline PACIENTE 02 & 8,9 & 7,1 & 3,6 & $-3,5$ & 1,6 & 8,8 & 7,0 & 3,5 & $-3,5$ & 1,3 \\
\hline PACIENTE 03 & 12,5 & 10,7 & 5,4 & $-6,4$ & 10,6 & 10,2 & 8,4 & 4,2 & $-6,9$ & 9,7 \\
\hline PACIENTE 04 & 10,7 & 8,9 & 4,5 & $-1,2$ & 7,9 & 10,8 & 9,0 & 4,5 & $-1,0$ & 9,2 \\
\hline PACIENTE 05 & 8,0 & 6,2 & 3,1 & 10,9 & 6,5 & 8,0 & 6,2 & 3,1 & 11,2 & 6,0 \\
\hline PACIENTE 06 & 9,0 & 7,2 & 3,6 & $-9,9$ & $-0,5$ & 9,1 & 7,3 & 3,7 & $-8,9$ & $-0,6$ \\
\hline PACIENTE 07 & 8,9 & 7,1 & 3,6 & $-3,1$ & 8,5 & 8,8 & 7,0 & 3,5 & $-3,2$ & 8,0 \\
\hline PACIENTE 08 & 9,8 & 8,0 & 4,0 & $-11,5$ & $-2,1$ & 10,0 & 8,2 & 4,1 & $-12,6$ & $-1,8$ \\
\hline PACIENTE 09 & 9,3 & 7,5 & 3,8 & $-4,7$ & 1,1 & 9,1 & 7,3 & 3,7 & $-5,2$ & 0,0 \\
\hline PACIENTE 10 & 9,3 & 7,5 & 3,8 & 2,0 & $-2,7$ & 9,1 & 7,3 & 3,7 & 0,7 & $-1,6$ \\
\hline Média & 9,66 & 7,86 & 3,96 & $-2,14$ & 2,67 & 9,41 & 7,61 & 3,82 & $-2,33$ & 2,56 \\
\hline $\mathrm{DP}$ & 1,25 & 1,25 & 0,633 & 6,909 & 5,285 & 0,853 & 0,853 & 0,421 & 7,031 & 5,188 \\
\hline Normalid. (Shapiro- Wilk) & 0,261 & 0,261 & 0,237 & 0,784 & 0,389 & 0,496 & 0,496 & 0,665 & 0,847 & 0,264 \\
\hline Diferença das Médias & & & & & & 0,25 & 0,25 & 0,14 & 0,19 & 0,11 \\
\hline Valor $\mathrm{P}$ (t pareado) & & & & & & 0,308 & 0,308 & 0,275 & 0,401 & 0,671 \\
\hline Significante T1 X T2? & & & & & & ns & ns & ns & ns & ns \\
\hline Erro Casual (Dahlberg) & & & & & & 0,3 & 0,3 & 0,2 & 0,5 & 0,7 \\
\hline
\end{tabular}

Tabela 10 - Resultados estatísticos para o dente 41

\begin{tabular}{|c|c|c|c|c|c|c|c|c|c|c|}
\hline \multirow{2}{*}{ DENTE 41} & \multicolumn{4}{|c|}{ T1 } & \multirow[b]{2}{*}{ ANG } & \multirow[b]{2}{*}{ CA } & \multirow[b]{2}{*}{$\mathrm{CC}$} & \multirow{2}{*}{$\begin{array}{c}\text { T2 } \\
\text { EV } \\
\end{array}$} & \multirow[b]{2}{*}{ INC } & \multirow[b]{2}{*}{ ANG } \\
\hline & CA & CC & EV & INC & & & & & & \\
\hline PACIENTE 01 & 9,5 & 7,7 & 3,9 & 5,5 & 10,7 & 9,7 & 7,9 & 4,0 & 5,7 & 9,5 \\
\hline PACIENTE 02 & 9,1 & 7,3 & 3,7 & $-4,3$ & $-5,3$ & 8,9 & 7,1 & 3,6 & $-4,7$ & $-5,8$ \\
\hline PACIENTE 03 & 10,9 & 9,1 & 4,6 & $-1,5$ & $-5,3$ & 11,0 & 9,2 & 4,6 & $-0,8$ & $-6,0$ \\
\hline PACIENTE 04 & 8,1 & 6,3 & 3,2 & 6,5 & $-5,3$ & 8,2 & 6,4 & 3,2 & 6,8 & $-5,9$ \\
\hline PACIENTE 05 & 9,2 & 7,4 & 3,7 & $-6,9$ & $-0,3$ & 9,3 & 7,5 & 3,8 & $-6,5$ & $-1,1$ \\
\hline PACIENTE 06 & 9,1 & 7,3 & 3,7 & 0,0 & $-1,6$ & 9,0 & 7,2 & 3,6 & $-1,6$ & $-2,8$ \\
\hline PACIENTE 07 & 9,8 & 8,0 & 4,0 & $-10,2$ & $-3,1$ & 9,8 & 8,0 & 4,0 & $-10,9$ & $-2,8$ \\
\hline PACIENTE 08 & 9,2 & 7,4 & 3,7 & $-4,3$ & 2,5 & 9,0 & 7,2 & 3,6 & $-5,0$ & 1,0 \\
\hline PACIENTE 09 & 9,1 & 7,3 & 3,7 & 4,5 & 3,7 & 9,1 & 7,3 & 3,7 & 3,4 & 3,0 \\
\hline PACIENTE 10 & & & & & & & & & & \\
\hline Média & 9,333 & 7,533 & 3,8 & $-1,19$ & $-0,44$ & 9,333 & 7,533 & 3,789 & $-1,51$ & $-1,21$ \\
\hline $\mathrm{DP}$ & 0,743 & 0,743 & 0,371 & 5,819 & 5,352 & 0,781 & 0,781 & 0,389 & 5,928 & 5,104 \\
\hline Normalid. (Shapiro- Wilk) & 0,173 & 0,173 & 0,068 & 0,61 & 0,175 & 0,369 & 0,369 & 0,398 & 0,747 & 0,194 \\
\hline Diferença das Médias & & & & & & 0 & 0 & 0,011 & 0,322 & 0,767 \\
\hline Valor $\mathrm{P}$ (t pareado) & & & & & & 1 & 1 & 0,681 & 0,245 & 0,002 \\
\hline Significante $\mathrm{T} 1 \mathrm{X} \mathrm{T} 2$ ? & & & & & & ns & ns & ns & ns & $\mathrm{P}<0.05$ \\
\hline Erro Casual (Dahlberg) & & & & & & 0,1 & 0,1 & 0,1 & 0,6 & 0,8 \\
\hline
\end{tabular}


Tabela 11 - Resultados estatísticos para o dente 42

\begin{tabular}{|c|c|c|c|c|c|c|c|c|c|c|}
\hline \multirow{2}{*}{ DENTE 42} & \multirow[b]{2}{*}{ CA } & \multirow[b]{2}{*}{$\mathrm{cc}$} & \multicolumn{3}{|l|}{ T1 } & \multirow[b]{2}{*}{ CA } & \multirow[b]{2}{*}{$\mathrm{CC}$} & \multicolumn{2}{|l|}{ T2 } & \multirow[b]{2}{*}{ ANG } \\
\hline & & & EV & INC & ANG & & & EV & INC & \\
\hline PACIENTE 01 & 9,8 & 8,0 & 4,0 & 2,7 & 11,7 & 10,0 & 8,2 & 4,1 & 3,0 & 11,9 \\
\hline PACIENTE 02 & 9,4 & 7,6 & 3,8 & $-4,4$ & $-2,4$ & 9,3 & 7,5 & 3,8 & $-4,4$ & $-2,7$ \\
\hline PACIENTE 03 & 10,6 & 8,8 & 4,4 & $-10,3$ & 5,9 & 10,3 & 8,5 & 4,3 & $-10,0$ & 4,8 \\
\hline PACIENTE 04 & 10,7 & 8,9 & 4,5 & $-3,7$ & 2,7 & 10,6 & 8,8 & 4,4 & $-3,0$ & 2,3 \\
\hline PACIENTE 05 & 8,6 & 6,8 & 3,4 & 6,0 & 4,9 & 8,7 & 6,9 & 3,5 & 6,4 & 6,2 \\
\hline PACIENTE 06 & 10,0 & 8,2 & 4,1 & $-7,0$ & 2,4 & 10,2 & 8,4 & 4,2 & $-6,9$ & 2,0 \\
\hline PACIENTE 07 & 9,5 & 7,7 & 3,9 & 0,0 & 3,7 & 9,4 & 7,6 & 3,8 & $-0,9$ & 3,2 \\
\hline PACIENTE 08 & 10,2 & 8,4 & 4,2 & $-12,0$ & 0,0 & 10,2 & 8,4 & 4,2 & $-11,8$ & 0,4 \\
\hline PACIENTE 09 & 9,6 & 7,8 & 3,9 & $-6,5$ & 5,5 & 9,7 & 7,9 & 4,0 & $-7,3$ & 5,3 \\
\hline PACIENTE 10 & 9,7 & 7,9 & 4,0 & 2,5 & 9,3 & 9,6 & 7,8 & 3,9 & 0,6 & 9,1 \\
\hline Média & 9,81 & 8,01 & 4,02 & $-3,27$ & 4,37 & 9,8 & 8 & 4,02 & $-3,43$ & 4,25 \\
\hline DP & 0,614 & 0,614 & 0,312 & 5,935 & 4,136 & 0,57 & 0,57 & 0,274 & 5,793 & 4,221 \\
\hline Normalid. (Shapiro- Wilk) & 0,749 & 0,749 & 0,769 & 0,786 & 0,97 & 0,785 & 0,785 & 0,81 & 0,963 & 0,989 \\
\hline Diferença das Médias & & & & & & 0,01 & 0,01 & 0 & 0,16 & 0,12 \\
\hline Valor $\mathrm{P}$ (t pareado) & & & & & & 0,847 & 0,847 & 1 & 0,54 & 0,568 \\
\hline Significante $\mathrm{T} 1 \mathrm{X} \mathrm{T} 2$ ? & & & & & & ns & ns & ns & ns & Ns \\
\hline Erro Casual (Dahlberg) & & & & & & 0,1 & 0,1 & 0,1 & 0,6 & 0,5 \\
\hline
\end{tabular}

Tabela 12 - Resultados estatísticos para o dente 43

\begin{tabular}{|c|c|c|c|c|c|c|c|c|c|c|}
\hline \multirow{2}{*}{ DENTE 43} & \multicolumn{5}{|c|}{ T1 } & \multirow[b]{2}{*}{ CA } & \multirow[b]{2}{*}{$\mathrm{CC}$} & \multicolumn{2}{|l|}{ T2 } & \multirow[b]{2}{*}{ ANG } \\
\hline & CA & $\mathrm{CC}$ & EV & INC & ANG & & & EV & INC & \\
\hline PACIENTE 01 & 10,4 & 8,6 & 4,3 & $-1,5$ & 24,5 & 10,9 & 9,1 & 4,6 & $-1,1$ & 22,4 \\
\hline PACIENTE 02 & 11,0 & 9,2 & 4,6 & $-2,0$ & 12,1 & 10,9 & 9,1 & 4,6 & $-1,9$ & 11,4 \\
\hline PACIENTE 03 & 10,6 & 8,8 & 4,4 & $-8,1$ & 11,6 & 12,0 & 10,2 & 5,1 & $-6,3$ & 12,8 \\
\hline PACIENTE 04 & 13,1 & 11,3 & 5,7 & $-4,4$ & 6,6 & 13,0 & 11,2 & 5,6 & $-4,0$ & 7,2 \\
\hline PACIENTE 05 & 9,3 & 7,5 & 3,8 & 1,3 & 22,3 & 9,5 & 7,7 & 3,9 & 2,2 & 20,8 \\
\hline PACIENTE 06 & 11,1 & 9,3 & 4,7 & $-5,4$ & 8,1 & 11,5 & 9,7 & 4,9 & $-5,8$ & 7,7 \\
\hline PACIENTE 07 & 9,3 & 7,5 & 3,8 & $-3,4$ & 9,5 & 9,3 & 7,5 & 3,8 & $-3,2$ & 9,1 \\
\hline PACIENTE 08 & 11,9 & 10,1 & 5,1 & $-16,5$ & 4,0 & 12,0 & 10,2 & 5,1 & $-14,5$ & 4,7 \\
\hline PACIENTE 09 & 10,7 & 8,9 & 4,5 & $-6,4$ & 4,9 & 10,8 & 9,0 & 4,5 & $-7,7$ & 4,8 \\
\hline PACIENTE 10 & 11,3 & 9,5 & 4,8 & $-4,1$ & 14,9 & 11,1 & 9,3 & 4,7 & $-5,3$ & 13,8 \\
\hline Média & 10,87 & 9,07 & 4,57 & $-5,05$ & 11,85 & 11,1 & 9,3 & 4,68 & $-4,76$ & 11,47 \\
\hline $\mathrm{DP}$ & 1,132 & 1,132 & 0,57 & 4,815 & 6,958 & 1,123 & 1,123 & 0,545 & 4,476 & 6,165 \\
\hline Normalid. (Shapiro- Wilk) & 0,582 & 0,582 & 0,644 & 0,192 & 0,098 & 0,637 & 0,637 & 0,679 & 0,609 & 0,283 \\
\hline Diferença das Médias & & & & & & $-0,23$ & $-0,23$ & $-0,11$ & $-0,29$ & 0,38 \\
\hline Valor $\mathrm{P}$ (t pareado) & & & & & & 0,154 & 0,154 & 0,185 & 0,426 & 0,273 \\
\hline Significante $\mathrm{T} 1 \mathrm{X} T 2$ ? & & & & & & ns & ns & ns & ns & ns \\
\hline Erro Casual (Dahlberg) & & & & & & 0,3 & 0,3 & 0,2 & 0,9 & 0,9 \\
\hline
\end{tabular}




\section{Anexo 2 - Ofício de Aprovação do Comitê de Ética em Pesquisa}

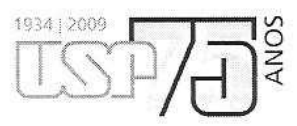

Ofício $n^{\circ}$ 008/2009-SVAPEPE-CEP

Bauru, 19 de fevereiro de 2009.

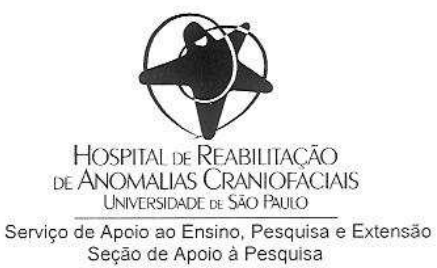

HOSPITAL DE REABILITACÄO ANOMALIAS CRANIOFACI
UNIVERSDADE DE SÄO PAUIO Seção de Apoio à Pesquisa

Prezado(a) Senhor(a)

O projeto de pesquisa encaminhado a este Comitê de Ética em Pesquisa em Seres Humanos, denominado "Avaliação da angulação e inclinação dos dentes anteriores através da tomografia computadorizada por feixe cônico, em pacientes com fissura de lábio e palato completa unilateral", de autoria de BRUNA CONDI P. DE MORAES desenvolvido sob sua orientação, foi enviado ao relator para avaliação.

$\mathrm{Na}$ reunião de 17 de fevereiro de 2009, o parecer do relator aprovando o projeto, foi aceito pelo Comitê, considerando que não existem infrações éticas pendentes para início da pesquisa. Solicitamos a V.Sa. a gentileza de comunicar o parecer ao(à) pesquisador(a) e anexar o presente ofício ao projeto pois o mesmo será necessário para futura publicação do trabalho.

O(A) pesquisador(a) fica responsável pela entrega na SVAPEPE - Apoio ao Projeto de Pesquisa dos relatórios semestrais, bem como, comunicar ao CEP todas as alterações que possam ocorrer no projeto.

Informamos que após o recebimento do trabalho concluído, este Comitê enviará o parecer final para publicação.

Atenciosamente,

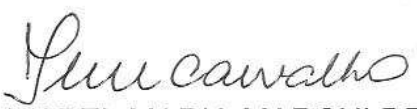

PROFA. DRA. IZABEL MARIA MARCHI DE CARVALHO Coordenadora do Comitê de Ėtica em Pesquisa em Seres Humanos do HRAC-USP

IImo(a) $\operatorname{Sr}(a)$

Prof. Dr. Leopoldino Capelozza Filho

Ortodontia - HRAC/USP 